\title{
Consumer Behaviour: Theory and Empirical Evidence--A Survey
}

\section{Richard Blundell}

The Economic Journal, Vol. 98, No. 389. (Mar., 1988), pp. 16-65.

Stable URL:

http://links.jstor.org/sici?sici=0013-0133\%28198803\%2998\%3A389\%3C16\%3ACBTAEE\%3E2.0.CO\%3B2-9

The Economic Journal is currently published by Royal Economic Society.

Your use of the JSTOR archive indicates your acceptance of JSTOR's Terms and Conditions of Use, available at

http://www.jstor.org/about/terms.html. JSTOR's Terms and Conditions of Use provides, in part, that unless you have obtained prior permission, you may not download an entire issue of a journal or multiple copies of articles, and you may use content in the JSTOR archive only for your personal, non-commercial use.

Please contact the publisher regarding any further use of this work. Publisher contact information may be obtained at http://www.jstor.org/journals/res.html.

Each copy of any part of a JSTOR transmission must contain the same copyright notice that appears on the screen or printed page of such transmission.

The JSTOR Archive is a trusted digital repository providing for long-term preservation and access to leading academic journals and scholarly literature from around the world. The Archive is supported by libraries, scholarly societies, publishers, and foundations. It is an initiative of JSTOR, a not-for-profit organization with a mission to help the scholarly community take advantage of advances in technology. For more information regarding JSTOR, please contact support@ jstor.org. 


\section{CONSUMER BEHAVIOUR: THEORY AND EMPIRICAL EVIDENGE - A SURVEY}

\section{Richard Blundell*}

There are very few aspects of economic policy that do not require some knowledge of household or individual consumer behaviour. Moreover, the close interplay between theoretical and empirical considerations together with the rapid expansion in the availability of different types of data have continued to make the analysis of consumer behaviour an attractive area for research. For some policy questions the importance of empirical evidence on consumer behaviour is indisputable. Amongst these stand the optimality and impact of tax proposals, the effect of credit constraints, real interest rate changes and uncertainty on savings behaviour and the appropriate choice of cost of living indices. However, the methods of analysis in modern consumer theory and empirical research are applicable to a much wider set of problems. Although I have compiled an extensive, if not exhaustive, bibliography at the end of this survey, the principal aim is to present and evaluate some of the more recent ideas and methods of investigation relating to consumer behaviour rather than to provide a complete literature survey.

Perhaps the most appealing feature of economic research into consumer behaviour is the close relationship between theoretical specification and appropriate estimation technique. This is most apparent when empirical analysis and testing takes place at the individual or micro level. However, even at the macro or aggregate level, given that some notion of consumer optimising behaviour is often assumed to underlie the evolution of the aggregate data, effective assessment of the model specification requires judgment from the theoretical as well as the empirical standpoint. Indeed empirical models can often be unwittingly restrictive once viewed from an appropriate theoretical perspective.

Although far from profound, some illustrations of these points are probably warranted. Empirical demand systems are often used to design and analyse the impact of indirect tax policy. Commonly used specifications of empirical demand systems typically rule out many theoretically plausible types of substitution behaviour and thus prejudge the indirect tax results. Additive linear models (the Stone-Geary for example), still popular in many policy based studies, not only rule out complementarity but essentially tie substitution effects directly to income effects allowing little independent role for relative

* I am grateful to Gordon Anderson, Paul Baker, Vanessa Fry, Costas Meghir, John Micklewright, Panos Pashardes, Ranjan Ray, Richard Smith, Ian Walker and Guglielmo Weber for allowing me to draw on jointly authored material and for their comments on this work. Additional comments on earlier drafts by John Burbidge, John Ham, John Muellbauer and Andrew Oswald have also resulted in significant improvements. However, all remaining errors are mine alone. Finance for this research was provided by the ESRC under project Bo225 0004. 
prices or real wages in forecasts of consumer behaviour (see Deaton, I974a). Indeed, models that express commodity demand in terms of prices and total expenditure alone, implicitly assume separability between consumption and labour supply decisions and thereby emasculate most optimal tax theory. As a result, welfare improving directions for tax changes are governed almost entirely by the properties underlying the estimated model and not necessarily those underlying the data.

At another level, theoretically consistent dynamic consumption models are often surprisingly simple (see Hall (1978), for example). However, this simplicity is usually a result of particularly strong underlying assumptions, namely intertemporal separability, perfect credit markets and the separability of consumption and labour market decisions. Very little empirical evidence supports such hypotheses but the specification of theoretically consistent models that relax these assumptions requires considerable ingenuity. For example, theory tells us that, despite its popularity, there may be little to be learnt from simply adding lagged variables to an otherwise static or at least intertemporally separable model. If one is not careful the resulting model is only rationalisable under completely myopic consumer behaviour-an assumption almost as restrictive as the separability and capital market assumptions themselves. This is not to say that only theoretically consistent models should be entertained. Without confronting theoretical restrictions with a more general empirical model, there would be little progress in economic thought. However, unless the implications of a general theoretical process determining the consumer's behaviour are fully understood, estimated models may often unknowingly rule out plausible types of behaviour and empirical specification searches may look in uninformative directions.

It is not the intention of this survey to provide a catalogue of empirical results or to cover all theories of consumer behaviour but rather to point out areas where analysing the interplay between theoretical and empirical considerations has either produced or is likely to produce new insights into consumer behaviour. The main areas which will be considered fall into two broad levels of analysis and are reflected in the two main sections of this survey. The first is the study of disaggregate behaviour. By this I shall mean the disaggregation of consumption into its components. These will include the consumption of specific commodity groups like clothing and alcohol as well as the allocation of time including the supply of labour. The interest here will be on the relative size and sign of substitution effects indicating the degree of separability and commodity grouping that can take place. It will also allow us to assess the impact of rationing in some markets (housing, labour), the implications for tax policy design and the construction of cost of living indices. The temporal aspect of behaviour will largely be ignored in this work. Under certain theoretical restrictions on the consumer's optimising model this is a legitimate approach to take but under more general intertemporal or dynamic behaviour these models will need to be extended. In the second broad area the emphasis will be placed more directly on dynamic and life-cycle behaviour.

There is often little reason to believe that theoretical predictions will hold in 
aggregate even if they hold at the individual level. In both of these broad areas, therefore, the most persuasive level of analysis must be at the individual consumer or household level. However, reliable longitudinal data sets that follow the same consumers over long time periods are rare and some form of aggregation prior to empirical analysis is often inevitable. Precisely how this aggregation should be done and the relationship between micro and macro level analyses is a highly interesting aspect of applied consumer economics in its own right. The clear attraction of individual level data is that they avoid aggregation bias. Such bias can result both because of the complex interactions between individual characteristics and price/income effects and also because of nonlinearities in consumption behaviour due to nonlinear Engel curves, corner solutions, rationing, nonlinear taxation and imperfect credit markets. However, working at some level of aggregation may often be unavoidable and some time will be spent in this survey in the analysis of exact aggregation.

Despite the progress that has been achieved since the Brown and Deaton ( I972) survey, there still remain major areas of reconciliation between different levels of behavioural modelling and between the theoretical models and the data themselves. Two obvious applications stand out here. First, is the precise nature of the relationship between the mostly rather static disaggregated analyses of household behaviour (both concerning the demand for commodities and the supply of labour) and the more aggregate dynamic models. Second, is the ability of the various theoretically based dynamic models to match the data process. There seems no doubt that the major advances that are currently occurring and that will occur in the empirical analysis of consumer behaviour will be predominantly in these two areas. The layout of this survey is chosen to reflect this. However, we shall consider other loosely related aspects of consumer theory and testing that have more distinct bearing on welfare analysis and public policy.

Before setting off on this survey it is fair to say that without the landmark in writings on consumer behaviour provided by the Deaton and Muellbauer $(1980 b)$ volume this task would be unthinkable. At a more practical level the Deaton and Muellbauer book provides a useful historic point from which to define recent developments in the area in which this survey, albeit at a less technical level, will concentrate.

\section{DISAGGREGATED DEMAND ANALYSIS}

\section{I. Separability, Additivity and Preference Restrictions}

The ability to group commodities by type or time period stands as one of the most valuable forms of restrictions on consumer preferences. Precisely what different types of grouping imply for consumer behaviour is an important preliminary before any application of consumer theory. For example, grouping prices 'price aggregation' has somewhat different implications than grouping commodities 'direct separability'. The requirements for a single price aggregator or index, something that is often assumed in application, are even stronger. However, without some form of grouping, all relative prices for all goods both within and outside the current period may have an independent 
effect on the commodity demand under consideration. This very fact suggests that, if consumers optimise at all, they probably will use some form of grouping to enable some simplification of the decision-making process.

The most obvious method of grouping and one which is used extensively in empirical application rests on the hypothesis of two-stage budgeting. This idea dates back to at least the work of Gorman (1958) and yet still underlies many new innovations in applied consumer theory (see, for example Browning et al. ( 1985 ) and MaCurdy ( 1983$)$ ). Under two-stage budgeting the direct utility function is weakly separable and consumers allocate expenditure first to broad commodity groups and then to detailed within group demands. This enables allocations within groups to be determined solely by the within group relative prices and the allocation of expenditure to that group. If $x_{1}, \ldots, x_{n}$ represents all consumption goods (including leisure time or labour supply) and $\mathbf{q}_{1}, \ldots, \mathbf{q}_{k}$ represents a smaller number of commodity vectors to which $x_{1}, \ldots, x_{n}$ can be uniquely allocated, then if utility is weakly separable across these groups, direct utility may be written

$$
U\left(x_{1}, \ldots, x_{n}\right)=F\left[U_{1}\left(\mathbf{q}_{1}\right), \ldots, U_{k}\left(\mathbf{q}_{k}\right)\right] .
$$

The allocation of expenditure to any $x_{i}$ in $\mathbf{q}_{s}$ may then be expressed as

$$
p_{i} x_{i}=f_{i}\left(\mathbf{p}_{s}, y_{s}\right) \text { for } i=\mathrm{I}, \ldots, n \text { and } s=\mathrm{I}, \ldots, k,
$$

where $f_{i}$ is related to the utility function, $\mathbf{p}_{s}$ is the vector of prices corresponding to $\mathbf{q}_{s}$ and $y_{s}$ is the allocation of total expenditure to group $s$. Of course, underlying this result are concavity and continuity conditions on $U(),. F($.$) ,$ and each $U_{s}\left(\mathbf{q}_{s}\right)$ as well as the linearity of the budget constraint. These imply that the expenditure equations (2) are linear homogenous in $\mathbf{p}_{s}$ and $y_{s}$ and that the Hicksian or compensated price derivatives are symmetric forming a negative semi-definite Slutsky substitution matrix. Once $y_{s}$ is determined at the first stage, each $\mathbf{q}_{s}$ can be determined without reference to prices outside this group.

Under intertemporal weak separability, once the optimal level of saving is determined for each period, prices outside any period have no independent effect on within period allocations. The variable $y_{s}$ acts as a sufficient statistic for all intra group substitution allowing no further impact of prices outside the group in question. Separability conditions are as vital to the recent temporally separable 'surprise' consumption function of Hall (1978) as they were to Stone (1954) and his colleagues in their Linear Expenditure System. In addition separability of goods and leisure is a crucial assumption in the 'separate' modelling of consumption and labour supply decisions. Being perhaps the most important of assumptions in applied consumer theory, separability must also stand as one of the most unreasonable in many applications, including those mentioned above.

Certain additional requirements are often placed on consumer behaviour which are rather stronger than we have mentioned so far. One of these is additive separability in which case (I) is replaced by

$$
U\left(x_{1}, \ldots, x_{n}\right)=F\left[\sum_{s} U_{s}\left(\mathbf{q}_{s}\right)\right] .
$$


where $\Sigma_{s}$ refers to the summation of arguments indexed by $s$. As Deaton (1974a) illustrated, this assumption can be quite restrictive. However, it is typically used in intertemporal consumer behaviour where maximisation is expressed over expected life-time utility conditional on current information and each $s$ refers to a separate time period. Under expected utility maximisation some form of forward looking additivity is reasonably plausible although we may well expect $U_{s}($.$) to depend on past period behaviour. We shall return to$ this point later in Section II.

A popular further condition to place on preferences is for the top stage allocation to each sub group expenditure $y_{s}$ out of total (life-time) expenditure $y$ to depend on single sub-group price indices $P_{s}\left(\mathbf{p}_{s}\right)$. In this case the determination of each $y_{s}$ can be written

$$
y_{s}=f_{s}\left[P_{\mathbf{1}}\left(\mathbf{p}_{\mathbf{1}}\right), \ldots, P_{k}\left(\mathbf{p}_{k}\right), y\right] \text {, }
$$

where each $P_{s}\left(\mathbf{p}_{s}\right)$ represents the true price index for group $s$. For example, in the intertemporal allocation problem, each period's consumption expenditure could then be expressed in terms of a single price index for each period. Although this is a common enough assumption it is restrictive. Weak separability (or even additive separability for that matter) is not a sufficient condition for such a price aggregation result. If preferences are homothetic within each group, that is elasticities with respect to total within group expenditure are unity, then weak separability is sufficient. However, if homotheticity is to be relaxed only a very particular set of preferences derived by Gorman (1959) will generate expenditure equations of the form (4).

In the homothetic case we may write each expenditure equation (2) as

$$
p_{i} x_{i}=f_{i}\left(\mathbf{p}_{s}\right) y_{s}
$$

so that each expenditure share of good $i$ out of group $s$ expenditure $y_{s}$

$$
s_{i}^{s}=f_{i}\left(\mathbf{p}_{s}\right)
$$

is independent of $y_{s}$ and only depends on within group prices. Group $s$ preferences then have the most simple of forms since although substitution elasticities are not directly restricted they are deemed independent of the level of $y_{s}$, guaranteeing a unitary income or expenditure elasticity $\left(\partial \ln x_{i} / \partial \ln y_{s}\right)$. Using Roy's Identity (see Deaton and Muellbauer, $198 \mathrm{o} b, \mathrm{p} .4 \mathrm{I}$ ), indirect utility for group $s$ in the homothetic case is given by

$$
V_{s}=G_{s}\left[y_{s} / b_{s}\left(\mathbf{p}_{s}\right)\right],
$$

where $G_{s}$ is some monotone increasing function and $b_{s}\left(\mathbf{p}_{s}\right)$ is a general linear homogenous function of prices conveniently expressed as

$$
\ln b_{s}\left(\mathbf{p}_{s}\right)=\sum_{i} f_{i}\left(\mathbf{p}_{s}\right) \ln p_{i} .
$$

Notice that in this case the 'Stone' price index which weights each $\ln p_{i}$ by $s_{i}$ is exact as can be seen by comparing (8) and (6). Replacing $U_{s}$ by $V_{s}$ in the weakly separable utility function yields

$$
V\left(\mathbf{p}_{1}, \ldots, \mathbf{p}_{k}, y\right)=G\left\{G_{\mathbf{1}}\left[y_{1} / b_{\mathbf{1}}\left(\mathbf{p}_{1}\right)\right], \ldots, G_{k}\left[y_{k} / b_{k}\left(\mathbf{p}_{k}\right)\right]\right\}
$$


so that the $b_{s}\left(\mathbf{p}_{s}\right)$ are exactly the appropriate single group price indices $P_{s}\left(\mathbf{p}_{s}\right)$ that uniquely deflate each $y_{s}$.

If we wish to generalise (5) to allow linear Engel (expenditure/income) curves with non-zero intercepts so that expenditure on good $i$ may be written

$$
p_{i} x_{i}=a_{i}\left(\mathbf{p}_{s}\right) p_{i}+f_{i}\left(\mathbf{p}_{s}\right) y_{s}
$$

then indirect utility (6) takes the form

$$
V_{s}=G_{s}\left\{\left[y_{s}-a_{s}\left(\mathbf{p}_{s}\right)\right] / b_{s}\left(\mathbf{p}_{s}\right)\right\},
$$

where $a_{s}\left(\mathbf{p}_{s}\right)=\sum_{i} p_{i} a_{s i}\left(\mathbf{p}_{s}\right)$. Preferences (I I) are known generally as Gorman Polar Form and display quasi-homothetic (linear Engel curve) behaviour. Although restrictive, they do not imply unitary elasticities with respect to total within group expenditure and underly the Linear Expenditure System of Stone (1954) as well as motivating more recent work on consumer behaviour (see, for example, Atkinson and Stern (1980), Blackorby, Boyce and Russell (1978), Blundell and Walker (I982), Browning et al. (1985) and Pollak and Wales ( 1978$)$ ). Notice that if $G_{s}$ is linear and overall utility is explicitly additive then $V$ may be written

$$
V=\Sigma_{s}\left[y_{s}-a_{s}\left(\mathbf{p}_{s}\right)\right] / b_{s}\left(\mathbf{p}_{s}\right)
$$

in which case only $b_{s}\left(\mathbf{p}_{s}\right)$ enters the determination of $y_{s}$. However, although we are back to a single index result (the $b_{s}\left(\mathbf{p}_{s}\right)$ indices alone determine $\left.y_{s}\right)$ the solution for $y_{s}$ is not continuous since both $V$ and the budget constraint are linear in $y_{s}$. More specifically, all expenditure over and above $a_{s}\left(\mathbf{p}_{s}\right)$ is placed in the group with the lowest price index $b_{s}\left(\mathbf{p}_{s}\right)$.

To avoid the problems associated with (I 2) we may follow Anderson's ( 1979) application of Gorman's result and allow for single price aggregates and nonlinear Engel curves. If we assume explicit additivity at the top stage and write indirect utility as

$$
V_{s}=G_{s}\left[y_{s} / b_{s}\left(\mathbf{p}_{s}\right)\right]+h_{s}\left(\mathbf{p}_{s}\right),
$$

where $h_{s}\left(\mathbf{p}_{s}\right)$ is a linear homogenous concave function then, provided $G_{s}($.$) is$ not linear, a well behaved solution can be found under which the determination of $y_{s}$ depends only on $b_{\mathbf{1}}\left(\mathbf{p}_{s}\right), \ldots, b_{k}\left(\mathbf{p}_{k}\right)$ and $y$ as required. However, as $G_{s}($. approaches linearity all expenditure over and above $a_{s}\left(\mathbf{p}_{s}\right)$ is placed in the group with the lowest price index $b_{s}\left(\mathbf{p}_{s}\right)$. This is exactly the discontinuous solution referred to above. This case must therefore be taken as the exception that proves the rule: a single price aggregator or index for group expenditure is in general difficult to justify.

At a more general level we can see that even for the quasi-homothetic case, under weak separability two price indices $a_{s}\left(\mathbf{p}_{s}\right)$ and $b_{s}\left(\mathbf{p}_{s}\right)$ are crucial in the determination of any $y_{s}$. For in that case overall utility may be written

$$
V=G\left(G_{1}\left\{\left[y_{\mathbf{1}}-a_{\mathbf{1}}\left(\mathbf{p}_{\mathbf{1}}\right)\right] / b_{\mathbf{1}}\left(\mathbf{p}_{\mathbf{1}}\right)\right\}, \ldots, G_{k}\left\{\left[y_{k}-a_{k}\left(\mathbf{p}_{k}\right)\right] / b_{k}\left(p_{k}\right)\right\}\right)
$$

so that maximising $V$ subject to the constraint $y_{1}+y_{2}+\ldots+y_{k}=y$ results in group expenditures of the general form

$$
y_{s}=f_{s}\left[a_{\mathbf{1}}\left(\mathbf{p}_{\mathbf{1}}\right), b_{\mathbf{1}}\left(\mathbf{p}_{\mathbf{1}}\right), \ldots, a_{\mathbf{2}}\left(\mathbf{p}_{\mathbf{2}}\right), b_{\mathbf{2}}\left(\mathbf{p}_{\mathbf{2}}\right), \ldots, a_{k}\left(\mathbf{p}_{k}\right), b_{k}\left(\mathbf{p}_{k}\right), y\right] .
$$


These points will crop up time and again throughout this survey indicating the absolutely crucial role both separability and homotheticity (or lack of them) play in applications of consumer theory.

Before moving on to our discussion of functional forms for describing indirect or direct preferences it may be worth briefly deriving the form for the consumer's cost or expenditure functions which correspond to the indirect utility representations described above. As we shall see the cost function has achieved wide use in recent applied consumer theory taking a special place in welfare measurement. Since it is defined as the minimum expenditure necessary to achieve some given level of utility it has a natural use in measures of compensating variations and equivalence scales.

The cost function corresponding to homothetic preferences described above in (5) has the form

$$
C\left(\mathbf{p}_{s}, U_{s}\right)=b_{s}\left(\mathbf{p}_{s}\right) U_{s},
$$

where $b_{s}\left(\mathbf{p}_{s}\right)$ is the linear homogenous concave function of prices described in equation (8). Since the price derivatives of $C$ are the corresponding Hicksian or compensating demands, traditional Marshallian demands (5) can be derived by simply substituting the corresponding indirect utility for $U_{s}$ in the compensated demand function. Compensated demands are given by

$$
C_{i}\left(\mathbf{p}_{s}, U_{s}\right)=p_{i}^{-1} f_{i}\left(\mathbf{p}_{s}\right) b_{s}\left(\mathbf{p}_{s}\right) U_{s},
$$

where $C_{i}$ is the $i$ th price derivative of $C$ and Marshallian demands by

$$
x_{i}=p_{i}^{-1} f_{i}\left(\mathbf{p}_{s}\right) y_{s}
$$

identical to those in equation (5). Of course, inverting (I6) will give the corresponding indirect utility function up to some monotonic transformation. The relationship between the cost function and the compensated demand curve has some considerable appeal, not least because the second order price derivatives give the constant utility 'Slutsky' substitution effects.

\section{2. Some Functional Forms}

Choice of functional form for the representation of consumer preferences must stand as one of the most important issues in any aspect of the empirical analysis of consumer behaviour. Our ability to assess the importance of preference restrictions described in the previous section relies on choosing a functional form that is tractable without being unduly restrictive. For example, testing for additive separability in a model that assumed homothetic preferences may be easy but is probably worthless. The degree of misspecification that is engendered by the homotheticity assumption of unit income elasticities could severely distort the additivity test. However, theoretically consistent models that allow general income and price effects which also nest interesting simplifying specifications are few and far between.

The widespread use of the consumer's cost or indirect utility function as a representation of preferences in empirical analysis has produced a number of attractive specifications. The majority of these are well known and I shall only pick on those that appear particularly convenient. The first is the translog 
indirect utility function of Christensen et al. (1975) which is one of a class of flexible functional forms discussed by Diewert (1974). In this model indirect utility is written as the following second order logarithmic expansion

$$
V=\alpha_{0}+\sum_{j} \alpha_{j} \ln p_{j}^{*}+\frac{1}{2} \sum_{j} \sum_{i} \beta_{i j} \ln p_{j}^{*} \ln p_{i}^{*},
$$

where $p_{j}^{*}=p_{j} / y$ and the $\alpha_{0}, \alpha_{j}$ and $\beta_{i j}$ refer to unknown preference parameters. Using Roy's Identity the expenditure share equations have the form

$$
s_{j}=\left(\alpha_{j}+\sum_{i} \beta_{j i} \ln p_{j}^{*}\right) / k,
$$

where $k=-\mathrm{I}+\Sigma_{i} \Sigma_{j} \beta_{i j} \ln p_{j}^{*}$. Within this broad group of flexible specifications for expenditure shares should also be placed the Generalised Leontief form of Diewert (I97I) in which the $\ln p_{j}^{*}$ terms in (20) would be replaced by $\left(p_{j}^{*}\right)^{\frac{1}{2}}$. Clearly, $(20)$ can be used to investigate the validity of symmetry and homogeneity restrictions. Moreover, when $\beta_{i j}=o$ for all $i$ and $j$, the model describes homothetically additive preferences.

Closely related to these 'flexible functional form' models are the models of Muellbauer (1975, I976) and Deaton and Muellbauer (I980a). In these papers a particularly convenient specification entitled 'Almost Ideal' was developed from a more general class of Price Independent Generalised Linear (PIGL) models. In its various forms we shall be returning to this general class of models at a number of points in this survey. There is no doubt that this specification displays some considerably attractive features. In general the PIGL class has an indirect utility function of the form

$$
V=G\left\{\left[y^{\alpha}-a(\mathbf{p})^{\alpha}\right] /\left[b(\mathbf{p})^{\alpha}-a(\mathbf{p})^{\alpha}\right]\right\},
$$

where $a(\mathbf{p})$ and $b(\mathbf{p})$ are linear homogenous, concave functions of prices. Clearly, when $\alpha=$ I the indirect utility equation (2 I) becomes quasihomothetic and by appropriate choice of $a(\mathbf{p})$ and $b(\mathbf{p})$ can be made to nest the popular Stone-Geary or LES model. However, the share equations corresponding to (2 I) are highly nonlinear and to avoid this, Deaton and Muellbauer (I980 $a$ ) work with the logarithmic (PIGLOG) case in which $\alpha \rightarrow 0$. Choosing $\ln a(\mathbf{p})$ to be of a Translog form and $\ln b(\mathbf{p})$ to $\Pi_{j} p_{j}^{\beta_{j}}+\ln a(\mathbf{p})$ the share model reduces to the Almost Ideal form

$$
s_{j}=\alpha_{j}+\sum_{j} \theta_{i j} \ln p_{j}+\beta_{j} \ln [y / a(\mathbf{p})],
$$

where the $\alpha_{j}, \theta_{i j}$, and $\beta_{j}$ are all constant unknown parameters. If $a(\mathbf{p})$ in each share equation is approximated by some readily available price index, then (22) is linear in parameters and variables. Homotheticity requires $\beta_{j}=0$ for all $j$ whereas homogeneity requires $\Sigma_{j} \theta_{i j}=0$. Similarly, symmetry implies $\theta_{i j}=\theta_{j i}$ for all $i$ not equal $j$. As we shall mention later these specifications possess some attractive aggregation characteristics which was clearly the initial motivation of Muellbauer's work. As might be expected, they do restrict preferences to some degree and one might certainly wish to investigate higher order income terms in (22) (see, for example, Gorman (I98I)) as well as more general forms for $b(\mathbf{p})$.

In this direction of functional form specification Blundell and Ray ( 1984 ) and Blundell and Walker (I986) use a class of preferences similar to (2 I) but 
with certain simplifying characteristics. In their model the indirect utility function is written

$$
V=G\left\{\left[y^{\alpha}-a(\mathbf{p}, \alpha)^{\alpha}\right] / b(\mathbf{p}, \alpha)^{\alpha}\right\}, \quad \alpha>0
$$

in which $a(\mathbf{p}, \alpha)$ and $b(\mathbf{p}, \alpha)$ are linear homogeneous functions which are allowed to depend directly on $\alpha$. Share equations corresponding to (24) have the same general form as in the PIGL case, quasi-homothetic preferences occurring when $\alpha=\mathrm{I}$. However, by defining $p_{i}^{*}=p_{i} / y$ and expressing

$$
a(\mathbf{p}, \alpha)=\left[\sum_{i j} \theta_{i j}\left(p_{i}^{*} p_{j}^{*}\right)^{\alpha / 2}\right]^{1 / \alpha},
$$

and

$$
b(\mathbf{p}, \alpha)=\left[\Pi_{i} p_{i}^{f_{i}(\mathbf{p}) \alpha}\right]^{1 / \alpha}
$$

where $\Pi_{i}$ represents the product over arguments indexed by $i$, the expenditure share equations take the form

$$
s_{j}=\sum_{i} \theta_{i j}\left(p_{i}^{*} p_{j}^{*}\right)^{\alpha / 2}+f_{j}(\mathbf{p})\left[\mathrm{I}-\sum_{i j} \theta_{i j}\left(p_{i}^{*} p_{j}^{*}\right)^{\alpha / 2}\right]
$$

in which case the nonlinearity appears simply through the $\alpha$ in the $\left(p_{i}^{*} p_{j}^{*}\right)^{\alpha / 2}$ terms. A simple grid search over $\alpha>$ o can be used to choose $\alpha$. When $\alpha=\mathrm{I}$, setting $\theta_{i j}=\mathrm{o}$ for $i \neq j$ and setting all $f_{j}(\mathbf{p})=\beta_{j}$ generates the popular additive LES or Stone-Geary system. The advantage of this latter system is that it easily nests (and can therefore be used to test the Linear Expenditure System. However, if on prior grounds it is felt that LES is not worth entertaining and a PIGLOG system is more likely, then working directly with the PIGL model would seem preferable.

\section{3. Rationing, Corner Solutions and Zero Expenditures}

In many instances observations will relate to consumers whose behaviour is in some way constrained. It may be, for example, that consumers are rationed with respect to their current level of housing consumption or their current level of labour supply. Alternatively, they may face binding non-negativity constraints (corner solutions) which at current income and prices make it optimal to consume only some commodities. Not all zero expenditures, however, will reflect corner solutions or rationed behaviour. Indeed, in household surveys of limited duration, we may not observe consumption at all! Infrequency of purchase or durability may result in expenditures that reflect stocking-up for consumption in future periods rather than simply for consumption within the given period.

These problems are real enough. It is difficult to believe that all consumers are free to vary consumption and labour supply at will. It is also reasonable to believe that consumption of some items and indeed some labour supplies may well be zero because the current price or wage makes such a corner solution optimal. Finally, the durability of some goods makes a deviation of recorded expenditure from consumption quite likely. Nevertheless, it is only recently that, following the move to use more micro level data, empirical analysis has sought to deal with these issues in any depth.

The theoretical framework for analysing the first two of these issues is well established and hinges on the discussion of virtual prices - the price at which 
the rationed level would just be chosen. The best single source for this work is Neary and Roberts ( I980) although Deaton and Muellbauer (I98I) provide a more detailed guide to functional form specification under rationing. However, as empirical models of female labour supply have had to cope with the single corner solution at zero hours many of the economic and econometric developments can also be found in that earlier literature (see, for example, Heckman $(1974 b))$. Moreover, as constraints are never very far from any empirical analysis of labour supply, models of rationing can also be found in the labour supply literature (see, for example, Ashenfelter and Ham (1979) and Ham (I982)). Perhaps the most important feature of the Neary and Roberts work is in the study of rationing or binding constraints within a system of consumer decisions. What impact will labour market unemployment or rationing in the housing market have on the demand for clothing or services? To answer this we need to analyse how virtual prices or wages, themselves functions of the ration, feed through to affect unrationed consumer decisions.

Needless to say separability is as crucial here as in any other aspect of applied consumer theory. Quite simply, if a good that is rationed is weakly separable from the one under consideration the only impact of rationing will be via the total budget or total expenditure available. This is useful in many respects. Labour market rationing has only an income effect on disaggregated commodity demand if separability between goods and 'leisure' time can be assumed. Under intertemporal separability, rationing in the current period only affects future period consumption decisions via the total amount of wealth allocated to that future period. Again separability is a convenient but invariably strong assumption.

Things get considerably worse, at least for the empirical economist, when more than one non-negativity or other inequality constraint is allowed to bind simultaneously. Again the theoretical issues are not too arduous but finding a suitable empirical specification that relaxes additive separability can be extremely tough and has generally prohibited work in this area. Two notable exceptions to this are the papers by Wales and Woodland (1983) and Lee and Pitt (1986). However, in these studies only non-negativity constraints are considered, which for the Translog model used in the Lee and Pitt study provides a particularly convenient simplification. Before discussing these issues in rather more detail it should be pointed out that possibly the main difficulty faced in this work is in the econometric rather than economic specification. For even under preference separability, although rationing of one decision variable may have rather straightforward effects on the systematic part of other decisions, correlation between the stochastic components on the rationed and unrationed equations results in bias if standard least squares estimators are utilised.

Perhaps the neatest way to deal with rationing or binding inequality constraints on consumer behaviour is via the expenditure or cost function. Suppose that good $j$ is rationed at $x_{j}^{r}$, then the cost minimising problem for the consumer may be written as

$$
C^{r}\left(\mathbf{p}^{j}, x_{j}^{r}, U^{r}\right)=\min _{x_{j}}\left(\mathbf{p}^{j} \mathbf{x}^{j} \mid U \geqslant U^{r}\right)-p_{j} x_{j}^{r},
$$


where the superscript $j$ refers to a vector with the $j$ th element excluded. The cost function $C^{r}$ describes the minimum cost over unconstrained expenditures of achieving $U^{r}$ at prices $\mathbf{p}^{j}$ and with the consumption of $x_{j}$ fixed at $x_{j}^{r}$. The variable $x_{j}^{r}$ may represent hours of work in which case the constraint could refer to involuntary unemployment. The system of 'conditional' demand functions for unrationed goods is then simply obtained from the derivatives of (27). In practice, defining $p_{j}^{r}$ to be the virtual price at which $x_{j}^{r}$ would be freely chosen, enables $C^{r}$ to be derived by replacing $p_{j}$ in the unconditional cost function by $p_{j}^{r}$ itself a function of all other prices, $x_{j}^{r}$ and $U^{r}$.

As an illustration, which has been used to assess both rationing and separability, consider the following simple extension to the LES model in which $x_{j}$ - the good to be rationed or to have a corner solution - is allowed to be nonseparable from other goods. The unconditional cost function is written

$$
C\left(\mathbf{p}, U^{r}\right)=a(\mathbf{p})+d\left(\mathbf{p}^{j}\right) p_{j}+b(\mathbf{p})^{1-\theta_{j}} p_{j}^{\theta_{j}} U,
$$

where

$$
a(\mathbf{p})=\Sigma_{r} p_{r} \alpha_{r}
$$

$$
d\left(\mathbf{p}^{j}\right)=\delta_{j} \Pi_{r} p_{r}^{\delta_{r}} \quad \text { not including } r=j,
$$

and

$$
b(\mathbf{p})=\Pi_{r} p_{r}^{\beta_{r}} \text {, also not including } r=j \text {. }
$$

The unrationed demand equations take the form

$$
p_{i} x_{i}=p_{i} \alpha_{i}+\delta_{i} \delta_{j} p_{j}+\left(\mathrm{I}-\theta_{j}\right) \beta_{i}\left[y-a(\mathbf{p})-d\left(\mathbf{p}^{j}\right) p_{j}\right] \quad \text { for all } i \neq j
$$

and

$$
p_{j} x_{j}=\left(\mathrm{I}-\theta_{j}\right) p_{j} d\left(\mathbf{p}^{j}\right) p_{j}+\theta_{j}\left[y-a(\mathbf{p})-d\left(\mathbf{p}^{j}\right) p_{j}\right]
$$

which are all but identical to the Linear Expenditure System apart from the 'non-separability' term $\delta_{i} \delta_{j} p_{j}$ in (29).

The convenience of this system is that the reservation price for good $j$ at which $x_{j}^{r}$ would just be chosen can be solved explicitly from (30) as

$$
p_{j}^{r}=\left\{\left[\beta_{j} b^{\left(1-\theta_{j}\right)} U\right] /\left[x_{j}^{r}-d\left(\mathbf{p}^{j}\right)\right]\right\}^{1 /\left(1-\theta_{j}\right)} .
$$

This enables derivation of the 'matched pair' of rationed and unrationed demand equations. Indeed, the rationed expenditure equations for other goods corresponding to (29) are of the form

$$
p_{i} x_{i}=p_{i} \alpha_{i}+\left\{\beta_{i}+k d\left(\mathbf{p}^{j}\right) \delta_{i} /\left[x_{j}^{r}-d\left(\mathbf{p}^{j}\right)\right]\right\}\left[y-a(\mathbf{p})-p_{j} x_{j}^{r}\right],
$$

where $k=\theta_{j} /\left(\mathrm{I}-\theta_{j}\right)$. These conditional or rationed demand equations show immediately the ways in which rationing on one good may influence other consumption decisions. First, there is the direct income effect $p_{j} x_{j}^{r}$ which is subtracted from (supernumerary) total expenditure. Secondly, there is the effect on the marginal propensity to consume which alters $\beta_{i}$ to the extent by which $\delta_{i}$ differs from zero. If $\delta_{i}=$ o then separability would prevail and only the income effect would remain. Blundell and Walker (1982) use this 'matched pair' specification (with more general forms for $a(\mathbf{p})$ and $b(\mathbf{p}))$ to test the separability of commodity demand decisions from labour supply. In that illustration the separability assumption is rejected whether or not labour supply is considered rationed. 


\section{4. Estimation Issues}

Aggregation. As much of the empirical evidence concerning consumer theory relates to models using aggregate data, it is worth considering the issue of aggregation across consumers. This is tied intimately with the degree of nonlinearity in individual level behaviour. For example, suppose the individual level Engel curve is quadratic in income. Further, suppose the objective of the empirical exercise is to recover parameters describing the time series relationship between mean expenditure and mean income. In this case aggregation bias will depend on the importance of the quadratic term and the sample covariance (over time) between the first and second order moments of income. In general, if movements in the higher order characteristics of the income distribution are related to movements in the mean and if the Engel curve is nonlinear then bias will occur. Of course, even where the aggregation bias is small, knowing how the distribution of expenditures over individuals or households evolves over time may be of considerable interest in its own right.

The importance of linear Engel curves for the micro foundations of aggregate consumer demand relationships was highlighted by Gorman ( I953). If we wish to provide an exact micro interpretation of an aggregate relationship between per capita consumers' expenditure and per capita income then individual Engel curves must be linear and parallel. Intercept shifts across individuals are all that is allowed. Given the inherent nonlinearity between expenditures and income (see, Working ( I943), for example) this result of Gorman's provides a fairly pessimistic story for aggregate analysis. The breakthrough in this stalemate came with Muellbauer's (1975) and (1976) papers. Herein lay the reconciliation between the shape of individual Engel curves preferred by the Working study - expenditure shares linear in the logarithm of income or total expenditure - and the popular translog demand systems for aggregate level analysis of Jorgenson and his colleagues (see equation (i9) above). Muellbauer's work showed that aggregation was possible within demand systems generated by the PIGL family described by equation (26) above. As we noted, this includes the Almost Ideal model (22) which has many similar features to both the Working Engel curves and the translog demand model.

The importance of the aggregation debate cannot be underplayed since, if reasonably general forms for demand patterns can be found that aggregate consistently, then we can simultaneously recover information about individual level behaviour from aggregate data and expect consistent predictions from aggregate models. One important consideration in this debate which had also attracted Gorman's attention in his 1953 paper, is the incorporation of individual characteristics. How do requirements on aggregate demand systems change if we not only wish to allow nonlinear Engel curves as in Muellbauer's work, but also wish individual level behaviour to depend on household characteristics? This question was considered by Lau (1982), Jorgenson et al. ( 1982 ) and Stoker (1984). They showed that for exact aggregation to underpin an aggregate model (where labelling of consumers or households is un- 
important) demand equations must be expressed as the sum of terms each one being the product of a function of prices and a function of individual income or expenditure and characteristics. Moreover, these latter indeces must be additive in the individual characteristics. Imposing integrability conditions on these demand equations further restricts the class. Indeed, as Gorman ( $198 \mathrm{I}$ ) shows (see also Browning $(\mathrm{I} 987 b$ ) and Russell ( 1983$)$ ), at most three independent terms are allowed in the sum referred to above. Since one must be total expenditure in order to preserve adding-up and the others must be chosen to preserve homogeneity the form for individual demands is significantly restricted but clearly not as tightly as in the original Gorman (1953) linear class. Although this ties one's hand in choosing suitable aggregate demand functions, certain specifications of both the translog and the Almost Ideal model satisfy these requirements.

Perhaps the most illuminating way of illustrating the relationship between aggregate and micro-level studies is to take the Almost Ideal model (22) and make it household specific by adding an ' $h$ ' subscript to denote household ' $h$ '. A 'household' here refers to the micro level consuming unit and may refer to an individual, a family or some other collection of individuals whose consumption decisions are taken together. Household specific expenditure shares are then given by

$$
s_{i h}=\alpha_{i h}+\sum_{j} \theta_{i j h} \ln p_{j}+\beta_{i h} \ln \left(y_{h} / P\right),
$$

where we have replaced $a(\mathbf{p})$ by the price index $P$. Equation (33) focuses attention on various important issues in aggregation. Indeed, premultiplying (33) by $y_{h} / \Sigma_{h} y_{h}$ and summing over $h$ generates the aggregate share equation

$$
s_{i}=\Sigma_{h} \mu_{h} \alpha_{i h}+\Sigma_{h} \sum_{j} \mu_{h} \theta_{i j h} \ln p_{j}+\sum_{h} \mu_{h} \beta_{i h} \ln \left(y_{h} / P\right),
$$

where $\mu_{h} \equiv y_{h} / \Sigma_{h} y_{h}$. If $\theta_{i j h}$ and $\beta_{i h}$ are constant across $h$ and if in addition, $\alpha_{i h}$ depends linearly on a vector of characteristics $\mathbf{z}_{h}$, then (34) becomes

$$
s_{i}=\boldsymbol{\alpha}_{i}^{\prime} \mathbf{z}^{\mathbf{0}}+\sum_{j} \theta_{i j} \ln p_{j}+\beta_{i} \ln \bar{y}+\beta_{i} \ln y^{*},
$$

where $\mathbf{z}^{0}$ is the vector of total expenditure shares out of aggregate total expenditure associated with each of the characteristics, $\ln \bar{y}$ is the $\log$ of mean total expenditure and $\ln y^{*}$ equals $\Sigma_{h} \mu_{h} \ln \left(y_{h} / \bar{y}\right)$. Interestingly $\ln y^{*}$ is an entropy measure of income inequality. In populations where $\mathbf{z}^{\mathbf{0}}$ and $\ln y^{*}$ are approximately constant over reasonable time intervals, aggregate time series data could be used to recover estimates of $\theta_{i j}$ and $\beta_{i}$ consistently. Where $\ln y^{*}$ was constant over time and $\mathbf{z}^{\mathbf{0}}$ varied, the consistency of resulting parameter estimates from aggregate data hinges on the independence or otherwise of the evolution of the mean characteristics with the $\ln p_{j}$ and $\ln \bar{y}$. As $\mathbf{z}^{0}$ would normally contain slowly changing characteristics such as the average size of demographic groups it could well be captured by a simple trend. Even so since $\ln \bar{y}$ can also be expected to trend, estimation of $\beta_{i}$ may be biased unless trend terms are included. Moreover, the correlation of omitted $\mathbf{z}^{\mathbf{0}}$ factors over time may appear as autocorrelated disturbances or misspecified dynamics (see Stoker, I986). 
In general, census or survey data could be used to construct the $\mathbf{z}^{0}$ and $\ln y^{*}$ components which could then be introduced into aggregate demand systems. Indeed, (35) shows how evidence on income inequality entering through $\ln y^{*}$ helps pin down the $\beta_{i}$ coefficient. However, this relies on the parameters $\theta_{i j h}$ and $\beta_{j h}$ being independent of household characteristics. This seems unlikely, and in the microeconometric study of fuel expenditures by Baker et al. (1987), for example, both price and income coefficients are found to vary systematically across households. Moreover, we shall see in the empirical evidence from household data provided later on in this section, the variables that are likely to influence preference parameters are many and cover not only demographic but also tenure, ownership and employment status variables.

Zero Expenditures and Corner Solutions. Household expenditure patterns often differ radically from the simple continuous expenditure share expressions of the model described above. We have seen earlier how rationing and/or corner solutions can lead to the introduction of reservation or virtual prices. In general and for a number of different possible reasons, we may observe households with zero expenditures in any period over which we survey them. Although at the micro level, provided we can identify the cause of the zero expenditure, modelling and estimation can proceed using standard micro econometric procedures (see Blundell and Meghir ( $1987 b$ ) for a more detailed analysis) at the aggregate level life is not so easy. Indeed, aggregation across corner solutions poses some interesting econometric problems in itself.

To examine the issues involved we first define the indicator variable

$$
I_{t h}= \begin{cases}\mathrm{I} & \text { if individual } h \text { buys } \\ 0 & \text { otherwise }\end{cases}
$$

which describes whether in period $t$ individual $h$ is observed buying a particular good. In order to allow for a general process determining the buy/non-buy decision, we suppose that the buy decision depends on observable characteristics $\mathbf{z}_{t h}$ and unobservables $v_{t h}$ and we write the following reduced form latent equation

$$
I_{t h}^{*}=\mathbf{z}_{t h}^{\prime} \boldsymbol{\beta}+v_{t h}
$$

for which $I_{t h}=\mathrm{I}$ if $I_{t h}^{*}>\mathrm{o}$ and $I_{t h}=\mathrm{o}$ if $I_{t h}^{*} \leqslant \mathrm{o}$. In this framework, 'latent' demand is given by $x_{t h}^{*}=d_{t h}\left(p_{t}, y_{t h}\right)+u_{t h}$ where $d_{t h}()$ can be thought of as $f_{i} / p_{i}$ in (2) for some commodity $i$ and each $u_{t h}$ represents other random factors influencing demand. Observed demand may then be written as

$$
x_{t h}=I_{t h} d_{t h}\left(p_{t}, y_{t h}\right)+\theta_{t h}+e_{t h}
$$

where $\theta_{t h}=E\left\{I_{t h} . u_{t h}\right\}$ and by definition $e_{t h}=I_{t h} u_{t h}-\theta_{t h}$. Assuming a joint normal distribution for $u_{t h}$ and $v_{t h}$ (rather weaker assumptions can be made), the expectational term $\theta_{t h}$ is proportional to the standard normal density $\phi\left(\mathbf{z}_{t h}^{\prime} \boldsymbol{\beta}\right)$.

Now suppose that $\mathbf{Z}_{t}$ represents the per capita values of $\mathbf{z}_{t h}$ and suppose these exogenous average measures were available at the aggregate level. Similarly, let $\mathbf{D}_{t}$ be the per buyer demand functions (i.e. averaged across buyers only) and let it be assumed that each $d_{t h}\left(p_{t}, y_{t h}\right)$ is linear in parameters and not dependent 
on $\mathbf{z}_{t h}$. In this case standard aggregation conditions for a model without corners or rationing would prevail. However, the aggregate relationship corresponding to $\left(3^{8}\right)$ above satisfies

$$
X_{t}=\mathbf{I}_{t} \cdot \mathbf{D}_{t}(\cdot)+\theta_{t}+e_{t},
$$

where $X_{t}$ is per capita demand, $\mathbf{I}_{t}$ is the proportion of buyers and $\theta_{t}$ can be written proportional to $\phi\left(\mathbf{Z}_{t}^{\prime} \boldsymbol{\beta}\right)$ (see MaCurdy (I986)). Notice that (39) is nonlinear in $\mathbf{Z}_{t}$ and depends on the per buyer variables in $\mathbf{D}_{t}$ (income, for example). Even assuming both per buyer and per capita variables are available, the aggregate equation is still nonlinear. Indeed, a model of the form

$$
X_{t}=\mathbf{D}_{t}(\cdot)+w_{t}
$$

where $w_{t}$ was assumed to have the same properties as $e_{t}$ in (39), would display instability and general misspecification in so far as $I_{t}$ varies over time and in so far as the nonlinear term $\theta_{t}$ was important in (39). Simply including the proportion of buyers as an additional explanatory variable in estimation at the macro level model may well pick up the misspecification underlying (40) but would be unlikely to provide consistent estimates of the parameters in (39).

Although the corner solution problem described above invalidates the usual interpretation of aggregate consumer relationships, estimation at the micro level is also complicated by corner solutions. Essentially, estimation requires the evaluation of the expectation of the unrestricted demands conditional on those at corner solutions. This in turn involves the evaluation of the joint probability of the corner solutions. Since corner solutions are expressed as an inequality constraint this probability will require the evaluation of an integral for each corner. Where the stochastic terms on commodities are correlated, multiple integrals have to be solved. Until the recent work of McFadden (I986) such computations have been virtually intractable and only systems with relatively few corners (Wales and Woodland (1983) and Lee and Pitt (1986), for example) have been considered.

In assessing the importance of corner solutions, the level of commodity aggregation is crucial. If, for example, consumption of individual clothing items are under analysis, then multiple corner solutions for any individual household in an expenditure survey seem highly likely. However, at a more aggregate level - the total of clothing for example - zero expenditures are more likely to derive from the infrequency of purchase relative to the period of survey. Purchase infrequency implies that the theoretical concept of consumption differs from its measured counterpart: expenditure. As this discrepancy affects both the dependent variable and the total expenditure variable, Ordinary Least Squares estimates of the share equations are biased.

All surveys on individual or household expenditures cover purchases over a limited period of time. Indeed, the more accurate the measurement in terms of precise diary records the shorter the period over which the survey can be afforded and the more likely the occurrence of reported zero expenditures. Even where the expenditure in question relates to an item or group of items for which actual consumption is positive, infrequency of purchase or the 
'durability' of the good may result in a recorded zero expenditure. Deaton and Irish (I 984), Kay et al. (I 984), Pudney (1987) and Blundell and Meghir (I987) have developed a class of bivariate models for the joint determination of the purchase and expenditure decision. Measurement error in total consumption is critical in the estimation of the parameters of utility consistent demand systems since it is usually assumed that total consumption is measured without error and demand analysis can proceed to examine the way in which consumption on specific commodities is allocated conditional on total consumption. Keen ( 1986 ) has shown that an instrumental variable estimator (which will be described in the following discussion of exogeneity) is also sufficient to remove the OLS bias in the infrequency of purchase model. In the more structural infrequency of purchase models, a purchase probability is explicitly introduced. For example, in the Blundell and Meghir (I987a) approach this probability is allowed to vary with income and other household characteristics so as to minimise the extent to which 'unobservable' characteristics are left to explain the distribution of purchases.

Exogeneity and Corner Solutions. In general, although total expenditure is treated as an appropriate conditioning variable, there is no reason why it should be assumed exogenous. Any exogeneity assumption of this type can be checked against the data at the outset. Two difficulties arise at this point. How do we test this (or any other) exogeneity assumption across a system of equations where corner solutions may occur and how should we re-estimate if exogeneity is rejected?

For estimation purposes, we shall write the system of $y$-conditional demands as

$$
\mathbf{s}_{t h}=\mathbf{d}_{t}\left(\mathbf{p}_{t}, y_{t h}\right)+\mathbf{u}_{t h},
$$

where $\mathbf{s}_{t h}$ represents a vector of expenditure (or earnings) shares for household $h$ in period $t$ and $\mathbf{u}_{t h}$ the corresponding vector of stochastic error terms. If the demand model is estimated from panel data then $\mathbf{d}_{t h}($.$) may include a$ household or individual fixed effect for each commodity. For aggregate time series we may drop the $h$ subscript. For the purposes of testing the exogeneity assumption we shall approximate the equation for $y_{t}$ by

$$
y_{t}=\boldsymbol{\gamma}^{\prime} \mathbf{z}_{t}+v_{t}
$$

where $\mathbf{z}_{t}$ are a vector of observed exogenous (instrumental) variables with $\gamma$ as their unknown constant coefficients and $v_{t}$ is a random error term. The question of focus here relates to the exogeneity of $y_{t}$ for the estimation of the preference parameters in the model $(4 \mathrm{I})$. Where $\mathbf{z}_{t}$ contains prices alone, so that homogeneity is required to generate an exclusion restriction on (4I), Attfield (I985) has neatly shown the equivalence of the exogeneity and homogeneity tests. However, using the two stage budgeting theory described earlier, we may expect to be able to define many other additional instruments in (42) allowing the separate assessment of exogeneity and homogeneity.

Where there are no corner solutions, the procedure for testing (and estimation) is straightforward and follows the analysis of Hausman (I978). Inclusion of the reduced form residual $\hat{v}_{t}$ in each equation in $(4 \mathrm{I})$ and 
estimation of the extended system provides consistent estimates for the demand parameters. In addition, an F-test for the exclusion of the residual in the demand system provides an asymptotically efficient exogeneity test.

Where corner solutions arise, Smith and Blundell ( 1986 ) show that little of the standard analysis for exogeneity testing discussed above changes. Consistency of the estimates in the extended system under the alternative remains and the exogeneity test is again asymptotically efficient. The only problem to note under this limited dependent variable case is that the form for $y_{t h}$ which depends on either the market or reservation price switches when any decision variable is rationed or at a corner solution. As Ransom (1987) has shown, the coherency conditions (see Gourieroux et al., I980) required for estimation are equivalent to the integrability conditions (concavity, symmetry, ...) for utility maximising behaviour. This is a general result for switching models derived from consumer behaviour and extends to the case of many binding non-negativity constraints or corner solutions discussed earlier. Integrability is by no means an innocuous condition since concavity restrictions can severely restrict the flexibility of commonly used 'flexible' demand systems. This point has been highlighted in the recent paper of Diewert and Wales ( 1987 ).

Cross Equation Restrictions and the Minimum Chi-Square Estimator. Even though each of the above issues - aggregation, corner solutions, purchase infrequency and exogeneity - are important the principles of estimating demand systems referred to in the earlier survey by Brown and Deaton (1972) are still relevant. Briefly, adding-up across expenditure or expenditure share equations implies a singular variance-covariance matrix for the stochastic terms across equations the stochastic term on any one share equation cannot be independent of all other share equations. However, provided there are no cross-equation restrictions single equation estimation remains efficient. Endogeneity of total expenditure and purchase infrequency do not detract from this result. However, since restrictions like Slutsky symmetry are an integral part of empirical demand analysis, estimation under cross-equation restrictions has played a major role in producing parsimonious theoretically consistent demand systems.

Estimation under such restrictions requires system wide estimation and for large samples this can be computationally difficult. The Minimum Chi-Square (MCS) approach introduced into the econometrics literature by Rothenberg ( 1973) provides a simple and yet relatively underutilised method of deriving estimates subject to system wide restrictions. Moreover, these are equivalent to those derived from application of the Full Information Maximum Likelihood approach. The attraction of the MCS method relates to the separate stages of unrestricted and restricted estimation. At the first stage estimates of the parameters of the unrestricted model are recovered which for a standard demand system (the LES or AI system, for example) would involve estimating unrestricted share equations. These estimates together with their covariance matrix summarise all information available in the data concerning preference parameter estimation. In effect they act as sufficient statistics for the purposes of demand system estimation. 
Denoting the unrestricted parameters by $\boldsymbol{\theta}$, theoretical restrictions (symmetry, homogeneity, etc.) may usually be expressed as

$$
\boldsymbol{\theta}=\mathbf{S} \boldsymbol{\theta}^{*} \text {. }
$$

To impose these restrictions the MCS method chooses $\hat{\boldsymbol{\theta}}^{*}$ so as to minimise the quadratic form

$$
m=\left(\hat{\boldsymbol{\theta}}-\mathbf{S} \boldsymbol{\theta}^{*}\right)^{\prime} \hat{\boldsymbol{\Sigma}}_{\boldsymbol{\theta}}^{-\mathbf{1}}(\hat{\boldsymbol{\theta}}-\mathbf{S} \boldsymbol{\theta} *),
$$

where $\hat{\boldsymbol{\Sigma}}_{\boldsymbol{\theta}}$ is the estimated variance-covariance matrix for $\hat{\boldsymbol{\theta}}$. Indeed, consistency of the resulting MCS estimator simply requires that the restrictions are correct and that $\hat{\boldsymbol{\theta}}$ is a consistent estimator. Any positive definite weight matrix can be used to replace $\hat{\boldsymbol{\Sigma}}_{\boldsymbol{\theta}}^{-1}$. However, where the optimal weight matrix is used, the MCS estimator is asymptotically equivalent to the maximum likelihood estimator and the minimised value of $m$ is an optimal chi-squared test of the restrictions (see Ferguson, I958). Under linear restrictions like (43) the MCS estimator itself is given by

$$
\hat{\boldsymbol{\theta}} *=\left(\mathbf{S}^{+\prime} \mathbf{S}^{+}\right)^{-1} \mathbf{S}^{+\prime} \boldsymbol{\theta}^{+},
$$

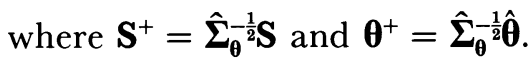

In practice, this method proceeds as follows. First, each unrestricted demand equation is estimated separately. Then the restricted estimators are recovered by fitting the restrictions using (44) which, being in the dimension of $\boldsymbol{\theta}$, can be significantly less than the number of observations. The application of the MCS method therefore makes constrained estimation and testing available in very large samples. To implement constrained maximum likelihood estimation there is no need therefore to exclude observations for computational tractability - all information in the unrestricted model is exploited and summarised by simply defined statistics in the first stage of unrestricted estimation. An application of this technique is provided in the empirical illustration reported below.

\section{5. Assessing the Evidence}

Rather than providing a comprehensive catalogue of empirical results in the literature, this section will be used to present a summary of some empirical results based on micro-data. The idea here is to provide the reader with an example of the power of empirical demand analysis and the attractiveness of working at the individual household level. Given the different levels of aggregation and commodity grouping used in other empirical studies, it should be clear that comparison of estimated parameters (or elasticities for that matter) can be a hazardous activity. Working at the household level reveals a more detailed analysis of the distribution of elasticities by household type and will also have implications for the degree of aggregation bias one might expect. These results, drawn from the Blundell et al. (I987) study, adopt the minimum chi-squared principle described in the previous section, to recover estimates of a seven good Almost Ideal model of demand from a pooled cross section over I5 annual time series covering more than 65, ooo non-pensioner households. These data are drawn from the annual UK Family Expenditure Survey for the years $1970-84$ and provide an ideal basis for the application of the minimum 
chi-squared method. In one form or another this data base has been the cornerstone of many empirical studies of consumer behaviour including, for example, the papers by Atkinson and Stern (I980), Browning et al. (1985), Muellbauer (1977) and Pollak and Wales (I98I).

On micro data the wide variation in demographic and other individual characteristics is all too evident. The extent to which price and income parameters vary with these characteristics is clearly important for the aggregation results described earlier in this Survey. Estimation results for the price and income variables in the homogeneity and symmetry constrained model are presented in Table I. Here to account for the likely endogeneity and measurement error due to purchase infrequency discussed in Section I.4 we have instrumented the total expenditure variable. As already mentioned many individual demographic, locational and labour market characteristics were allowed to enter each share equation and each of these was used as an instrument for the total expenditure variable. In addition instruments included normal disposable income, other prices, interest rates and local unemployment rates. It was found necessary to interact the seasonal dummies $\left(S_{1}, S_{2}\right.$ and $\left.S_{3}\right)$ and young child dummy $(C)$ with the $\log$ of total expenditure $\ln y$. These are

Table I

Restricted Price and Income Parameter Estimates*

\begin{tabular}{|c|c|c|c|c|c|c|c|}
\hline Variable & Food & Alcohol & Fuel & Clothing & Transport & Services & Other \\
\hline $\ln P F O O D$ & $\begin{array}{c}\text { o.096247 } \\
\text { (o.01006) }\end{array}$ & $\begin{array}{c}\text { o.ol } 2 \text { I I } 4 \\
(\text { o.00687) }\end{array}$ & $\begin{array}{r}-0.01389 \text { I } \\
(0.00554)\end{array}$ & $\begin{array}{r}-0.00447 \mathrm{I} \\
(0.008 \mathrm{I} 3)\end{array}$ & $\begin{array}{r}-0.040401 \\
(0.01120)\end{array}$ & $\begin{array}{c}-0.015352 \\
\text { (o.0083o) }\end{array}$ & $-0.034^{246}$ \\
\hline $\ln P A L C L$ & $\begin{array}{c}\text { o.0 I } 2 \text { I I } 4 \\
(0 \cdot 00687)\end{array}$ & $\begin{array}{r}-0.062385 \\
(0 \cdot 00898)\end{array}$ & $\begin{array}{c}\text { o.06433 I } \\
\left(0^{\circ} 00598\right)\end{array}$ & $\begin{array}{r}-0.006507 \\
(0.00629)\end{array}$ & $\begin{array}{c}\text { o.041337 } \\
(\text { o.01067) }\end{array}$ & $\begin{array}{c}-0 \cdot 005995 \\
(\text { o.00804) }\end{array}$ & $\begin{array}{c}-0.042895 \\
-\end{array}$ \\
\hline $\ln P F U E L$ & $\begin{array}{r}-0.01389 \mathrm{I} \\
(0.00554)\end{array}$ & $\begin{array}{c}0.06433 \mathrm{I} \\
(0 \cdot 00598)\end{array}$ & $\begin{array}{l}0.006570 \\
(0 \cdot 00670)\end{array}$ & $\begin{array}{r}-0.0019 \text { I } 7 \\
(0.00534)\end{array}$ & $\begin{array}{c}-0.050553 \\
(0 \cdot 00876)\end{array}$ & $\begin{array}{c}-0.016588 \\
\left(0^{\circ} 00634\right)\end{array}$ & $\begin{array}{c}\text { o.o } 2049 \\
-\end{array}$ \\
\hline ln PCLOTH & $\begin{array}{r}-0.00447 \text { I } \\
(0 \cdot 008 \text { I3) }\end{array}$ & $\begin{array}{r}-0.006507 \\
(0.00629)\end{array}$ & $\begin{array}{r}-0.001917 \\
(0.00534)\end{array}$ & $\begin{array}{c}\text { о.0 } 6439 \\
\text { (о.00948) }\end{array}$ & $\begin{array}{c}-0.003078 \\
(0.01075)\end{array}$ & $\begin{array}{c}-0.014020 \\
(0.00801)\end{array}$ & $\begin{array}{l}\text { o.013554 } \\
-\end{array}$ \\
\hline $\ln P T R P T$ & $\begin{array}{r}-0.04040 \text { I } \\
(0.01 \text { I } 20)\end{array}$ & $\begin{array}{c}\text { o.041 } 337 \\
(0.01067)\end{array}$ & $\begin{array}{c}-0 \cdot 050553 \\
(0 \cdot 00876)\end{array}$ & $\begin{array}{c}-0.003078 \\
(\text { o.01075) }\end{array}$ & $\begin{array}{c}0.0555^{\circ} \text { o } \\
\left(0^{\circ} 02390\right)\end{array}$ & $\begin{array}{c}0.007 \text { I } 29 \\
\text { (0.01323) }\end{array}$ & $\begin{array}{c}-0.009994 \\
-\end{array}$ \\
\hline $\ln P S E R V$ & $\begin{array}{c}-0.015352 \\
(0.00830)\end{array}$ & $\begin{array}{r}-0.005995 \\
(0 \cdot 00804)\end{array}$ & $\begin{array}{c}-0.016588 \\
(\text { (o.00634) }\end{array}$ & $\begin{array}{c}-0.014020 \\
(0.00801)\end{array}$ & $\begin{array}{c}0.007 \text { I } 29 \\
(0.01323)\end{array}$ & $\begin{array}{c}\text { o॰o I } 7884 \\
\text { (o॰o I } 338)\end{array}$ & $\begin{array}{c}0.026943 \\
-\end{array}$ \\
\hline $\ln$ PFUEL & -0.013891 & $0 \times 06433^{I}$ & $\begin{array}{c}0.006570 \\
-\end{array}$ & -o.0oIgI 7 & -0.050553 & $\begin{array}{c}-0.016588 \\
-\end{array}$ & $\begin{array}{c}\text { o.o } 2049 \\
-\end{array}$ \\
\hline$C \ln y$ & $\begin{array}{c}0.002523 \\
\left(0^{\circ} 00033\right)\end{array}$ & $\begin{array}{c}-0.002844 \\
(0.00027)\end{array}$ & $\begin{array}{l}\text { o.00095o } \\
\text { (o.00019) }\end{array}$ & $\begin{array}{c}0.002197 \\
(0.00036)\end{array}$ & $\begin{array}{r}-0.004886 \\
(0 \cdot 00045)\end{array}$ & $\begin{array}{c}0.001003 \\
(0.00037)\end{array}$ & $\begin{array}{c}0.001057 \\
-\end{array}$ \\
\hline$S_{I} \ln y$ & $\begin{array}{r}-0^{\circ} 006934 \\
\left(0^{\circ} 00240\right)\end{array}$ & $\begin{array}{c}-0.0041^{72} \\
(0.00198)\end{array}$ & $\begin{array}{r}-0.005013 \\
(0.00138)\end{array}$ & $\begin{array}{r}-0.005053 \\
(0.0026 \mathrm{I})\end{array}$ & $\begin{array}{c}\text { o.015405 } \\
\left(0^{\circ} 00330\right)\end{array}$ & $\begin{array}{c}0.010654 \\
(0.00270)\end{array}$ & $\begin{array}{c}-0.004886 \\
-\end{array}$ \\
\hline$S 2 \ln y$ & $\begin{array}{r}-0.012277 \\
(0.00240)\end{array}$ & $\begin{array}{r}-0.004 \text { II } 3 \\
(0.00198)\end{array}$ & $\begin{array}{c}\text { o.004914 } \\
(\text { o.00I37) }\end{array}$ & $\begin{array}{r}-0.0074^{24} \\
\left(0^{\circ} 00260\right)\end{array}$ & $\begin{array}{c}\text { 0.010277 } \\
(0.00330)\end{array}$ & $\begin{array}{c}0.013280 \\
(0.00270)\end{array}$ & $-0.00465^{8}$ \\
\hline$S_{3} \ln y$ & $\begin{array}{r}-0.015690 \\
(0.00235)\end{array}$ & $\begin{array}{r}-0.007975 \\
(0.00194)\end{array}$ & $\begin{array}{c}\text { o.0 I 2040 } \\
\text { (o.001 } 35)\end{array}$ & $\begin{array}{c}-0.006440 \\
(0.00255)\end{array}$ & $\begin{array}{c}0 \cdot 005457 \\
(0 \cdot 00324)\end{array}$ & $\begin{array}{c}0.014733 \\
(0.00264)\end{array}$ & $\begin{array}{c}-0.002126 \\
-\end{array}$ \\
\hline $\ln y$ & $\begin{array}{c}-0 \cdot 123882 \\
(0 \cdot 00204)\end{array}$ & $\begin{array}{c}\text { o.057474 } \\
(0.00169)\end{array}$ & $\begin{array}{c}-0.059123 \\
(0.001 \text { I } 8)\end{array}$ & $\begin{array}{c}0.028762 \\
(0.00221)\end{array}$ & $\begin{array}{c}0 \cdot 034726 \\
(0 \cdot 0028 \mathrm{I})\end{array}$ & $\begin{array}{c}0.07094^{8} \\
\left(0^{\circ} 00230\right)\end{array}$ & $\begin{array}{c}-0 \cdot 008906 \\
-\end{array}$ \\
\hline
\end{tabular}

* Source: for Tables I, 2 and 3 : Blundell et al. (1987). Other explanatory variables included demographic, tenure, regional and seasonal dummies.

Standard errors in parentheses. 
presented along with the price coefficients in Table $\mathrm{I}$. It is comforting to note that many of the price coefficients are significant despite the large number of other characteristics allowed to influence expenditure shares.

To gauge the importance of working with individual data and to provide an example of the type of price and income elasticities one can expect to elicit from empirical demand systems of this type, Tables $2(a)$ and $2(b)$ provide a detailed description of Marshallian price and budget elasticities for households with and without children. It should be noted that our sample excludes all pensioners. In Tables $3(a)$ and $3(b)$ a similar analysis is conducted for two of the commodity categories to assess the distribution of elasticities across households with differing income in our sample. These results show that household characteristics have important impacts on consumer behaviour acting both through income and price effects.

Table 2

Price and Income Elasticities

\begin{tabular}{|c|c|c|c|c|c|c|}
\hline & \multicolumn{6}{|c|}{ Commodity Group } \\
\hline & Food & Alcohol & Fuel & Glothing & Transport & Services \\
\hline \multicolumn{7}{|c|}{ (a) Households with Children } \\
\hline Budget elasticities & o-668 & $2 \cdot 014$ & $0 \cdot 329$ & $I \cdot 269$ & $\mathrm{I} \cdot 2 \mathrm{I} 2$ & $I \cdot 654$ \\
\hline \multicolumn{7}{|c|}{ Uncompensated price elasticities } \\
\hline Food & $-0 \cdot 494$ & $-0 \cdot 006$ & $0 \cdot 05 \mathrm{I}$ & -0.005 & -0.088 & -0.076 \\
\hline Alcohol & $-0.54 \mathrm{I}$ & $-\mathrm{I} \cdot 983$ & $0 \cdot 865$ & $-o \cdot 136$ & o.668 & $0^{\bullet} \circ 00$ \\
\hline Fuel & $0 \cdot 34^{2}$ & -0.653 & -0.747 & $-0 \cdot 008$ & -0.534 & $-0 \cdot 25^{8}$ \\
\hline Clothing & -0.242 & -0.030 & -0.089 & $-0 \cdot 85^{2}$ & $-0 \cdot 045$ & $-0 \cdot 103$ \\
\hline Transport & -0.404 & $0 \cdot 276$ & -0.364 & -0.023 & -0.674 & o॰o66 \\
\hline Services & -0.629 & $0 \times 020$ & -0.327 & $-0 \cdot 143$ & 0.027 & $-0 \cdot 767$ \\
\hline \multicolumn{7}{|c|}{ Compensated price elasticities } \\
\hline Food & $-0 \cdot 246$ & 0.032 & O. IIO & o.066 & $0.02 \mathrm{I}$ & $-0 \cdot 004$ \\
\hline Alcohol & 0.210 & $-\mathrm{r} \cdot 869$ & I·043 & 0.080 & o॰999 & 0.218 \\
\hline Fuel & $0 \cdot 464$ & $0.67 \mathrm{I}$ & -0.718 & 0.027 & -0.480 & -0.223 \\
\hline Cloth & 0.231 & $0 \cdot 042$ & 0.023 & $-0 \cdot 716$ & $0 \cdot 163$ & $0 \cdot 045$ \\
\hline Transport & $0 \cdot 048$ & $0 \cdot 345$ & -0.257 & o. I 06 & -0.475 & $0 \cdot 197$ \\
\hline Services & -0.012 & O. I I 4 & $-0 \cdot 18 \mathrm{I}$ & $0 \cdot 034$ & $0 \cdot 298$ & $-0.5^{87}$ \\
\hline \multicolumn{7}{|c|}{ (b) Households without Children } \\
\hline Budget Elasticities & $0 \cdot 6$ I 3 & $I \cdot 73^{8}$ & $0 \cdot 278$ & $I \cdot 30 I$ & $I \cdot I 80$ & I·556 \\
\hline \multicolumn{7}{|c|}{ Uncompensated Price Elasticities } \\
\hline Food & $-0.43^{I}$ & 0.00 I & 0.057 & -0.010 & $-0 \cdot 092$ & $-0 \cdot 08 \mathrm{I}$ \\
\hline Alcohol & $-0 \cdot 355$ & $-\mathrm{I} \cdot 73 \mathrm{I}$ & $0 \cdot 635$ & -0.090 & 0.465 & -0.014 \\
\hline Fuel & o*330 & 0.717 & -0.733 & -0.017 & -0.553 & $-0 \cdot 264$ \\
\hline Clothing & $-0 \cdot 255$ & -0.040 & -0.098 & -0.830 & -0.059 & $-0.12 \mathrm{I}$ \\
\hline Transport & $-0 \cdot 333$ & 0.231 & -0.308 & -0.018 & -0.728 & 0.052 \\
\hline Services & -0.504 & $0 \cdot 006$ & -0.274 & -0.115 & o॰0o6 & -0.813 \\
\hline \multicolumn{7}{|c|}{ Compensated Price Elasticities } \\
\hline Food & -0.235 & o॰049 & $0 \cdot 107$ & $0 \cdot 048$ & 0.027 & -0.003 \\
\hline Alcohol & 0.201 & $-r^{\cdot} 596$ & 0.777 & 0.076 & 0.80 I & $0 \cdot 208$ \\
\hline Fuel & 0.419 & 0.739 & -0.710 & o॰oio & -0.499 & -0.228 \\
\hline Clothing & $0 \cdot 16 I$ & 0.062 & $0 \bullet 008$ & -0.706 & $0 \cdot 192$ & $0 \cdot 045$ \\
\hline Transport & $0 \cdot 044$ & 0.323 & -0.212 & o•095 & -0.500 & 0.203 \\
\hline Services & -0.007 & 0.127 & $-0 \cdot 147$ & $0 \cdot 034$ & 0.307 & $-0.6 \mathrm{I} 4$ \\
\hline
\end{tabular}


Table 3

Distribution of Elasticities by Income Group

\begin{tabular}{|c|c|c|c|c|c|c|}
\hline \multirow[b]{2}{*}{ Income Percentile } & \multicolumn{2}{|c|}{ Children } & \multicolumn{2}{|c|}{ No children } & \multicolumn{2}{|c|}{ All } \\
\hline & Mean & STD & Mean & STD & Mean & STD \\
\hline
\end{tabular}

(a) Uncompensated Own Price Elasticities

Food

\begin{tabular}{|c|c|c|c|c|c|c|}
\hline Low $5 \%$ & $-0.5 \mathrm{I}$ & $0 \cdot 06$ & $-0 \cdot 48$ & 0.07 & $-0 * 49$ & 0.06 \\
\hline $6-10 \%$ & -0.50 & 0.07 & -0.44 & $0 \cdot 10$ & -0.47 & 0.07 \\
\hline I I $-25 \%$ & -0.48 & 0.04 & $-0 * 40$ & o.10 & $-0 * 45$ & 0.05 \\
\hline Mid $50 \%$ & -0.42 & $0 \% 04$ & $-0 \cdot 32$ & o॰09 & -0.39 & 0.04 \\
\hline $7^{6-90} \%$ & -0.36 & 0.10 & -0.24 & 0.21 & -0.31 & O. I I \\
\hline Тор го \% & $-0 \cdot 29$ & 0.23 & $-0 \cdot 12$ & $0 \cdot 44$ & -0.22 & 0.24 \\
\hline All & -0.40 & 0.04 & -0.29 & $0 \cdot 07$ & $-0 \cdot 36$ & 0.04 \\
\hline \multicolumn{7}{|c|}{ Fuel } \\
\hline Low $5 \%$ & -0.92 & 0.04 & $-0 \circ 08$ & 0.05 & -0.90 & $2 \cdot 04$ \\
\hline $6-10 \%$ & -0.90 & 0.04 & -0.83 & 0.07 & -0.87 & 2.04 \\
\hline I I $-25 \%$ & -0.86 & 0.03 & -0.78 & $0 \cdot 06$ & -0.83 & 3.03 \\
\hline Mid $50 \%$ & -0.77 & $0 \cdot 03$ & $-0 \cdot 68$ & $0 \cdot 05$ & -0.74 & $4^{\circ} 02$ \\
\hline $76-90 \%$ & -0.67 & $0 \cdot 08$ & -0.55 & $0 \cdot I_{I}$ & -0.62 & 6.07 \\
\hline Тор го \% & -0.56 & O. I4 & $-0 \cdot 4 \mathrm{I}$ & 0.19 & -0.50 & $9^{\circ} 12$ \\
\hline All & -0.75 & 0.03 & -0.65 & 0.04 & -0.71 & $5^{\circ} 02$ \\
\hline
\end{tabular}

(b) Income (Budget) Elasticities

Food

\begin{tabular}{|c|c|c|c|c|c|c|}
\hline Low $5 \%$ & $0 \cdot 72$ & 0.05 & 0.67 & o.06 & $o \cdot 69$ & 0.05 \\
\hline $6-10 \%$ & $0.7 \mathrm{I}$ & 0.06 & 0.64 & 0.08 & 0.68 & 0.05 \\
\hline I I $-25 \%$ & 0.69 & 0.03 & $0.6 \mathrm{I}$ & $0 \circ 08$ & $0 \cdot 66$ & 0.03 \\
\hline Mid $50 \%$ & 0.65 & 0.03 & $0_{5} 6$ & 0.06 & 0.62 & 0.08 \\
\hline $76-90 \%$ & $0.6 \mathrm{I}$ & 0.07 & $0.5 \mathrm{I}$ & $\mathrm{O} \cdot \mathrm{I} 4$ & 0.52 & $0 \cdot 16$ \\
\hline Тор го $\%$ & 0.56 & 0.15 & 0.43 & 0.28 & $0.5 \mathrm{I}$ & $0 \cdot 16$ \\
\hline All & $o \cdot 64$ & 0.03 & $0 \cdot 54$ & 0.05 & $0 \cdot 60$ & 0.03 \\
\hline \multicolumn{7}{|c|}{ Fuel } \\
\hline Low $5 \%$ & 0.62 & $0 ॰ 08$ & 0.53 & 0.04 & $0_{5} \cdot 6$ & 0.07 \\
\hline 6-10\% & $0.5^{8}$ & 0.08 & 043 & 0.13 & $0.5^{2}$ & 0.08 \\
\hline I I $-25 \%$ & $0 * 49$ & 0.05 & $0 * 35$ & O.II & 0.44 & $0 \cdot 06$ \\
\hline Mid $50 \%$ & $0 \cdot 33$ & 0.04 & 0.17 & $0 \circ 08$ & 0.28 & 0.04 \\
\hline $76-90 \%$ & 0.17 & O. I 3 & -0.03 & $0 \cdot 18$ & 0.09 & O. II \\
\hline Тор го \% & $-0.0 \mathrm{I}$ & 0.23 & $-0 \cdot 24$ & $0.3 \mathrm{I}$ & $-0 \cdot I_{I}$ & 0.19 \\
\hline All & $0 \cdot 31$ & 0.04 & $0 \cdot 13$ & o॰o6 & $0 \cdot 24$ & 0.04 \\
\hline
\end{tabular}

In terms of the historical development of empirical demand analysis an important consideration is the degree of consistency between household behaviour and integrability conditions-homogeneity, symmetry and concavity. One interesting outcome of the empirical study described above is that homogeneity is acceptable across all goods. This contrasts markedly with results on aggregate data - see, for example, Deaton and Muellbauer (I98o $a$ ). Moreover, both in the Deaton and Muellbauer study and in many that follow - Anderson and Blundell ( 1983 ), for example-dynamic misspecification is suggested as the root cause of homogeneity rejections. As was noted earlier in 
the survey and emphasised by Stoker (I986), the omitted characteristics in aggregate models implied from this study may evolve in a way that is captured by the introduction of dynamic adjustment or trend like terms.

The symmetry restriction is less coherent with data within the empirical illustration described above. The symmetry test has a Chi-Square value of $79^{\cdot 20}$ with I 5 degrees of freedom. However, further analysis suggests two possible problems with these results. First, is the degree of heteroscedasticity underlying the model and second the likely importance of interactions between prices and individual household characteristics. Neither of these two considerations are accounted for in Table I. Adjusting for heteroscedasticity tends to lower the test statistic referred to above while allowing price coefficients to depend on characteristics may make symmetry more acceptable. Nevertheless, the symmetry and homogeneity constrained parameter estimates reported in Table I display well determined coefficients with plausible values for the elasticities presented in Tables 2 and 3. By looking at the matrix of compensated price elasticities in Table 2 it can be observed that own price effects are large and negative while the cross effects are generally positive. This shows a close adherence to concavity and taken together with the above results suggests, perhaps surprisingly, that integrability conditions are not too much at odds with observed micro behaviour once individual characteristics are allowed for.

From the discussion in Section I.4, the implications for work on aggregate data are clear. Even ignoring the interaction of the income and price coefficients with individual characteristics, aggregate models that explain demands in terms of price and total expenditure variables exclude many important explanatory factors. These factors - for example, the proportion of total expenditure associated with particular family size or tenure groups change over time in a way that is probably correlated with real total expenditure and relative price movements making it difficult to identify the separate effects from aggregate data. In turn without the separate identification of these factors, it is difficult to test theoretical hypotheses concerning pure price and income terms. Once it is also acknowledged that the total expenditure, and to some extent price, coefficients in the estimated Almost Ideal model vary systematically with individual characteristics, then the conditions for exact aggregation described in Section I.4 themselves fail.

These results suggest particular care should be taken in interpreting estimated demand elasticities and tests of theoretical restrictions based on them from studies using aggregate data. They also suggest that a comparison of estimates either across different time periods or different countries in which important characteristics (or the income shares going to households with such characteristics) may not be constant and may very likely display coefficient instability. It is quite possible that polynomial time trends or dynamic adjustment terms may correct for these omitted factors and thereby make results more comparable. However, the importance of these issues coupled with intertemporal considerations that will be raised in the next section point to exciting research areas that have yet to be satisfactorily explored. As a result, 
in writing this survey paper, I have been drawn towards a more detailed discussion of these issues rather than towards a comparison of estimates from other empirical studies. However, a reasonably detailed list of empirical demand studies is to be found in the bibliography.

Turning to dynamic considerations we may note from our discussion of intertemporal separability in Section I.2 that, if intertemporal substitution is possible, then consumers will adjust the total expenditure variable in response to intertemporal price and interest rate changes. In order to assess, therefore, the total effect of price and other variables on consumer behaviour one cannot simply work within the models described in this section. Moreover, if intertemporal separability is not satisfied then the two-stage budgeting rules for life-cycle expenditure allocations which can be used to justify most of the 'static' models described in this section, will be subject to misspecification and may not even recover within period preference parameters consistently. It is to the assessment of these intertemporal issues and the dynamic process of consumer behaviour to which we now turn.

\section{THE LIFE-GYGLE MODEL AND DYNAMIC GONSUMER BEHAVIOUR}

\section{I. Overview}

At the aggregate consumption level some form of dynamic behaviour has usually been incorporated in empirical specification. Broadly speaking two types of model have emerged - those that take a more traditional time series view of the dynamic specification leaving theory to play most of its role in the long run or steady state solution and those that explicitly incorporate forward looking behaviour distinguishing between unanticipated and anticipated effects. Both of these approaches have their drawbacks just as both have led to major developments in our understanding of intertemporal consumer behaviour. The forward looking models are in principle better suited to policy analysis since they can identify the effect of an unanticipated temporary or permanent shock which in turn reflects many policy changes. However, the dynamic paths and underlying preferences in the majority of the empirical specifications of these models are highly restrictive. They have tended to ignore adjustment problems, habits and liquidity constraints and have been subjected to the apparently contradictory criticisms of both excess sensitivity to current income changes and excess smoothness of consumption. Moreover, empirical work at the aggregate level generally appeals to the notion of a representative consumer, even though modelling dynamic behaviour places even stricter aggregation conditions than those discussed in Section I.4 since agents must now be comparable across time. Indeed, unless individuals entering the population can be assumed to take on the same expectations and place in the wealth distribution as individuals leaving, estimation will generally result in some degree of aggregation bias.

As with all good empirical research, a synthesis of these two strands of research is producing a new breed of dynamic forward looking models which appear a good deal more satisfactory. Even more encouraging, although not 
without its own difficulties, is the application to individual panel data where aggregation bias, at least, is removed. It is these recent developments on which I wish to concentrate. However, before turning to the importance of the debate over life-cycle models and dynamics, we briefly return to the models of the previous section to evaluate their place in all this.

Although apparently static, we noted earlier that under intertemporal two stage budgeting the models of the previous sections can be given a life-cycle consistent interpretation. This will be dealt with in more detail in the next section where the simplest, and to some extent most popular, life-cycle models are considered more critically. Nevertheless, it is correct to say that models in which disaggregated commodity expenditures are explained in terms of within period prices and the total current period expenditure allocation can easily be generated by an intertemporally separable life-cycle model. In this application of a two-stage budgeting, (expected) life-cycle wealth is allocated across periods so as to equalise the discounted marginal utility of wealth while each period's optimal allocation is distributed across goods. This simple idea applies equally well to models of the joint determination of commodity demand and labour supply decisions. However, the intertemporal separability assumption on which they rest is precisely that which rules out the liquidity constraints, habits and explicit dynamics alluded to above.

It is worth, at this stage, stressing the strength of the capital markets assumptions which enable the budget constraint to be written as a single additive life time (expected) wealth constraint. Where borrowing is restricted by asset levels or some fixed multiple of current earnings, additional constraints may well bind, thus invalidating the simple perfect capital markets model (see Mariger ( $1987 b)$ and Hayashi ( $1985 b)$, for example). Moreover, as King ( I986) demonstrates, a differential rate between borrowing and lending ensures that marginal utility may not be equalised. These issues seem particularly relevant for interpreting the relationship between macro and micro estimates of intertemporal consumer behaviour since a good deal of the empirical evidence (Hall and Mishkin (I982), for example) suggests that the importance of capital market imperfections may differ systematically across the population.

The problem for empirical analysis in this life-cycle or dynamic framework is choosing the most appropriate avenues for generalisation that maintain some degree of parsimony. The debates in this area are by no means over and the choice of model will, as ever, be determined by the objective to which the model is to be used. However, whether one is working with a pooled time series of cross sections, a true household panel or simply with aggregate time series there are clear avenues which must be explored in order to evaluate the restrictiveness of any assumed specification. As this survey is designed specifically to investigate the interplay between theory and testing, our initial discussion in the next section will be concerned with the restrictiveness of the (implicit) theoretical models of consumer behaviour underlying various of the life-cycle specifications. 


\section{2. Empirical Representations of Life-Cycle Models}

Initially we shall assume that consumers have perfect foresight and that utility is separable over time. In each period decisions are made so as to maximise discounted lifetime utility subject to time and asset constraints with perfectly predicted future market wages, prices, transfer income and demographic characteristics.

An attraction of the time separable life-cycle framework is the ease by which the perfect foresight assumption can be relaxed so as to allow uncertainty and replanning. This is not altogether surprising since, as we saw in Section I.2, the separability assumption allows the direct application of two-stage budgeting theory and ensures that life-cycle consistent current demands can be written in terms of a single variable capturing both past decisions and future anticipations. With uncertainty or dynamic replanning care needs to be taken in assessing the exogeneity of any explanatory factors; however, in this case the theoretical model also provides a partition of variables into those that may be assumed exogenous for the purposes of estimating intertemporal preference parameters.

Defining $\mathbf{x}_{s}$ to be the choice vector in period $s$, lifetime utility in any period ' $t$ ' may be written as the following discounted sum of (concave twice differentiable) period by period utility indices $U_{s}\left(\mathbf{x}_{s}\right)$

$$
U_{t}^{*}=\Sigma_{s} \phi^{s-t} U_{s}\left(\mathbf{x}_{s}\right) \text { for } s=t, \ldots, L,
$$

where $L$ is the number of periods in the lifetime of the household decision maker and $\phi(=\mathrm{I} /(\mathrm{I}+\delta))$ represents the subjective time discount factor (see. Ghez and Becker, 1975). Although $\mathbf{x}_{s}$ can easily include leisure or labour supply components, for ease of illustration it will initially be assumed to include consumption goods alone. Life-cycle utility is then maximised subject to the combination of a within period budget identity

$$
\mathbf{p}_{s}^{\prime} \mathbf{x}_{s}=y_{s},
$$

where $y_{s}$ is total period $s$ consumption expenditure, and the asset accumulation constraint

$$
y_{s}=\mu_{s}+r_{s} A_{s-1}-\Delta A_{s},
$$

where $y_{s}$ is the sum of earned and transfer income $\mu_{s}$, interest income $r_{s} A_{s-1}$ and asset decumulation $-\Delta A_{s} ; A_{s}$ being the level of household assets at the end of period $s, r_{s}$ the certain rate of interest earned on $A_{s-1}$ during period $s$ and $\Delta$ is the first difference operator. $\Delta A_{s}$ is therefore the change in assets over period $s-\mathrm{I}$. In developing this life-cycle framework we have added the crucial perfect capital markets condition. Under this assumption the interest rate $r_{s}$ is independent of current net worth $A_{s}$ so that given perfect foresight any amount of future labour or nonlabour income can be discounted into current period income. In this case a sequence of asset levels $A_{s}$ or savings decisions for $s=\mathrm{I}, \ldots, L$ can be freely chosen so as to maximise life-cycle utility.

To complete this outline of the life-cycle framework it is useful to combine the two budget 'constraints' above to define the following life-time wealth constraint

$$
\begin{aligned}
\sum_{s} \mathbf{p}_{s}^{\prime} \mathbf{x}_{s} & =\left(\mathrm{I}+r_{t}\right) A_{t-1}+\sum_{s} \mu_{s} \\
& =W_{t},
\end{aligned}
$$


where each $\Sigma_{s}$ refers to summation for $s=t, \ldots, L$ and where for convenience we define all prices, wage rates and transfer incomes to be discounted back to period $t$. If $\mathbf{x}_{s}$ contains 'leisure' time as well as goods then $y_{s}$ can be redefined to represent full income as described in Section I. I. A fuller description of the life-cycle model incorporating labour market considerations is developed in Blundell (1986). For the most part it will be convenient to interpret $y_{t}$ to be total consumption expenditure. However, this is equivalent to assuming that life-cycle utility (46) is explicitly additive in goods and labour supply. The marginal utility of consumption in any period is then completely independent of current period labour supply decisions - except for their effect on life-cycle wealth. Although we shall argue later that explicit additivity assumptions of this kind are excessively restrictive and largely unnecessary, they have been commonly adopted in empirical studies of intertemporal consumption behaviour and serve as a useful starting point for our discussion.

Under the two-stage budgeting allocation of total consumption expenditure in period $t$ of the life-cycle, $y_{t}$ is given by

$$
y_{t}=g_{t}\left(\mathbf{p}_{t}, \mathbf{p}_{t+1}, \ldots, \mathbf{p}_{L}, W_{t}\right),
$$

where $g_{t}$ is homogeneous of degree zero in discounted prices $\mathbf{p}_{t}, \mathbf{p}_{t+1}, \ldots, \mathbf{p}_{L}$ and wealth $W_{t}$. If perfect foresight is relaxed $g_{t}($.$) can be replaced by its conditional$ expectation given information in period $t$. It is clear from $(48)$ that $g_{t}($. accounts for the influence of all future expectations concerning economic (and demographic) variables on current period as well as for the influence of past decisions through $A_{t-1}$ in $W_{t}$.

The demand models of the previous section which explained commodity demands as a function of within period prices and total expenditure are therefore fully consistent with this life-cycle story. However, if the life-cycle model is valid, we can see from (48) that the price elasticities generated from these demand equations will not describe the full effects of a price change. In general price changes will affect the period allocation of total expenditure through the life-cycle 'consumption function' (48). The second stage allocation then determines within period demands according to

$$
\mathbf{x}_{t}=\mathbf{d}_{t}\left(\mathbf{p}_{t}, y_{t}\right),
$$

where $\mathbf{d}_{t}$ is a vector of 'standard' Marshallian demand equations homogeneous of degree zero in the price vector $\mathbf{p}_{t}$ and the conditioning variable $y_{t}$.

Should there be a corner solution or other binding constraint on an element of $\mathbf{x}_{t}$, the forms of the demand equations for all remaining choice variables will generally change. The effect of a corner in the budget constraint is precisely the same as described in the 'static' models of Section I.3 so long as the total expenditure variable $y_{t}$ is correctly measured in each of the regimes. Binding constraints on $\mathbf{x}_{s}$ where $s>t$ will simply alter the form of $(48)$ and will have no direct impact on (49). Indeed, where the emphasis is on estimating life-cycle consistent within period preferences, the precise form for $g_{t}($.$) in (48)$ across regimes is unimportant.

Under certain representations for $U_{s}\left(\mathbf{x}_{s}\right)$ in $(46)$, the total expenditure equation (48) takes particularly convenient forms. For example, from Section 
I. I we have seen that where within period commodity allocations are homothetic the corresponding indirect utility functions can be written solely in terms of real consumption expenditure $y_{s} / P\left(\mathbf{p}_{s}\right)$, where $P\left(\mathbf{p}_{s}\right)$ is an appropriate price index. Defining $c_{s}$ to be $y_{s} / P\left(\mathbf{p}_{s}\right)$, we may then replace each $U_{s}\left(\mathbf{x}_{s}\right)$ by the indirect utility measure $V_{s}\left(c_{s}\right)$. Then, assuming a quadratic form for $V_{s}($.$) ,$ equation (48) becomes

$$
c_{t} p_{t}=r W_{t}
$$

where $p_{t}=P\left(\mathbf{p}_{t}\right)$ and where we have also assumed a real interest rate equal to the subjective discount rate $\delta$ and an infinite horizon. This in turn may be written more familiarly as

$$
c_{t}=r^{*} W_{t}^{*}
$$

where $r^{*}$ is the real interest rate and $W_{t}^{*}$ is real life-cycle wealth as seen or expected in period $t$. From $\left(5^{\mathrm{O}}\right)$ and $\left(5^{\mathrm{I}}\right)$ we can see that consumption is allocated to 'low cost' periods in such a way as to equalise expenditure. Notice that in deriving this consumption model we have not only restricted the form of within period preferences to be homothetic but have also restricted the form of intertemporal preferences - both through the explicit additivity assumptions (across the life-cycle and between consumption and other decisions) and through the choice of monotonic transformation on within period preferences over consumption goods. These together permit the extremely simple description of the life-cycle consumption path described above.

Although $\left(5^{\mathrm{O}}\right)$ and (5I) are based on strong underlying preference restrictions they serve as a useful illustration of the predictions of life-cycle theory. Under uncertainty, for example, specific expressions for the movement of consumption behaviour over time can be derived. More precisely in moving from period $t$ to $t+\mathrm{I}$, once real interest rates are assumed constant it is only through the discounted income terms $\mu_{t+1}, \mu_{t+2}$, etc. in (47) that revisions to wealth can occur. As a result, if we define $\mathrm{E}_{t+1}$ and $\mathrm{E}_{t}$ to be the expectation operator conditional on period $t+\mathrm{I}$ and period $t$ information respectively, then apart from transitory consumption effects, revisions to real consumption take the form

$$
c_{t+1}-c_{t}=r^{*} \sum_{s=t}^{\infty}\left(\mathrm{E}_{t+1}-\mathrm{E}_{\mathrm{t}}\right) \mu_{s},
$$

where $\mu$ now refers to real (discounted) income. For example, if real (undiscounted) income follows a random walk so that $\left(\mathrm{I}+r^{*}\right) \mu_{s}=\mu_{s-1}+\epsilon_{s}$ where $\epsilon_{s}$ is an unpredictable innovation, then the right-hand side of $(52)$ reduces to $\epsilon_{t}$ alone. That is consumption would adjust to take full account of the latest innovation or 'surprise' in real income. An extremely attractive alternative way of expressing $\left(5^{2}\right)$ is provided by the 'rainy day' saving equation of Campbell (I987) (see also Deaton and Campbell (ig87)). If we define $s_{t}$ to be real saving in period $t$ then we may write

$$
s_{t}=-\sum_{s=t}^{\infty} \mathrm{E}_{t}\left(\mu_{s}-\mu_{s-1}\right)
$$

explaining saving as the present value of expected declines in discounted real income. Of course, more complicated forms for preferences, real interest rates 
and the process generating real income may be adopted but the basic idea, developed by Hall ( 1978 ), that consumption responds only to unpredictable events underlies all 'surprise' consumption models.

Although extremely convenient for both estimation and interpretation surprise models like (52) rest on extremely strong restrictions both on within and between period preferences. In order to assess these specifications of the time separable life-cycle model and their extensions more formally, it is worth turning to the first order Euler conditions for the intertemporal utility maximising problem (see Heckman and MaCurdy (I980) or Hansen and Singleton ( 1983$)$ ) in which

and

$$
\begin{gathered}
\partial U_{t} / \partial x_{i t}=\lambda_{t} p_{i t}, \\
\tau_{t+1} \lambda_{t+1}=\lambda_{t}
\end{gathered}
$$

for each good $i=\mathrm{I}, \ldots, n$ and all time periods $t=\mathrm{I}, \ldots, L-\mathrm{I}$. In (53) and (54) the Lagrange multiplier $\lambda_{t}$ represents the marginal utility of wealth in period $t$ and $\tau_{t+1}$ is the discount factor $\left[\phi\left(\mathrm{I}+r_{t+1}\right)\right]$. In equation (54) the marginal utility of wealth in each period can be seen to provide the link between current and other period decisions. Indeed, apart from the discount factor, each $x_{i t}$ is chosen in such a way that marginal utility is kept constant over the life-cycle. Rearranging (53) to express within period demands $x_{i t}$ in terms of $\mathbf{p}_{t}$ and $\lambda_{t}$ generates the Frisch or $\lambda$-constant demand equations. In this formulation marginal utility $\lambda_{t}$ acts as a summary of between period allocations and therefore performs the same function as $y_{t}$ in (49) above representing the (expected) evolution of future variables. Each Frisch or $\lambda$-constant demand may then be written

$$
x_{i t}=f_{i t}\left(\mathbf{p}_{t}, \lambda_{t}\right),
$$

which is homogenous of degree zero in $\mathbf{p}_{t}$ and $\lambda_{t}^{-1}$.

The general properties of demand equations (55) are described in detail in Browning et al. (1985) and provide direct measures of the degree of intertemporal substitution. For example, the price derivatives of (55) conditional on $\lambda_{t}$ represent the effect of fully anticipated price changes. An important advantage of using (55) directly is that the Euler equation (54) can be usefully exploited to eliminate $\lambda_{t}$ in empirical implementation on time series or panel data. Under certain forms for (55) this will result in a system of first differenced commodity demand and labour supply functions similar to the surprise model above and attributable to the work of MaCurdy (I98I $a$ ).

An equivalent derivation of the $\lambda$-constant model is given by Browning et al. (1985) using the individual's profit function defined by

$$
\pi\left(\mathbf{p}_{t}, \mathrm{I} / \lambda_{t}\right)=\max _{U_{t}}\left[U_{t} / \lambda_{t}-C\left(\mathbf{p}_{t}, U_{t}\right)\right],
$$

where $C\left(\mathbf{p}_{t}, U_{t}\right)$ is the consumer's expenditure or cost function as defined in Section I.I. The profit function $\pi\left(\mathbf{p}_{t}, \mathrm{I} / \lambda_{t}\right)$ is linear homogeneous in $\mathbf{p}_{t}$ and $\mathrm{I} / \lambda_{t}$, decreasing in $\mathbf{p}_{\mathbf{t}}$ and increasing in $\mathrm{I} / \lambda_{t}$. The $\lambda$-constant demands are derived from the negative of the price derivatives of $\pi$, i.e.

$$
x_{i t}=-\partial \pi\left(\mathbf{p}_{t}, \mathrm{I} / \lambda_{t}\right) / \partial p_{i t} .
$$


Equations (57) are equivalent to demands derived from a rearrangement of (53).

In comparison to the $y$-conditional models of Section I.2 the $\lambda$-constant demands directly measure the parameters of intertemporal substitution and therefore require an explicit choice for the complete description of life-cycle utility (46). That is any system of $\lambda$-constant demands rests on the choice of a particular monotonic transformation of within period preferences. For example, if we represent within period preferences by a quasi-homothetic indirect utility with a logarithmic monotonic transformation (i.e. $G\{$.$\} is the log$ transformation and $\alpha=\mathrm{I}$ in (23)), then the marginal utility $\lambda_{t}$ is simply given by

$$
\lambda_{t}=\mathrm{I} /\left[y_{t}-a_{t}\left(\mathbf{p}_{t}\right)\right] \text {. }
$$

In this case the $\lambda$-constant demands take the form

$$
x_{i t}=a_{i t}\left(\mathbf{p}_{t}\right)+\left[b_{i t}\left(\mathbf{p}_{t}\right) / b_{t}\left(\mathbf{p}_{t}\right)\right] \lambda_{t}^{-1} .
$$

If time series or panel data were available $\lambda_{t}$ could be written using (54) in terms of initial period marginal utility $\lambda_{\mathbf{0}}$. If $b_{i t}() / b_{t}()$ were constant as in the LES model, $\lambda_{0}$ would enter as a fixed or individual specific effect over the panel.

In most empirical representations of the life-cycle model the consumer is allowed to be uncertain about future prices, wages and other relevant future events. Revisions to life-cycle wealth occur as new information or 'surprises' arise. In this case it is expected life-cycle utility that is maximised and the Euler equation (54) is replaced by

$$
\mathrm{E}_{t}\left(\tau_{t+1} \lambda_{t+1}\right)=\lambda_{t} .
$$

Hansen and Singleton ( 1983 ) use this condition directly to derive an optimal estimator for the time separable model and we will discuss some further details of this approach in Section II.3. Combining (53) or (55) with (6o) provides an extremely attractive framework for analysing life-cycle demand systems. For example, if we assume sufficient conditions on preferences so that marginal utility can be written in terms of real consumption alone then we can use (6o) to generate the surprise consumption models described earlier.

As an illustration we can examine how (6o) could generate the loglinear surprise models popularised by Breeden (1979), Mankiw et al. (1985) and Heckman and MaCurdy (I980) among others. We first assume that the distribution of $\tau_{t+1} \lambda_{t+1}$ can be approximated by a lognormal with (conditional) variance $\sigma_{t}^{2}$, so that $\mathrm{E}_{t} \ln \left(\tau_{t+1} \lambda_{t+1}\right)=\ln \mathrm{E}\left(\tau_{t+1} \lambda_{t+1}\right)+\frac{1}{2} \sigma_{t}^{2}$. Combining this result with (6o) the consequent revision of $\lambda_{t+1}$ is given by

$$
\ln \lambda_{t+1}-\ln \left(\tau_{t+1}\right)=\ln \lambda_{t}+\frac{1}{2} \sigma_{t}^{2}+e_{t+1},
$$

where $e_{t+1}$ is a random variable representing all new information. Indeed, from condition (6o), $e_{t+1}$ is by definition independent of all information dated $t$ or earlier. In the case where $\lambda_{t}$ is a non-stochastic function of the expenditure variable $y_{t},(6 \mathrm{I})$ defines a straightforward dynamic process for $y_{t}$ and therefore a dynamic process for life-cycle savings and consumption. Where $\ln \lambda$ can be 
assumed proportional to the log of consumption, (6I) reduces to a simple first differenced log consumption model similar to $\left(5^{2}\right)$ above. These models and the restrictions underlying them will be further discussed in Section II.3. Even though the models impose strong conditions on intertemporal and atemporal preferences, their simplicity and the properties of the innovation error $e_{t+1}$ have made them popular in empirical research.

The underlying dynamics of the intertemporally separable models discussed above are not easy to extend in a theoretically consistent manner while retaining empirical tractability. Anderson and Blundell ( $198_{3}, 1984$ ), for example, start with the time separable specification of the $y$-conditional model and generalise that structure by allowing flexible interrelated dynamics. This assumes that the $y$-conditional model represents steady state behaviour but does not capture disequilibrium short-run responses. These 'ad hoc' disequilibrium dynamic models clearly act as a useful test of intertemporal separability and can be partially rationalised in a life-cycle framework. However, where intertemporal separability is rejected their use in policy analysis is limited to the extent that they do not identify the separate sources of dynamic adjustment. For this objective some sort of theoretical model of short-run adjustment under uncertainty is required that relaxes the time separability assumption.

Deriving theoretical models that are fully consistent with life-cycle utility maximisation under costs of adjustment or habit persistence, for example, is in principle a straightforward extension of the previous discussion. The remainder of this section will briefly examine some of the rather more popular ways of relaxing the critical separability assumption. To begin with we will consider specifications where (expected) life-cycle utility $(46)$ is replaced by

$$
U_{t}^{*}=U_{t}\left(\mathbf{x}_{t}, \mathbf{x}_{t-1}\right)+\mathrm{E}_{t}\left[\Sigma_{s} \phi^{s-t} U_{s}\left(\mathbf{x}_{s}, \mathbf{x}_{s-1}\right)\right],
$$

where the presence of $\mathbf{x}_{t-1}$ may reflect adjustment costs in consumption (Weissenberger, I983) or habit persistence (Pollak and Wales, I982; Boyer, I982; Phlips and Spinnewyn, I98ı; Spinnewyn, I98ı and Muellbauer and Pashardes, 1982). The first order conditions are now written

$$
\partial V_{t} / \partial x_{i t}=\partial U_{t} / \partial x_{i t}+\mathrm{E}_{t} \partial U_{t+1} / \partial x_{i t}=\lambda_{t} p_{i t}
$$

with $\mathrm{E}_{t}\left(\tau_{t+1} \lambda_{t+1}-\lambda_{t}\right)=\mathrm{o}$ as before and retain homogeneity in terms of $\mathrm{I} / \lambda_{\tau}$ and prices $p_{i t}$.

Under certain circumstances the explicitly dynamic form of life-cycle expected utility considered in the model above can be reduced by a suitable transformation of variables into simple forms that correspond to those considered in the time separable case. For example, in the habit persistence model where utility in each period is defined over consumption after removing habitual consumption (see Pollak (1970)), (63) reduces to a system similar to the time separable Marshallian demand model. However, in this case each price term depends on the whole future of expected prices. Nevertheless, this model forms the basis of the useful studies of Spinnewyn (I98I) and Muellbauer and Pashardes (1982). 
As an alternative to the procedure of breaking time separability by adding in lags to the arguments of direct utility, Browning (1987a) has developed a useful class of non-separable models using the profit function representation of preferences. The idea is to extend the $\lambda$-constant or Frisch demands described above to include prices from other periods. That is we may wish to extend the profit function $(56)$ so that each demand equation becomes

$$
\mathbf{x}_{t}=f_{t}\left(\mathbf{p}_{t-1}, \mathbf{p}_{t}, \mathbf{p}_{t+1}, \lambda_{t}\right)
$$

where $\mathbf{p}_{t+1}$ and $\mathbf{p}_{t-1}$ refer to appropriately discounted future and past prices. The reason for their inclusion is shown to derive from the form of the consumer's profit function under non-separability. If we write the profit function corresponding to period $t$ preferences as $\pi\left(\mathbf{p}_{t-1}, \mathbf{p}_{t}, \mathrm{I} / \lambda_{t}\right)$, then the $\lambda$ constant demands are given by

$$
\mathbf{x}_{t}=-\partial \pi_{t} / \partial \mathbf{p}_{t}-\mathrm{E}_{t} \partial \pi_{t+1} / \partial \mathbf{p}_{t}
$$

analogous to $\left(6_{3}\right)$ above. Since the Euler equation for $\lambda_{t}$ is still valid the Hansen and Singleton approach to estimation can be adopted. The form of the profit function in this case is the mirror image of the habit persistence model with first order dynamics. Indeed, the form of $(65)$ will often allow the elimination of $\lambda_{t}$ using the within period budget constraint so that nonseparable analogues to the $y$-conditional models can be recovered. Just as in the time separable model these may, in certain situations, turn out to be more useful in estimation than the corresponding Euler equation form. These issues and others will be raised in more detail in the next two sections where we turn to estimation and empirical evidence.

\section{3. Preference Restrictions and Estimation in Intertemporally Separable Models}

In order to assess the restrictions underlying any specification of the life-cycle model, it is necessary to define a suitable measure of intertemporal substitution. Following Browning (1985), the elasticity which measures the $\lambda$-constant proportionate change in current period expenditure from a uniform change in current period prices can be written

$$
\Phi=V_{y} / y \cdot V_{y y}
$$

where $V_{y}$ is the $y$-derivative of indirect utility. Interestingly, $\Phi$ is the inverse of the standard risk aversion measure since it reflects the concavity of the monotonic transformation of within period preferences. Consider, for example, the log linear transformation of quasi-homothetic preferences (i.e. $G\{$.$\} is the$ $\log$ transformation and $\alpha=\mathrm{I}$ in (23)). The intertemporal elasticity is then given by

$$
\Phi=-\left[y_{t}-a_{t}\left(\mathbf{p}_{t}\right)\right] / y_{t} .
$$

Since this elasticity measure summarises intertemporal substitution behaviour it provides a useful way of evaluating the flexibility underlying particular forms for life-cycle models.

As we saw in Section II.2 there is no real need for the first order conditions underlying the intertemporally separable model to be linear or loglinear. 
Indeed, the Euler equation approach laid out by Hansen and Singleton (1983) allows quite general nonlinear forms for marginal utility. However, nonlinear forms will generally require that time varying stochastic terms enter only through innovations in marginal utility. Where measurement error is likely to be serious one may wish to choose a linear differenced specification precisely because it can be seen to relax this restriction. Nevertheless, the linear or loglinear models have a cost in so far as rather tighter restrictions on within period and intertemporal substitution than one would usually like to assume are imposed.

For the estimation of $\lambda$-constant or Euler equation models an instrumental variable estimator is suggested directly from the properties of the innovation error $-e_{t+1}$ in (6I), for example. As an illustration, consider the case where the demand equations from (53) or the derivatives of the profit function can be expressed with a term linear in $\ln \lambda_{t}$. This clearly contains the loglinear consumption models referred to above and as also noted above the unobservable marginal utility of wealth in such models can be eliminated by first differencing. The resulting differenced model now contains the innovation error $e_{t+1}$ as part of its disturbance term. The conditional variance term may either be assumed constant or used to assess the importance of risk terms in consumption. Although $e_{t+1}$ will not be independent of variables dated $t+\mathrm{I}$ appearing on the right-hand side of the differenced model that are not fully anticipated, it will be independent of variables dated $t$ or earlier. Provided there are no time aggregation problems (see Hall (1985), for discussion), a simple consistent estimator can therefore be derived using variables dated $t$ or earlier as instruments. In their generalisation of this linear estimator, Hansen and Singleton ( 1983 ) exploit the orthogonality condition underlying the Euler condition to derive a general nonlinear instrumental variable estimator.

Empirical applications to individual expenditure or labour supply decisions have generally required the $\lambda$-constant demands take the form:

$$
g\left(x_{i t}\right)=\mathbf{d}_{i}^{\prime} \mathbf{f}\left(\mathbf{p}_{t}\right)+\gamma_{i} \ln \lambda_{t}
$$

here $g($.$) is a \log$ or linear transformation, $\mathbf{d}_{i}$ is a vector of constant unknown parameters for the $i$ th equation and $\mathbf{f}\left(\mathbf{p}_{t}\right)$ is a known function of $\mathbf{p}_{t}$. Using (6I) the model may then be written (assuming a constant discount factor) as the following linear differenced specification

$$
\Delta g\left(x_{i t}\right)=\mathbf{d}_{i}^{\prime} \Delta \mathbf{f}_{t}\left(\mathbf{p}_{t}\right)+\gamma_{i} e_{t+1} .
$$

This equation represents a reasonably typical form for empirical versions of the time separable $\lambda$-constant equation models under uncertainty. For example, Attfield and Browning (1985) rather neatly exploit the symmetry and homogeneity restrictions on a system of $\lambda$-constant demands to derive consistent estimators of the $\mathbf{d}_{i}$ parameters.

A number of recent papers (Blundell et al., I985; Browning, I986 and Nickell, I986) have noted restrictions imposed on life-cycle and within period preferences from estimating models of the form (68) and (69). Working with the loglinear transformation for $g($.$) , the form of (69)$ generally requires the 
utility derivative in (53) be a function of $x_{i t}$ alone. That is, $U_{t}$ must be explicitly additive over time and goods. In this case the general form for $\lambda$-constant demands takes the form

$$
\ln x_{i t}=\gamma_{i} \ln \alpha_{i}-\gamma_{i} \ln p_{i t}-\gamma_{i} \ln \lambda_{t}
$$

as in Heckman and MaCurdy (1980). This explicit additivity restriction on atemporal preferences may be generalised but only at the expense of assuming homothetic preferences. That is, relaxing additivity in (70) requires unitary within period full income elasticities. For demand equations linear in $x_{i t}$, Browning et al. (1985) use the profit function to derive an alternative class of models. Moreover, their class of models implies neither explicit additivity nor homothetic preferences. It does, however, impose some strong restrictions on within-period and intertemporal preferences.

The $\lambda$-constant demands corresponding to $(68)$ in the Browning et al. class are of the form

$$
x_{i t}=n_{i}\left(\mathbf{p}_{t}\right)-k_{i} \ln p_{i t}-k_{i}-k_{i} \ln \lambda_{t},
$$

where $n_{i}\left(\mathbf{p}_{t}\right)$ is the $i$ th price (or wage) derivative of a general linear homogeneous function of prices $n\left(\mathbf{p}_{t}\right)$ and $k_{i}$ is some unknown parameter. Since $n_{i}$ can contain price interactions additivity is relaxed. Within-period preferences are quasi-homothetic (see (9)) with necessary costs are given by

$$
a\left(\mathbf{p}_{t}\right)=n\left(\mathbf{p}_{t}\right)-\sum_{i} k_{i} p_{i t} \ln \left[p_{i t} /\left(\sum_{i} k_{i} p_{i t}\right)\right]-\sum_{i} k_{i} p_{i t}
$$

and the price index for supernumerary consumption is given by

$$
b\left(\mathbf{p}_{t}\right)=\sum_{i} k_{i} p_{i t} .
$$

As $b\left(\mathbf{p}_{t}\right)$ describes the substitution possibilities for richer individuals (those with large supernumerary consumption) the Leontief form for $b\left(\mathbf{p}_{t}\right)$ implies these substitution effects tend to zero as consumption increases. Intertemporal preferences are also restricted through this choice of preferences. To see this consider the corresponding indirect utility function which has exponential form

$$
V_{t}=-\exp \left\{-\left[y_{t}-a\left(\mathbf{p}_{t}\right)\right] / b\left(\mathbf{p}_{t}\right)\right\}
$$

implying an intertemporal elasticity $\Phi_{t}=-b_{t}\left(\mathbf{p}_{t}\right) / y_{t}$. Although, the intertemporal elasticity $\Phi$ in this exponential case is always negative it approaches zero as the income allocation $y_{t}$ increases. For an arbitrarily rich household therefore this intertemporal elasticity of substitution is zero. This contrasts rather dramatically with the loglinear transformation whose corresponding intertemporal elasticity is given in $(67)$ and which is bounded between zero and $-_{I}$ approaching ${ }_{-} \mathrm{I}$ as the income allocation $y_{t}$ rises. The loglinear transformation allows the elasticity to grow away from zero with increasing income whereas the exponential transformation assumes the opposite.

It is useful to contrast these approaches with the alternatives that recover life-cycle consistent within period preferences by substituting out the unobservable marginal utility of wealth across two or more contemporaneous decisions (see Altonji, I982, I983) or eliminate it using the within period budget constraint (see Betancourt, I97ı; Blundell and Walker, I986 and MaCurdy, 1983). Where the monotonic transformation of within period 
preferences is fixed and not estimated as in the log case (59) or the explicitly additive case (70), the parameters estimated from such alternative representations are sufficient to identify all intertemporal substitution elasticities. Moreover, these estimates of within period preferences are invariant to the choice of monotonic transformation. In general one should attempt to work with a specification that breaks the tight structure placed on preferences in the models described above. However, as was noted above as soon as a nonlinear Euler equation is specified estimation requires tighter restrictions on the stochastic components of the model.

In an interesting application, MaCurdy (1983) uses standard Marshallian demands to recover within period preference parameters as in the alternative procedures described above. Given these parameters the remaining intertemporal parameters are estimated from the Euler condition. This seems possibly the most attractive estimation procedure for the time separable model. In the case of the quasi-homothetic model, this would involve estimating the $y$ conditional model and constructing $\left[y_{t}-a_{t}\left(\mathbf{p}_{t}\right)\right] / b_{t}\left(\mathbf{p}_{t}\right)$ for each time period of data available (having chosen a normalisation for the parameters of $\left.b_{t}\left(\mathbf{p}_{t}\right)\right)$. If we define this variable as real supernumerary outlay (income) $y_{t}^{r}$ then, introducing new intertemporal parameters $\alpha_{t}$ and $\beta$, we could define a suitable monotonic transformation of within period preferences as

$$
V_{t}=\alpha_{t}\left(y_{t}^{r}\right)^{\beta} / \beta \quad(\beta<\mathrm{I})
$$

similar to the transformation of within period preferences adopted by MaCurdy (1983). In this case the intertemporal elasticity of substitution $\Phi$ equals $\left(\mathrm{I}-a_{t} / y_{t}\right) /(\beta-\mathrm{I})$ and marginal utility is given by

$$
\lambda_{t}=\alpha_{t}\left(y_{t}^{r}\right)^{\beta-1} / b_{t}\left(\mathbf{p}_{t}\right) .
$$

Using the Euler equation for $\lambda_{\tau}$ described by (6o) we can then identify $\beta$ and $\alpha_{t}$ from a first difference model of the form

$$
\Delta \ln y_{t}^{r}=\rho \Delta \ln \alpha_{t}-\dot{\rho} \Delta \ln b_{t}\left(\mathbf{p}_{t}\right)+\rho \ln \tau_{t}-e_{t},
$$

where $\rho=\mathrm{I} /(\mathrm{I}-\beta)$. The intertemporal parameters can probably be most effectively recovered using panel data observations given the estimates of $b_{t}(\cdot)$ and $y_{t}^{r}$. Of course, there is no reason why quasi-homothetic preferences should be adopted and it may be preferred to recover within period preferences from a general nonlinear demand system of the PIGL type.

As one might have inferred from the discussion of equation (6I) above, the log differenced model (72) relates directly to the log linear 'surprise' consumption/ savings models. To be able to define $y_{t}$ over consumption expenditure alone we have already seen that consumption and labour supply have to be assumed explicitly additively separable in the life-cycle utility. Then, setting $a(\mathbf{p})$ to zero and approximating $b(\mathbf{p})$ by the retail price index, $y_{t}^{r}$ becomes equal to real consumers' expenditure $c_{t}$ and (77) may be written

$$
\Delta \ln c_{t}=\rho \Delta \ln \alpha_{t}+\rho\left(\ln \tau_{t}-\Delta \ln b_{t}\right)+e_{t} .
$$

Since $\ln \tau_{t} \simeq r_{t}-\delta$ the second term on the right-hand side of $(78)$ is equivalent to the real interest term introduced by Muellbauer ( 1983 ) and Wickens and 
Molana (1984). The intertemporal elasticity $\Phi$ is now directly measured by $-\rho$. However current dated variables in (78) may still be correlated with the error term and as a result instrumental variable estimation is required to recover the intertemporal substitution parameters consistently. Where there are many assets with uncertain returns, an Euler equation of the form (78) will exist for each asset (see Hansen and Singleton ( 1983$)$ ) and $-\rho$ will continue to measure the intertemporal elasticity. However, multiple asset information enables the degree of risk aversion to be separately identified (see Hall (1985)).

Where labour supply is included in estimation (or where explicit additive separability between time and goods is not assumed) rationing in the labour market from one period to the next will be reflected in the determination of savings or consumption behaviour through the price aggregators $a\left({ }^{\circ}\right)$ and $b($.$) .$ In periods where constraints occur, unconstrained elements of $\mathbf{x}_{t}$ will depend on the level of the rationed goods through the virtual price or wage. In this case these prices (and wages) for rationed goods can be replaced in the Euler condition for the unrationed demands by virtual price or wage. This provides a simple way of introducing unemployment or rationing into the savings function as has been suggested by King (1985) among others. Once explicit additivity between goods and leisure in life-cycle utility is relaxed, the level of labour supply or the wage in any period directly affects the marginal utility of consumption in that period. In this case the life-cycle consumption path will not be smoothed independently of labour market decisions and falls in consumption may occur during periods of unemployment or during retirement.

\section{4. Aggregation, Excess Sensitivity and the Evaluation of Empirical Evidence}

Aggregation. In order to assess the empirical evidence on life-cycle and dynamic behaviour and the debates therein it is worth extending the aggregation issues described in Section I.4 to cover the case of intertemporal models. The work of Stoker ( I 986 ) referred to in that section could have a particularly important bearing here because of the dynamic misspecification he observed when estimating aggregate consumption-income models. Similarly, corner solutions, rationing and liquidity constraints may well lead to misspecification at the aggregate level. More importantly perhaps for aggregation are the stationarity assumptions that need to be placed on the evolution of the population over time. These assumptions essentially rule out cohort specific effects since the 'representative consumer' results only hold if new individuals take the place of individuals leaving the sample. Also related to the aggregation issue is the argument by King ( I986) for a piecewise nonlinear Euler equation reflecting the nonlinear nature of the interest rate facing individuals as they move from saving to higher levels of borrowing. All of these arguments suggest that analysis at a more micro or at least cohort based level would be preferable. However, there is no one micro data set that is ideally suited to all aspects of life-cycle modelling and therefore it is worth going through each of these issues in order to assess their likely impact on aggregate estimates of consumption behaviour. 
Turning first to aggregation in the simple Euler equation model we work within a linear model since nonlinear models will not generally aggregate except where there are sufficient restrictions placed on the evolution of the mean in relation to the other moments of the distribution (see Section I.4). If utility is exponential and additive across goods (see MaCurdy (1986), for example), the $\lambda$-constant demand for household $h$ corresponding to (70) has the form

$$
x_{i t, h}=n_{i t, h}-k_{i} \ln p_{i t}-k_{i} \ln \lambda_{t, h}
$$

which is a restrictive form of the Browning et al. (1985) model (see equation (7I)). Indeed, where prices are constant across individuals in any time period the complete Browning et al. (1985) model will aggregate in the manner described below. This is assuming all individual specific characteristics enter linearly in (79). Before aggregation can take place we also require conditions on the stochastic terms entering the following individual level Euler equation

$$
\ln \lambda_{t, h}=\ln \tau_{t}+\ln \lambda_{t+1, h}+e_{t+1, h} .
$$

Splitting $e_{t+1, h}$ into its macro component and micro component, $u_{t+1}$ and $\epsilon_{t+1, h}$ respectively, and provided these two components are mutually independent (79) and (8o) can be written

$$
X_{i t+1}-X_{i t}=-k_{i} \ln \tau_{t}+N_{i t+1}-N_{i t}+k_{i}\left(\ln P_{i t+1}-\ln P_{i t}\right)+u_{t+1},
$$

where $X_{i t+1}$ refers to per capita summation of $x_{i t+1, h}$ over the population and so on.

In deriving (8I) it is implicitly assumed that it is the same individuals in each period over which aggregation occurs. If they are not the same then certain stationarity assumptions are required. Essentially new entrants must take the place (in terms of intertemporal preferences and wealth) of those leaving the population. This precludes cohort specific effects and suggests that aggregation over individuals by cohort may be more acceptable. However, aggregation of this type (as adopted by Browning et al. (1985)) requires accurate cohort level data. This would usually be built up from cross-section surveys in which case it may be better to use the individual survey level data directly to estimate in two steps following the procedure suggested for equation (77). Indeed, we might well expect preferences to change across cohorts and the proportion of the population in any stage of the life-cycle to change over time. In this case it is risky to assume that a linear differenced model of the form (8I), even if true at the micro level, will accurately estimate the intertemporal price elasticity $\left(k_{i}\right.$ in equation (79)) from aggregate data. Adding in factors to capture the changes in the higher order moments of the characteristics of the population may at least indicate the degree of bias.

Where corner solutions, rationing or piecewise linear marginal rates of return prevail, aggregation problems become quite severe. As an illustration consider first the corner solution case developed for the intertemporal labour supply model by MaCurdy (1985). Following the framework developed for aggregating over corner solutions in Section I.4 we define an indicator variable $I_{t h}$ which equals unity if there is an interior solution and zero for a corner 
solution. Underlying this indicator is the latent variable $I_{t h}^{*}=\mathbf{z}_{t h}^{\prime} \boldsymbol{\beta}+v_{t h}$ as in equation (37). Assuming the linear specification (79) is valid for the commodity in question, observed expenditure is now given by

$$
x_{t h}=I_{t h} n_{t h}-k I_{t h} \ln P_{t}-k I_{t h} \ln \lambda_{t h} .
$$

Corresponding to equation $(36)$ is the aggregate difference equation

$$
\Delta X_{t}=I_{t} N_{t}-I_{t-1} N_{t-1}-k\left(I_{t} \ln P_{t}-I_{t-1} \ln P_{t-1}\right)+k \ln \tau_{t}+\theta_{t}-\theta_{t-1}+e_{t},
$$

where $N_{t}$ again refers to the per buyer average and where $\theta_{t}$ is again proportional to the normal density evaluated at $\mathbf{Z}_{t}^{\prime} \boldsymbol{\beta}$. Clearly there is no longer an aggregate linear difference equation and in particular $\theta_{t}-\theta_{t-1}$ cannot be written in terms of the difference in $\mathbf{Z}_{t}$. As a result, interpreting the coefficient on $\ln P_{t}-\ln P_{t-1}$ in (8I) as a measure of intertemporal elasticity in the case where there is rationing or corner solutions is likely to be unreliable

These illustrations highlight the problems of aggregation in life-cycle models where individuals can be in different regimes of behaviour. Another example of this can arise under liquidity constraints. Indeed, where liquidity constraints act as a binding constraint on behaviour - borrowing constrained to be less than net worth would be a good example - a problem much like the corner solution case occurs and a similar analysis of aggregation bias will prevail. Where there exists a wedge between borrowing and lending rates of interest, King ( I 986) has developed a useful asymmetric information model. In this model the borrowing rate exceeds the lending rate and borrowers may default but are monitored so as not to exploit the consequences of default. The consumer may either then choose to lend, stay at the kink point determined by the wedge, borrow with no risk of default or borrow with risk. In equilibrium this leads to four regimes of behaviour and in each case a different Euler equation.

Working within the Euler equation (77), those households who are neither at a kink or in risk of default, find this wedge alters the discount factor $\tau_{t}$ so as to reflect the appropriate borrowing or lending rate. For those at the kink, on the other hand, the next period consumption level simply equals the next period exogenous expected income plus forecast error. Finally, for those in risk of default-borrowing in excess of net worth-a probability term is incorporated to reflect the chance of default occurring in which case only a basic 'subsistence' consumption level is achieved. These regimes are clearly endogenous just as in the corner solution case and aggregation would again involve summing across regimes much as in (83) above.

The Evidence. As in the discussion of disaggregate models in Section I, I have used this survey to evaluate the interplay between theoretical and empirical considerations rather than providing a catalogue of empirical estimates. To date the evidence on intertemporal elasticities is mixed and from our discussion above may simply reveal the underlying nature of the model being estimated rather than the process underlying the data itself. For this reason the studies described below will refer more to evaluation rather than estimation of the lifecycle model and will also reflect the bias in this survey towards micro-data 
based models. The literature in this area is still in its infancy and has generally focused on the degree to which the simplest of the intertemporally separable models described above can adequately summarise the path of consumers' expenditure. It has largely ignored the issue of time separability and the interaction of goods with labour supply decisions, emphasising instead the importance of liquidity constraints and the implied excess sensitivity of consumption to movements in current disposable income.

These are indeed important issues and perhaps the most impressive recent contributions to this debate are those of Hall and Mishkin (1982), Hayashi ( 1985$)$, Blinder and Deaton (1985), Deaton (1985), Altonji and Siow (1985), Altonji et al. (I986), Muellbauer and Bover ( I986), MaCurdy (I986), Mariger $(1987 a, b)$ and Campbell and Deaton (1987). These studies use a variety of data sources both at the aggregate and individual level. There is general agreement that time separable models of the form given by $(78)$ do not provide a complete description of intertemporal behaviour, at least for a significant group of consumers. Why this is so and how robust these results are is, however, more difficult to assess. Broadly speaking liquidity constraints provide an argument for excess sensitivity of consumption to current income innovations while habits or more generally lagged consumption terms lead to further smoothing. Of course, relaxation of the explicit additivity assumption between leisure and goods is sufficient to bring current income terms into these consumption models, even if labour supply is rationed. Nevertheless, the evidence for liquidity constraints in certain groups in the population - the young or unemployed - is reasonably compelling. As are habits for certain types of goods.

As Campbell and Deaton (1987) point out so clearly, the simple time separable life-cycle model is really defined by both the consumption and income process. Statements concerning the properties of the innovation error on such a consumption function relate directly to the income process since as we saw from equation (52) it is innovations to this process which drive the innovations to life-cycle wealth and in turn the marginal utility of wealth which underlies the stochastic Euler equation. If it is income innovations alone - and not liquidity constraints or habits - which drive the first difference of consumption then they should not be predictable from past income (or any other) information. Of course, time aggregation problems can cloud this simple condition, but leaving these aside the force of this point focuses attention on the joint process of both consumption and income. It is the study of this joint process that allows the evaluation rather than simply the estimation of the underlying model.

Although panel data provide possibly the best environment for this analysis, Altonji and Siow (1985) have emphasised the contaminating effects of measurement errors in dynamic panel data models. This is particularly true of the expenditure data from the Michigan PSID panel used in the time series studies of household income and consumption reported in the papers of Hall and Mishkin ( 1982 ) and Altonji and Siow (1985). Moreover, these data only record weekly expenditures on food derived from an annual average figure and 
provide little other information on commodity expenditure. Nevertheless the broad idea behind the tests proposed is simple and convincing.

Hall and Mishkin (I982) assume a constant real return on assets and work with a model similar in essence to $(5 \mathrm{I})$ and $\left(5^{2}\right)$. They allow for two types of innovation in real income by splitting nondeterministic income into two stochastic components $\mu_{t}^{L}$ representing fluctuations in lifetime prospects and $\mu_{t}^{S}$ representing transitory influences. This is a useful distinction since we may expect $\mu_{t}^{L}$ to follow a random walk while $\mu_{t}^{S}$ could well be a moving average of past transitory innovations. Under the life-cycle model, the impact of these innovations on the nondeterministic part of consumption should be equivalent to the annuity value of the added wealth implied by a unit amount of unexpected transitory income - the real interest rate under an infinite horizon. If this can be measured accurately then the life-cycle hypothesis can be tested by examining the coefficient of such a variable in the first differenced consumption model since the transitory components enter as one part in the innovation error process. Indeed if we redefine $c_{t}$ to be real consumption in period $t$ after having removed all deterministic components (i.e. the effect of age, demographics, trend...) then, under a quadratic utility assumption with constant real interest rates, the form for the marginal utility in (6o) will be linear in $c_{t}$. Moreover from this Euler equation or more directly from $\left(5^{2}\right)$ the change in $c_{t}$ is simply given by

$$
\Delta c_{t}=\epsilon_{t}+\beta_{t} n_{t}
$$

where $n_{t}$ is the transitory income component, $\beta_{t}$ is the annuity value described above and $\Delta$ is the first difference operator. The stochastic component $\epsilon_{t}$ is simply the innovation in $\mu_{t}^{L}$. This approach of splitting the innovation in 'surprise' consumption function into its various separate factors has some considerable attraction for interpreting rational expectations models of this form and will be examined in more detail below.

To identify the components on the right-hand side of $\left(8_{4}\right)$ separately the deterministic path for real income is first estimated so that the sum of the nondeterministic components $\mu_{t}^{L}$ and $\mu_{t}^{S}$ can be constructed. Calling this sum $\mu_{t}$, the innovations $\epsilon_{t}$ and $n_{t}$ enter the update of $\mu_{t}$ quite simply as

$$
\Delta \mu_{t}=\epsilon_{t}+n_{t}-n_{t-1},
$$

where it is assumed $\Delta \mu_{t}^{L}=\epsilon_{t}$ and where $\mu_{t}^{S}=n_{t}$ is assumed serially uncorrelated. This equation can then be used to show that the variance of $\Delta \mu_{t}$ is the variance of $\epsilon_{t}\left(\sigma_{\varepsilon}^{2}\right)$ plus twice the variance of $n_{t}\left(\sigma_{n}^{2}\right)$ while, from (85), the covariance of $\Delta \mu_{t}$ and $\Delta \mu_{t-1}$ is simply $-\sigma_{n}^{2}$.

Since the consumption measure in the Panel Data used by Hall and Mishkin refers to food they could not use (84) directly but by defining $\alpha$ to be the marginal propensity of food consumption out of permanent income, they rewrite $(84)$ as

$$
\Delta c_{t}=\alpha \epsilon_{t}+\alpha \beta n_{t},
$$

where the assumption of constant $\beta_{t}$ over time is also being made. Combining (85) and (86) we can evaluate the contemporaneous covariance of $\Delta c_{t}$ and $\Delta \mu_{t}$ as $\alpha \sigma_{\epsilon}^{2}+\alpha \beta \sigma_{n}^{2}$. Defining this to be $C_{0}$ and defining $C_{1}$ to be the 
corresponding covariance of $\Delta c_{t}$ and $\Delta \mu_{t+1}$, which from (85) and (86) equals $-\alpha \beta \sigma_{n}^{2}$, it is easy to see that

and

$$
\alpha=\left(C_{0}+C_{1}\right) / \sigma_{\epsilon}^{2}
$$

The procedure used by Hall and Mishkin to test the underlying model is to evaluate the sample analogs of $(87)$ and (88) in order to estimate $\alpha$ and $\beta$. In doing so they allow for measurement error in consumption as well as a more general process for the evolution of transitory income. Indeed, they also allow for advance information about income.

Although the Hall and Mishkin estimates are sensitive to this latter point, the main result is an estimate of the marginal food propensity $\alpha$ at around $o^{\circ}$ I I and an estimate of $\beta$ around $0^{\circ} 29$. Since the average propensity for food is approximately $\circ \cdot 19$, food is a necessity as expected. However, the value for $\beta$ is unreasonably high given its annuity value interpretation. The closer $\beta$ is to unity the more excessively sensitive current consumption is to transitory income innovations. Even though $\beta$ is larger than expected, the completely liquidity constrained case where consumption equalled current income and $\beta$ equals unity, is clearly rejected. In the light of these results they investigate the impact of $\Delta \mu_{t-1}$ on $\Delta c_{t}$ which in the life-cycle model should be zero but would be significant under liquidity constraints or excess sensitivity. They discover a small significant negative coefficient. Rewriting the model to allow a fraction $\delta$ of consumption to have $\beta$ equal to I, they find a $\delta$ of $0 \cdot 2$ and an estimate of $\beta$ for the remaining consumption equal $0^{\circ} \mathrm{I} 74$, a much more reasonable value, while $\alpha$ remains precisely estimated at $0^{\circ} \mathrm{I}$. The results therefore suggest that around $20 \%$ of consumption does not follow the simple life-cycle hypothesis and Hall and Mishkin interpret this as evidence of liquidity constraints. Hayashi ( $1985 a$ ) finds similar evidence for liquidity constraints in his study of a Japanese panel of household expenditures.

If liquidity constraints are important, consumption and therefore borrowing will be depressed which in turn suggests that saving will be too large. Moreover, the relative efficiency loss of income taxation in comparison with a consumption tax is reduced since liquidity constrained individuals behave as if they had a zero intertemporal substitution elasticity. The importance of liquidity constraints and the validity of the life-cycle model are therefore crucial to policy considerations and the Hall and Mishkin results have stimulated a number of further studies. One drawback of their results is that only two extremes of behaviour - either on the life-cycle path or on the current income constrained path - are allowed. Mariger $(1987 a, b)$ has recently developed a rather more attractive model of liquidity constraints in which current income constrained behaviour is only an extreme in a continuum of liquidity constrained positions. Here, as in the King model described earlier, liquidity constraints do not necessarily force consumption to relate directly to the contemporaneous level of disposable income alone.

Panel data on individual households seem by far the most reasonable source for both evaluating and estimating models of dynamic consumer behaviour. 
Indeed, Hall and Mishkin note 'aggregate data is not really powerful enough to settle the important questions about the behaviour of consumers'. Nevertheless, the shortness of typically available panels and the likely importance of measurement error could weaken the conclusions drawn from such sources. We have seen that issues such as corner solutions and constraints are not overcome in aggregate data; rather they are 'covered up'. However, measurement error, at least in linear models, can be reduced by grouping and it is useful to assess the robustness of the results described above to such error. Altonji and Siow (1985) and Altonji et al. (1986) using data drawn from the same source as Hall and Mishkin derive estimates for the factors on the righthand side of equations like (86) using additional information from other determinants of income - for example, wage rates, employment and other labour market information. Although these are also contaminated with measurement error, the extra information they contain provides a way of estimating parameters like $\beta$ consistently even though the income process itself suffers from measurement error. With the information used in the Hall and Mishkin study, $\beta$ cannot be identified when $\mu_{t}$ is measured with error. Since. measurement error in the Michigan panel may explain more than $50 \%$ of the variance in $\mathrm{D} \mu_{t}$ this is a severe drawback. The Altonji et al. studies confirm the rejection of the current income constrained model $(\beta=\mathrm{I})$ but do not find the same evidence of liquidity constraints. This suggests that the importance of the lagged income term found by Hall and Mishkin may not be robust model specification. However, rather than estimating $\beta$ directly they estimate the implied discount factor for consumers with infinite horizon. The estimates display considerable variation and range from $-0^{\circ} 04$ to ${ }^{\circ} \cdot 6$ underlining the difficulty of recovering precise estimates after dealing with measurement problems in panel data. These may be compared to the corresponding estimated discount factor in the Hall and Mishkin model of around $0^{*} 77$.

Focusing on the discount factor and with it the time horizon provides a useful approarh for analysing more general dynamic models with liquidity constraints. Mariger $(1987 b)$, for example, presents a description of a framework in which there is a minimum net worth constraint below which households cannot borrow. This type of 'asymmetric' model is close in spirit to that of King (1986) and suggests that one sensible way of viewing liquidity constraints is through their impact on the 'optimal' time horizon. Using two cross sections of survey data Mariger finds that only a very small percentage of households face one period horizons which would correspond to the extreme current income liquidity constraint used by Hall and Mishkin (I 982) and Hayashi $\left(\mathrm{I}^{8} 5^{b}\right)$ among others. Instead, many consumers have horizons much less than their remaining life time but are able to incur some intertemporal substitution. This could well explain much of the observed variation in discount factors alluded to above and such models are worthy of further analysis.

Whether or not consumption is excessively sensitive to current income innovations, it is useful to ask whether we might expect the resulting consumption series to be smoother or more variable than otherwise. The answer to this question depends critically on the relative smoothness of current 
compared with permanent income. Campbell and Deaton (1987) in a persuasive study of post war US aggregate income and consumption patterns not only confirm the excess sensitivity result of Hall and Mishkin but also note that the underlying smoothness of the current income process leads additionally to excess smoothing of consumption. This paper neatly ties together these apparently contradictory criticisms of the simple life-cycle model and sets the scene for a more extensive analysis of the other issues underlying life-cycle models that have been mentioned above.

Rather than providing a complete description of empirical estimates of intertemporal elasticities I will finish this section by summarising the results from the Blundell and Walker (I986) study. In that paper intertemporal elasticities for male and female labour supply as well as consumption are presented. Within-period preferences in that study are assumed to be quasihomothetic of the form described in equation (75) with $\beta$ equal zero. We can compare these intertemporal elasticities with those under more general assumptions concerning $\beta$. These elasticities are presented in Table 4 where the

Table 4

Some Intertemporal Elasticities*

\begin{tabular}{|c|c|c|c|c|c|}
\hline \multirow[b]{2}{*}{$\beta$} & \multirow[b]{2}{*}{ Sample } & \multicolumn{4}{|c|}{ Elasticities } \\
\hline & & $E_{f f}$ & $E_{m m}$ & $E_{q q}$ & $\Phi$ \\
\hline \multirow[t]{3}{*}{ o } & (a) & O.I9I & 0.020 & $-0.17 \mathrm{I}$ & -0.069 \\
\hline & (b) & 0.080 & $0 \cdot 046$ & -0.175 & -0.130 \\
\hline & (c) & 0.025 & 0.024 & -0.137 & -0.077 \\
\hline \multirow[t]{3}{*}{0.5} & (a) & $0 \cdot 618$ & $0 \cdot 078$ & $-0^{\circ} 496$ & $-o \cdot 138$ \\
\hline & (b) & o.299 & о. I06 & -0.520 & $-0 \cdot 160$ \\
\hline & (c) & 0.236 & 0.082 & -0.507 & $-\mathrm{O} \cdot \mathrm{I} 54$ \\
\hline \multirow{3}{*}{ o.75 } & (a) & o.8o8 & о· I 6 & $-o \cdot 659$ & $-0 \cdot 276$ \\
\hline & (b) & 0.408 & 0.135 & -0.693 & -0.520 \\
\hline & (c) & 0.354 & o. II & $-0.69^{2}$ & -0.308 \\
\hline
\end{tabular}

* $E_{f f}$ and $E_{m m}$ refer to labour supply elasticities. Source: Blundell (1986).

$E_{f f}, E_{m m}$ and $E_{q q}$ columns are the own female, male and goods $\lambda$-constant elasticities. These relate to the standard Marshallian price and income elasticities $\left(e_{i j}\right.$ and $\eta_{i}$ respectively) by $E_{i j}=e_{i j}+\eta_{i} \eta_{j} s_{j} \Phi+\eta_{i} s_{j}$ where $s_{j}$ is the share of good $j$. Again $\Phi$ is the overall $\lambda$-constant elasticity defined in Section II.3. The samples $(a),(b)$ and $(c)$ refer to three groups of households from data on families with working women. Group $(a)$ are families with two children aged 5 years or older, group $(b)$ are families where all children have left home and group $(c)$ are the total sample of $I, 378$ families with working women. These 3 groups were chosen from the 7 presented in the original study since they adequately displayed the range in intertemporal elasticities. Allowing $\beta$ to rise towards unity increases, as expected, the absolute value of all elasticities but even for group $(c)$ the male labour supply elasticities are small and the female 
elasticities remain below unity. The elasticities for consumption are of the correct sign and lie in a similar range. These estimates also appear of the same order as those reported in Altonji (1983) and Browning et al. (1985). The intertemporal elasticity $\Phi$ again is of the correct sign and is close to the values suggested in the study by Browning ( 1985 ).

The general conclusion from micro-data studies, although far from definitive, must be that the overall intertemporal substitution elasticity is small and probably less than $-0^{\circ} 5$. Referring to the commodity specific $\lambda$-constant intertemporal elasticities, that for the labour supply of prime-aged men is small and imprecise, the corresponding elasticities for married women are larger but more various and mirror the pattern of the consumption elasticity. However, given the discussion earlier in this survey we might expect the ranges of these reported elasticities to be somewhat constrained by the underlying preference restrictions.

\section{GONGLUSIONS AND LESSONS}

To suggest that this survey has provided or could have provided anything but a glimpse at a rapidly expanding area would be foolish. Moreover, the view taken has been biased towards the perspective of demand analysis - stressing the importance of preference restrictions and questioning the interpretation of models using aggregate data. Much to the annoyance of many I have shied away from providing a catalogue of empirical estimates choosing instead to emphasise the interplay between theory and empirical analysis that can be found in the more exciting recent developments in this field. This was not just for reasons of space but also to underline a belief that much is still to be learned and received results, although useful, could hardly be considered definitive.

The increasing availability of micro or individual level data has forced the student of applied consumer behaviour to consider many new aspects of analysis hitherto overlooked. Rationing, corner solutions, infrequency of purchase and liquidity constraints are among those that have been emphasised in this survey and can be expected to form the motivation for many new publications in the field. Our increased knowledge of individual level behaviour has focused attention once again on the conditions under which simple relationships between aggregate measures can be justified. It is not satisfactory, for example, to assume that all individual consumers are either liquidity constrained or not, rationed in the labour market or not, etc. It is more likely that individuals switch in and out of these different regimes of behaviour and that in any population at any one period no one relationship holds for all consumers. As has been emphasised throughout this survey, aggregate models that ignore these issues do so at their peril. Resulting policy prescriptions for tax reform or fiscal policy, for example, will, in general, be misleading.

Perhaps one of the most attractive areas of current research - certainly one of the most popular - is the further development of intertemporal models. For example, knowledge of intertemporal substitution elasticities is crucial to the debate on the taxation of consumption versus income. In this survey I have tried to put this research in the context of general consumer demand analysis so as to emphasise the importance of preference restrictions underlying many 
popular empirical models that have been used to bring evidence to bear on this debate. We have seen that many models assume explicit additivity between consumption and labour market decisions implying that the marginal utility of consumption in any period is essentially independent of labour market considerations. Thus apart from an overall wealth effect, periods of retirement or unemployment are assumed to have no impact on the path of consumption. Additivity and separability conditions more generally were shown to be crucially important here. Liquidity constraints have a similar implication for the importance of current (earned) income in consumption decisions and we can expect (or hope for) many new empirical and theoretical results in this area.

Devising methods for cutting through the strong assumptions that underlie many applications of consumer behaviour while maintaining empirical tractability has been a focal point of this survey. We have shown that the evaluation of models is rarely the sole domain of empirical analysis. Understanding the theoretical properties of the model can be equally rewarding. The parameters of interest from a theoretical, and indeed, policy point of view may be overshadowed in absolute size and statistical significance by other determinants of behaviour but may be no less important.

Many aspects of consumer behaviour have been unavoidably omitted in this survey. Notable among these is the importance of durables - especially in intertemporal models where the level of net worth has been shown to play such an important role. Similarly, we have omitted certain new developments in the testing of consumer theory. Perhaps most significant is the work of Varian (I982, I983) on non-parametric testing. For this reason an extensive bibliography is included, many papers of which are unfortunately not referred to directly in this survey.

University College, London and Institute for Fiscal Studies

Date of receipt of final typescript: September 1987

BiBLIOGRAPHY

Abbott, M. and Ashenfelter, O. (1976). 'Labour supply, commodity demands, and the allocation of time.' Review of Economic Studies, vol. 43, pp. 389-4I I.

Altonji, J. G. (1982). 'The intertemporal substitution model of labour market fluctuations: an empirical analysis.' Review of Economic Studies, vol. 49, pp. 783-824.

(1983). 'Intertemporal substitution in labour supply: evidence from micro-data', Columbia University Working Paper. Journal of Political Economy, vol. 94 (3.2), pp. Si 76-S2 I 5.

- Martins, A. P. and Siow, A. (1986). 'Dynamic factor models of consumption, hours and income.' Mimeo, North Western University, November.

- and Siow, A. (1985). 'Testing the response of consumption to income changes with (noisy) panel data.' IRS Working Paper I86, Princeton University, forthcoming Quarterly Journal of Economics.

Amemiya, T. (1973). 'Regression analysis when the dependent variable is a truncated normal.' Econometrica, vol. 4I, pp. I 193-205.

Anderson, G. J. and Blundell, R. W. (1982). 'Estimation and hypothesis testing in dynamic singular equation systems.' Econometrica, vol. 5o, pp. I559-7I.

and - 1983$)$. $^{\prime}$ Testing restrictions in a flexible dynamic demand system: an application to consumers expenditure in Canada.' Review of Economic Studies, vol. 5o, pp. 397-410. 
Anderson, G. W. and Blundell, R. W. (1984). 'Consumer non-durables in the UK: a dynamic demand system.' Economic Journal (Conference Papers), pp. 35-44.

- and - ( 1985$)$. 'Empirical approaches to dynamic consumer demand.' McMaster University Economics Discussion Paper 85-16.

- and Browning, M. ( 1985 ). 'Allocating expenditure: demand systems and the consumption function, an integrated approach.' Mimeo, McMaster University, December.

Anderson, R. W. ( I 979). 'Perfect price aggregation and empirical demand analysis.' Econometrica, vol. 47, pp. I 209-30.

Ando, A. and Modigliani, F. ( 1963 ). 'The life-cycle hypothesis of saving: aggregate implications and tests.' American Economic Review, vol. 53, pp. 55-84.

Ashenfelter, O. and Ham, J. (I 979). 'Education, unemployment and earnings.' Journal of Political Economy, vol. 87, pp. S99-Si66.

Atkinson, A. B. and Stern, N. (1980). 'On the switch from direct to indirect taxation.' Journal of Public Economics, vol. I4, pp. I95-224.

—, Gomulka, J. and Stern, N. (I984). 'Household expenditure on tobacco I970-1980.' London School of Economics ESRC Programme on Taxation, Incentives and the Distribution of Income, Discussion Paper 57 .

Attfield, C. L. F. (1985). 'Homogeneity and endogenity in systems of demand equations.' Journal of Econometrics, vol. 27, pp. 197-2 Iо.

- and Browning M.J. (I985). 'A differential demand system, rational expectations and the life-cycle hypothesis.' Econometrica, vol. 53, pp. $33^{\mathrm{I}-48}$.

Baker, P., Blundell, R. W. and Micklewright, J. W. (I987). 'Modelling energy demand and household welfare using micro data.' UCL Discussion Paper in Economics, 87-14.

Barten, A. P. (1964). 'Family composition, prices and expenditure patterns.' In Colston Papers, vol. I6. Butterworths.

Bean, C. (I 986). 'The estimation of "surprise" models and the "surprise" consumption function.' Review of Economic Studies, vol. 53, pp. 497-516.

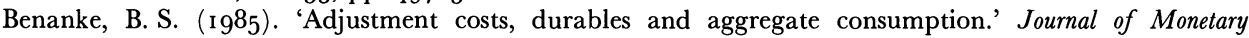
Economics, vol. I5, pp. $4^{\mathrm{I}-68 .}$

Betancourt, R. R. (I97I). 'Intertemporal allocation under additive preferences: implications for crosssection data.' Southern Economic Journal, vol. 37, pp. 458-68.

Bewley, T. (1977). 'The permanent income hypothesis: a theoretical formulation.' Journal of Economic Theory, vol. I6, pp. 252-92.

Blackorby, C., Primont, D. and Russell, R. R. (1978). Duality, Separability and Functional Structure. New York: North-Holland.

— Boyce, R. and Russell, R. R. (1978). 'Estimation of demand systems generated by the Gorman polar form: a generalization of the S-branch utility tree.' Econometrica, vol. 46, pp. $345^{-6} 3$.

Blinder, A. S. and Deaton, A. S. (1985). 'The time-series consumption function revisited.' Brookings Papers on Economic Activity, vol. 2, pp. 465-52 I.

Blundell, R. W. (I980). 'Estimating continuous consumer equivalence scales in an expenditure model with labour supply.' European Economic Review, vol. I4, pp. I45-57.

- (1986). 'Econometric approaches to the specification of life-cycle labour supply and commodity demand behaviour.' Econometric Reviews, vol. 5, pp. 89-1 7o.

—_ and Meghir, C. (I986a). 'Selection criteria for a microeconometric model of labour supply.' Journal of Applied Econometrics, vol. I, pp. 55-80.

- and - $\left(19^{87} a\right)$. 'Engel curve estimation with individual data.' In The Practice of Econometrics: Studies on Demand, Forecasting, Money and Income (ed. R. D. H. Heijmans and Heins Neudecker). Dordrecht: Martinus Nijhof Publishers.

and - $(1987 b)$. 'Bivariate alternatives to the Tobit model.' Journal of Econometrics, vol. 34, pp. I 79-200.

-$, Fry, V. and Meghir, C. ( 1985$)$. ' $\lambda$-Constant and alternative empirical models of life-cycle behaviour under uncertainty.' In Advances in Microeconometrics (eds. J. J. Laffont et al.). Tieto Press.

—- Ham, J. and Meghir, C. (I987). 'Unemployment and female labour supply.' Economic Journal, vol. 97, pp. 44-64.

—, Pashardes, P. and Weber, G. (1987). 'A household expenditure model for indirect tax analysis.' Institute for Fiscal Studies (Mimeo.).

— and Ray, R. (1984). 'Testing for linear Engel curves and additively separable preferences using a new flexible demand system.' Economic Journal, vol. 94, pp. 80o-i i .

— and Smith, R.J. (I984). 'Separability exogeneity and conditional demand models.' University of Manchester, Department of Econometrics. (Mimeo.)

— and Walker, I. ( 1982 ). 'Modelling the joint determination of household labour supplies and commodity demands.' Economic Journal, vol. 92, pp. $35^{\mathrm{I}-64}$.

— and - (1983). 'Limited dependent variables in demand analysis : an application to modelling family 
labour supply and commodity demand behaviour.' University of Manchester, Discussion Paper in Econometrics ES I 26.

Blundell, R. W. and Walker, I. (I984). 'A household production specification of demographic variables in demand analysis.' Economic Journal (Conference Papers), pp. 59-68.

— and - (1986). 'A life-cycle consistent empirical model of family labour supply using cross-section data.' Review of Economic Studies, vol. 53, pp. 539-58.

Boyer, M. (1983). 'Rational demand and expectations patterns under habit formation.' Journal of Economic Theory, vol. 58, pp. 99-1 22.

Breeden, D. T. (I979). 'An intertemporal asset pricing model with stochastic consumption and investment opportunities.' Journal of Financial Economics, vol. 7, pp. 265-96.

Brown, A. and Deaton, A. S. (1972). 'Models of consumer behaviour: survey no. 4 in applied economics.' ECONOMig Journal, vol. 82, pp. I I $45^{-2} 36$.

Brown, 'T. M. (1952). 'Habit persistence and lags in consumer behaviour.' Econometrica, vol. 20, pp. $355^{-7} \mathrm{I}$.

Browning, M. J. (1982). 'A dual approach to the analysis and testing of the life-cycle hypothesis.' University of Bristol. (Mimeo.)

- (I 1984 ). 'A non-parametric test of the life-cycle rational expectations hypothesis.' Department of Economics, McMaster University. (Mimeo.)

- (1985). 'Which demand elasticities do we know and which do we need to know for policy analysis.' McMaster Economics Discussion Paper 85-I3.

- (1986). 'The costs of using Frisch demand functions that are additive in the marginal utility of expenditure.' Economics Letters. (Forthcoming.)

_ $(\mathrm{I} 987 a)$. 'A simple non-additive class of intertemporal preferences.' McMaster University, February. (Mimeo.)

- $(\mathrm{I} 987 \mathrm{~b})$. 'Individual heterogeneity and perfect aggregation: a study of the Canadian microdata, I 969-82.' McMaster Economics Discussion Paper 87-07.

- Deaton, A. S. and Irish, M. ( 1985 ). 'A profitable approach to labour supply and commodity demands over the life-cycle.' Econometrica, vol. 53, pp. 503-44.

Campbell, J. Y. (1987). 'Does saving anticipate declining labour income? An alternative test of the permanent income hypothesis.' Econometrica. (Forthcoming.)

_ and Deaton, A. S. (1987). 'Is consumption too smooth?' NBER, January. (Mimeo.)

Cragg, J. G. (197I). 'Some statistical models for limited dependent variables with applications to the demand for durable goods.' Econometrica, vol. 39, pp. 829-44.

Christensen, L. R., Jorgenson, D. W. and Lau, L. J. (I975). 'Transcendental logarithmic utility functions.' American Economic Review, vol. 65, pp. $367-83$.

Davidson, J. E., Hendry, D. F., Srba, F. and Yeo, S. (1978). 'Econometric modelling of the aggregate time series relationship between consumers' expenditure and income in the United Kingdom.' Economic Journal, vol. 88, pp. $66 \mathrm{I}-92$.

Deaton, A. S. (1974a). 'Reconsideration of the empirical implications of additive preferences.' Economic Journal, vol. 84, pp. 338-48.

- $(1974 b)$. 'The analysis of consumer demand in the United Kingdom, I950-70.' Econometrica, vol. 42, pp. $344^{\mathrm{I}-67}$.

(1977). 'Involuntary saving through unanticipated saving.' American Economic Review, vol. 67, pp. 899-9го.

_ ( 1983 ).'Demand analysis.' In Handbook of Econometrics (eds Z. Griliches and M. Intriligator.) JAI Press.

- (1985). 'Life-cycle models of consumption: is the evidence consistent with the theory?' Invited paper for the Fifth World Congress of the Econometric Society, Cambridge, Mass. August, NBER Working Paper igio.

_ (I986). 'Consumers' expenditure.' Paper prepared for 'The New Palgrave'. Woodrow Wilson School, July. (Mimeo.)

_ and Irish, M. (1984). 'Statistical models for zero expenditures in household budgets.' Journal of Public Economics, vol. 23, pp. 59-80.

— and Muellbauer, J. (1980a). 'An almost ideal demand system.' American Economic Review, vol. 7o, pp. $3^{\text {I } 2-26 .}$

— and - $(1980 \mathrm{o} b)$. Economics and Consumer Behaviour. Cambridge: Cambridge University Press.

and - (I98I). 'Functional forms for labour supply and commodity demands with and without quantity restriction.' Econometrica, vol. 49, pp. I 52 I-32.

- and - (1986). 'On measuring child costs: with applications to poor countries.' Journal of Political Economy, vol. 94, pp. 720-44.

Diamond, P. A. and Hausman, J. A. (1984). 'Individual retirement and savings behaviour.' Journal of Public Economics, vol. 23, pp. 81-I I4.

Diewert, W. E. (197I). 'An application of the Shephard duality theorem: a generalised Leontief production function.' Journal of Political Economics, vol. 79, pp. 481-507. 
Diewert, W. E. (1974). 'Applications of duality theory.' In Frontiers of Quantitative Economics, II (eds M. D. Intiligator and J. W. Kendrick). North-Holland.

— and Wales T. J. ( 1987 ). 'Flexible functional forms and global curvature conditions.' Econometrica, vol. 55 , pp. $43^{-68 .}$

Duesenberry, J. S. (1949). 'Income, Saving and the Theory of Consumer Behaviour.' Gambridge, Mass. : Harvard University Press.

Eichenbaum, M., Hansen, L. P. and Singleton, K. J. (I986). 'A time series analysis of representative agent models of consumption and leisure choice under uncertainty.' Graduate School of Industrial Administration, Carnegie-Mellon University. (Mimeo.)

Epstein, L. G. ( I975). 'A disaggregate analysis of consumer demand under uncertainty.' Econometrica, vol. 43, pp. $877-95$.

— and Yatchew, A. (1985). 'The empirical determination of technology and expectations: a simplified procedure.' Journal of Econometrics, vol. 27(2), pp. 235-58.

Farrell, M. J. (1952). 'Irreversible demand functions.' Econometrica, vol. 20, pp. I 7 I-86.

Ferguson, T. (1958). 'A method of generating best asymptotically normal estimates with application to the estimation of bacterial densities.' Annals of Mathematical Statistics, vol. 29, pp. го46-6 г .

Flavin, M. (I98I). 'The adjustment of consumption to changing expectations about future income.' Journal of Political Economy, vol. 89, pp. 974-10og.

- (1985). 'Excess sensitivity of consumption to current income: liquidity constraints or myopia?' Canadian Journal of Economics, vol. i 8, pp. I I 7-36.

Friedman, M. (1975). A Theory of the Consumption Function. Princeton University Press.

Ghez, G. and Becker, G. S. (1975). The Allocation of Time and Goods over the Life Cycle. New York: Columbia University Press.

Gorman, W. M. (I953). 'Community preference fields.' Econometrica, vol. 21, pp. 63-80.

- (1959). 'Separable utility and aggregation.' Econometrica, vol. 27, pp. 469-8i .

- (1967). 'Tastes, habits and choices.' International Economic Review, vol. 8, pp. 2 I8-22.

- ( 1968 ). 'Conditions for additive separability.' Econometrica, vol. 36, pp. 605-9.

- (1976). 'Tricks with utility functions.' In Essays in Economic Analysis (eds M. Artis and R. Nobay). Cambridge: Cambridge University Press.

- (198I). 'Some Engel curves.' In Essays in the Theory and Measurement of Consumer Behaviour (ed. A. S. Deaton). Cambridge: Cambridge University Press.

- and Myles, G. D. (1986). 'Separability and characteristics.' Nuffield College Discussion Papers in Economics, 6, November.

Gourieroux, G., Laffont, J.-J. and Montfort, A. (1980). 'Disequilibrium econometrics in simultaneous equation systems.' Econometrica, vol. 48, pp. 75-96.

Hall, R. E. (1978). 'Stochastic implications of the life-cycle permanent income hypothesis: theory and evidence.' Journal of Political Economy, vol. 86, pp. $97 \mathrm{I}-88$. ( 1985 ). 'Real interest and consumption.' NBER Working Paper No. I694.

- ( I 986). 'Consumption.' Paper presented for Handbook of Modern Business Cycle Theory (ed. R. J. Barro). NBER, September. (Mimeo.)

- and Mishkin, F. ( 1982 ). 'The sensitivity of consumption to transitory income: estimates from panel data on households.' Econometrica, vol. 50, pp. 46I-8I.

Ham, J. (1982). 'Estimation of a labour supply model with censoring due to unemployment and underemployment.' Review of Economic Studies, vol. 49, pp. 335-53.

Hansen, L. P. and Sargent, T. (I98I). 'Linear rational expectations models for dynamically interrelated variables.' In Rational Expectations and Econometric Practice. (eds R. Lucas and T. Sargent). Minneapolis: University of Minnesota Press.

- and Singleton, K. J. ( 1982 ). 'Generalised instrumental variables estimation of non-linear rational expectations models.' Econometrica, vol. 5o, pp. i $269-86$.

- and - ( 1983$)$. 'Stochastic consumption, risk aversion and the temporal behaviour of asset returns.' Journal of Political Economy, vol. 91, pp. 249-65.

Hausman, J. A. (1978). 'Specification tests in econometrics.' Econometrica, vol. 48, pp. 697-720.

Hayashi, F. ( 1982 ). 'The permanent income hypothesis: estimation and testing by instrumental variables.' Journal of Political Economy, vol. 9o, pp. 895-918.

- $(1985 a)$ 'Permanent income hypothesis and consumption durability: analysis based on Japanese panel data.' Quarterly Journal of Economics, vol. 9o, pp. 895-9i6.

- $(1985 b)$. 'Tests for liquidity constraints: a critical survey.' NBER Working Paper No. I 720.

Heckman, J.J. (1974a). 'Life cycle consumption and labour supply: an explanation of the relationship between income and consumption over the life cycle.' American Economic Review, vol. 64, pp. I i 88-94. - $(1974 b)$. 'The effect of child care programs on women's work effort.' Journal of Political Economy, vol. 82, pp. Si $36-\mathrm{S} 63$.

and MaCurdy, T. E. ( 1980 ). 'A life cycle model of female labour supply.' Review of Economic Studies, vol. 47 , pp. $47^{-74}$. 
Hotz, V.J., Kydland, F. E. and Sedlacek, G. L. (I985). 'Intertemporal preferences and labour supply.' Carnegie-Mellon University. (Mimeo.)

Houthakker, H. S. (i96o). 'Additive Preferences.' Econometrica, vol. 3o, pp. 244-57.

- and Taylor, L. D. (1970). 'Consumer Demand in the United States 1929-70. 2nd ed. Cambridge, Mass.: Harvard University Press.

Jorgenson, D. W., Lau, L. J. and Stoker, T. M. (i980). 'Welfare comparisons and exact aggregation.' American Economic Review, vol. 70, pp. 268-72.

,- and $-(\mathrm{I} 982)$. 'The transcendental logarithmic model of aggregate consumer behaviour.' In Advances in Econometrics. (eds. R. L. Bassman and G. Rhodes). JAI Press, pp. 97-238.

Kay, J. A., Keen, M. J. and Morris, C. N. (1984). 'Estimating consumption from expenditure data.' Journal of Public Economics, vol. 23, pp. I69-82.

Keen, M. J. (1986). 'Zero expenditures and the estimation of Engel curves.' Journal of Applied Econometrics, vol. I, no. 3 , pp. $277-86$.

Kennan, J. ( I 979). 'The estimation of partial adjustment models with rational expectations.' Econometrica, vol. 47 , pp. I I $4{ }^{1}-65$.

Killingsworth, M. R. (1983). Labour Supply. Cambridge: Cambridge University Press.

King, M. A. (I980). 'An econometric model of tenure choice and demand for housing as a joint decision.' Journal of Public Economics, vol. I4(2), pp. 137-6o.

(1985). 'The economics of saving: a survey of recent contributions.' In Frontiers in Economics (eds K. Arrow and S. Houkapohja). Oxford: Basil Blackwell.

(1986). 'Capital market "imperfections" and the consumption function.' Scandinavian Journal of Economics. Conference Proceedings, pp. 59-84.

Lau, L. J. (1982). 'A note on the fundamental theorem of exact aggregation.' Economic Letters, vol. 9, pp. I $19-26$.

Lewbel, A. (I985). 'A unified approach to incorporating demographic or other effects into demand systems.' Review of Economic Studies, vol. 52, pp. I-I8.

Lee, L.-F. and Pitt, M. M. (1986). 'Microeconometric demand systems with binding nonnegativity constraints: the dual approach.' Econometrica, vol. 54, pp. I 237-42.

MaCurdy, T. E. ( $198 \mathrm{I} a$ ). 'An empirical model of labour supply in a life cycle setting.' Journal of Political Economy, vol. 89, pp. I059-85.

$-(198 \mathrm{r} b)$. 'Intertemporal analysis of taxation and work disincentives: an analysis of the Denver income maintenance experiment.' NBER Working Paper 624. (1982). 'Interpreting empirical models of labour supply in an intertemporal framework with uncertainty.' Stanford University. (Mimeo.)

- (1983). 'A simple scheme for estimating an intertemporal model of labour supply and consumption in the presence of taxes and uncertainty.' International Economic Review, vol. 24, pp. 265-89.

- (1985). 'A framework for relating microeconomic and macroeconomic evidence on intertemporal substitution.' Program in Quantitative Economic Analysis, Discussion Paper 8-22, Chicago.

- (1986). 'Modelling the time series implications of life-cycle theory.' Stanford University. (Mimeo.)

McFadden, D. ( 1980 ). 'Cost, revenue and profit functions.' In Production Economics: A Dual Approach to Theory and Application (eds M Fuss and D. McFadden). Amsterdam: North Holland.

- (1986). 'A method of simulated moments for estimation of multinomial probits without numerical integration.' Massachusetts Institute of Technology, Cambridge, MA. Econometrica. (In the Press.)

Mankiw, N. G., Rotemberg, J. J. and Summers, L. H. (I985). 'Intertemporal substitution in macroeconomics.' Quarterly Journal of Economics, G(I), no. 399, pp. 225-5I.

Mariger, R. P. ( $1987 a)$. Consumption Behaviour and the Effects of Government Fiscal Policies. Harvard University Press.

- $(1987 b)$. 'A life-cycle consumption model with liquidity constraints: theory and empirical results.' Econometrica, vol. 55, pp. 533-58.

Meghir, C. (I985a). 'The comparative statics of consumer demand under uncertainty.' UCL Economics Discussion Paper 85-2 I.

Modigliani, F. and Brumberg, R. (1955). 'Utility analysis and the consumption function: an interpretation of cross-section data.' In Post Keynesian Economics (ed. K. K. Kurihara). London: George Allen and Unwin.

Mortensen, D. ( 1973 ). 'Generalised costs of adjustment and dynamic factor demand theory.' Econometrica, vol. 4 I, pp. $657-66$.

Muellbauer, J. ( I 974). 'Household composition, Engel curves and welfare comparisons between households.' European Economic Review, vol. 5, pp. 103-22.

(1975). 'Aggregation, income distribution and consumer demand.' Review of Economic Studies, vol. 42, pp. $523-43$.

(1976). 'Community preferences and the representative consumer.' Econometrica, vol. 94, pp. 979-1000. 
Muellbauer, J. (1977). 'Testing the Barten model of household composition effects and the cost of children.' ECONOMIC JourNal, vol. 87 , pp. $460-87$.

(r983). 'Surprises in the consumption function.' Economic Journal (Conference papers), pp. $34^{-50 .}$

(1986). 'Habits, rationality and myopia in the life-cycle consumption function.' CEPR Discussion Paper No. I 12.

— and Bover, O. (1986). 'Liquidity constraints and aggregation in the consumption function under uncertainty.' Oxford Institute of Economics and Statistics, Discussion Paper, 7.

— and Pashardes, P. (1982). 'Tests of dynamic specification and homogeneity in demand systems.' Birkbeck College Discussion Paper, No. I 25.

Murphy, A. (I 986). 'Intertemporal substitution and consumption.' Maynooth College, Dublin. (Mimeo.)

Neary, J. P. and Roberts, K. W. S. (1980). 'The theory of household behaviour under rationing.' European Economic Review, vol. I3, pp. 25-42.

Nickell, S. J. (I986). 'The short-run behaviour of labour supply.' Oxford Institute of Economics and Statistics, Discussion Paper, 4.

Pashardes, P. (1987). 'Myopic and forward looking behaviour in a dynamic demand system.' International Economic Review, vol. 27(2), pp. 387-97.

Phlips, L. (1983). Applied Consumption Analysis, 2nd ed. Amsterdam: North-Holland.

and Spinnewyn, F. (198I). 'Rational and myopic demand system.' In Advances in Econometrics (eds R. Bassman and J. Rhodes). JAI Press.

— and - (1982). 'Rationality versus myopia in dynamic demand systems.' Advances in Econometrics, vol. I, pp. 3-33, JAI Press.

Pindyck, R. S. and Rotemberg, J. J. ( 1983 ). 'Dynamic factor demands under rational expectations.' Scandinavian Journal of Economics, vol. 85(2).

Pollak, R. A. (1970). 'Habit formation demand function.' Journal of Political Economy, vol. 78, pp. 77-8.

- (1971). 'Conditional demand functions and the implications of separability.' Southern Economic Journal, vol. 37 , pp. $423-33$.

- (1972). 'Generalised separability.' Econometrica, vol. 40, pp. $43^{\mathrm{I}-53}$.

— and Wales, T. J. (1969). 'Estimation of the linear expenditure system.' Econometrica, vol. 37, pp. 6 I I -28 .

— and (1979). 'Welfare comparisons and equivalence scales.' American Economic Review. Papers and Proceedings, vol. 69, pp. 2 I6-21.

- and - (198I). 'Demographic variables in demand analysis.' Econometrica, vol. 49, pp. I533-52.

Poterba, J. M. and Rotemberg, J. J. (1986). 'Money in the utility function: an empirical implementation.' NBER.

Pudney, S. E. (1981). 'An empirical method of approximating the separable structure of consumer preferences.' Review of Economic Studies, vol. 48, pp. $56 \mathrm{I}-78$.

- (1987). 'Frequency of purchase and Engel curve estimation.' London School of Economics. (Mimeo.)

Ransom, M. R. (1987). 'A comment on consumer demand systems with binding non-negativity constraints.' Journal of Econometrics, vol. 34, pp. 355-6o.

Ray, R. (1983). 'Measuring the costs of children: an alternative approach.' Journal of Public Economics, vol. 22 , pp. 89-I I 2.

Rothenberg, T. J. (1973). Efficient Estimation with A Priori Information. Gowles Foundation Monograph 23. Yale: Yale University Press.

Russell, R. T. (1983). 'On a theorem of Gorman.' Economics Letters, vol. i I, pp. 223-4.

Sargan, J. D. (1958). 'The estimation of econometric relationships using instrumental variables.' Econometrica, vol. 26 , pp. $393-415$.

Sargent, T. J. (1 978). 'Estimation of dynamic labour demand schedules under rational expectations.' Journal of Political Economy, vol. 86, pp. 10o9-44.

Smith, R. J. and Blundell, R. W. (1986). 'An exogeneity test for the simultaneous equation Tobit model with an application to labour supply.' Econometrica, vol. 54, pp. 679-86.

Spinnewyn, F. (1979). 'The cost of consumption and wealth in a model with habit formation.' Economics Letters, vol. 2, pp. I45-8.

- (I98I). 'Rational habit formation.' European Economic Review, vol. I5, pp. 9I-Iog.

Stern, N. (I986). 'On the specification of labour supply functions.' In Unemployment, Search and Labour Supply. (eds R. W. Blundell and I. Walker). Cambridge: Cambridge University Press.

Stoker, T. M. (1984). 'Completeness, distribution restrictions and the form of aggregate functions.' Econometrica, vol. 52, pp. 887-908.

(I 1986). 'Simple tests of distributional effects on macroeconomic equations.' Journal of Political Economy, vol. 94 , pp. $763-95$.

Stone, J. R. N. (1954). 'Linear expenditure systems and demand analysis: an application to the pattern of British demand.' Economic Journal, vol. 64, pp. 5 I I-27.

- (1964). 'Private saving in Britain, past, present and future.' Manchester School of Economic and Social 
Studies, vol. 32, pp. 79-I 12, reprinted in R. Stone, Mathematics in the Social Sciences and Other Essays. London: Chapman and Hall, ig66.

Stone, J. R. N. (Ig66). 'Spending and saving in relation in income and wealth.' L'Industria, 4, reprinted in R. Stone, Mathematical Models of the Economy and Other Essays. London: Chapman and Hall, 1970.

- and Rowe, D. A. (I 958). 'Dynamic demand functions: some econometric results.' Egonomic Journal, vol. 68 , pp. $256-70$.

- and - ( 1962$)$. 'A post-war expenditure function.' The Manchester School of Economic and Social Studies, vol. 30, pp. I87-201.

Tobin, J. (1958). 'Estimation of relationships for limited dependent variables.' Econometrica, vol. 26, pp. $24-36$.

Varian, H. R. (I982). 'The non-parametric approach to demand analysis.' Econometrica, vol. 50, pp. $945^{-73}$.

- (1983). 'Non-parametric tests of consumer behaviour.' Review of Economic Studies, vol. 50, pp. 99-I IO.

Wales, T.J. and Woodland, A. D. ( 1983 ). 'Estimation of consumer demand systems with binding nonnegativity constraints.' Journal of Econometrics, vol. 21 , pp. $26_{3}-85$.

Weissenberger, E. ( 1983 ). 'An intertemporal system of dynamic consumer demand functions.' London School of Economics, Centre for Labour Economics, Discussion Paper No. 186. (I 984$)$. 'Consumption adjustment costs and rational expectations: an application to UK consumers' data.' London School of Economics, Centre for Labour Economics, Discussion Paper No. I83.

Wickens, M. and Molana, H. (I984). 'Stochastic life-cycle theory with varying interest rates and prices.' Economic Journal, vol. 94, Supplement, pp. I $33-47$.

Working, H. (I 943$)$. 'Statistical laws of family expenditure.' Journal of the American Statistical Association, vol. $3^{8 .}$ 
http://www.jstor.org

\title{
LINKED CITATIONS
}

\author{
- Page 1 of 16 -
}

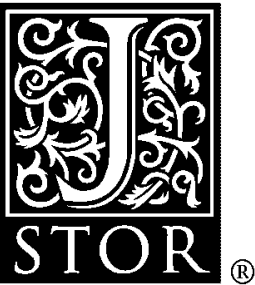

You have printed the following article:

Consumer Behaviour: Theory and Empirical Evidence--A Survey

Richard Blundell

The Economic Journal, Vol. 98, No. 389. (Mar., 1988), pp. 16-65.

Stable URL:

http://links.jstor.org/sici?sici=0013-0133\%28198803\%2998\%3A389\%3C16\%3ACBTAEE\%3E2.0.CO\%3B2-9

This article references the following linked citations. If you are trying to access articles from an off-campus location, you may be required to first logon via your library web site to access JSTOR. Please visit your library's website or contact a librarian to learn about options for remote access to JSTOR.

\section{Bibliography}

\author{
Labour Supply, Commodity Demand and the Allocation of Time \\ Michael Abbott; Orley Ashenfelter \\ The Review of Economic Studies, Vol. 43, No. 3. (Oct., 1976), pp. 389-411. \\ Stable URL: \\ http://links.jstor.org/sici?sici=0034-6527\%28197610\%2943\%3A3\%3C389\%3ALSCDAT\%3E2.0.CO\%3B2-O
}

\author{
The Intertemporal Substitution Model of Labour Market Fluctuations: An Empirical Analysis \\ Joseph G. Altonji \\ The Review of Economic Studies, Vol. 49, No. 5, Special Issue on Unemployment. (1982), pp. \\ 783-824. \\ Stable URL: \\ http://links.jstor.org/sici?sici=0034-6527\%281982\%2949\%3A5\%3C783\%3ATISMOL\%3E2.0.CO\%3B2-J
}

\section{Intertemporal Substitution in Labor Supply: Evidence from Micro Data}

Joseph G. Altonji

The Journal of Political Economy, Vol. 94, No. 3, Part 2: Hoover Institution Labor Conference. (Jun., 1986), pp. S176-S215.

Stable URL:

http://links.jstor.org/sici?sici=0022-3808\%28198606\%2994\%3A3\%3CS176\%3AISILSE\%3E2.0.CO\%3B2-6 
http://www.jstor.org

\section{LINKED CITATIONS}

- Page 2 of 16 -

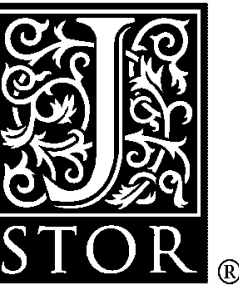

Estimation and Hypothesis Testing in Dynamic Singular Equation Systems

G. J. Anderson; R. W. Blundell

Econometrica, Vol. 50, No. 6. (Nov., 1982), pp. 1559-1572.

Stable URL:

http://links.jstor.org/sici?sici=0012-9682\%28198211\%2950\%3A6\%3C1559\%3AEAHTID\%3E2.0.CO\%3B2-C

Testing Restrictions in a Flexible Dynamic Demand System: An Application to Consumers' Expenditure in Canada

Gordon Anderson; Richard Blundell

The Review of Economic Studies, Vol. 50, No. 3. (Jul., 1983), pp. 397-410.

Stable URL:

http://links.jstor.org/sici?sici=0034-6527\%28198307\%2950\%3A3\%3C397\%3ATRIAFD\%3E2.0.CO\%3B2-F

\section{Consumer Non-Durables in the U.K.: A Dynamic Demand System}

Gordon Anderson; Richard Blundell

The Economic Journal, Vol. 94, Supplement: Conference Papers. (1984), pp. 35-44.

Stable URL:

http://links.jstor.org/sici?sici=0013-0133\%281984\%2994\%3C35\%3ACNITUA\%3E2.0.CO\%3B2-H

\section{Perfect Price Aggregation and Empirical Demand Analysis}

Ronald W. Anderson

Econometrica, Vol. 47, No. 5. (Sep., 1979), pp. 1209-1230.

Stable URL:

http://links.jstor.org/sici?sici=0012-9682\%28197909\%2947\%3A5\%3C1209\%3APPAAED\%3E2.0.CO\%3B2-G

The "Life Cycle" Hypothesis of Saving: Aggregate Implications and Tests

Albert Ando; Franco Modigliani

The American Economic Review, Vol. 53, No. 1, Part 1. (Mar., 1963), pp. 55-84.

Stable URL:

http://links.jstor.org/sici?sici=0002-8282\%28196303\%2953\%3A1\%3C55\%3AT\%22CHOS\%3E2.0.CO\%3B2-N

\section{Education, Unemployment, and Earnings}

Orley Ashenfelter; John Ham

The Journal of Political Economy, Vol. 87, No. 5, Part 2: Education and Income Distribution. (Oct., 1979), pp. S99-S116.

Stable URL:

http://links.jstor.org/sici?sici=0022-3808\%28197910\%2987\%3A5\%3CS99\%3AEUAE\%3E2.0.CO\%3B2-A 
http://www.jstor.org

\title{
LINKED CITATIONS
}

- Page 3 of 16 -

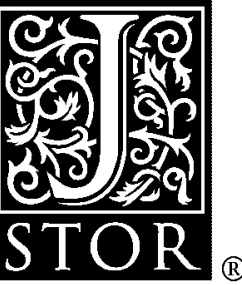

\author{
A Differential Demand System, Rational Expectations and the Life Cycle Hypothesis \\ C. L. F. Attfield; Martin J. Browning \\ Econometrica, Vol. 53, No. 1. (Jan., 1985), pp. 31-48. \\ Stable URL: \\ http://links.jstor.org/sici?sici=0012-9682\%28198501\%2953\%3A1\%3C31\%3AADDSRE\%3E2.0.CO\%3B2-U \\ The Estimation of "Surprise" Models and the "Surprise" Consumption Function \\ Charles R. Bean \\ The Review of Economic Studies, Vol. 53, No. 4, Econometrics Special Issue. (Aug., 1986), pp. \\ 497-516. \\ Stable URL: \\ http://links.jstor.org/sici?sici=0034-6527\%28198608\%2953\%3A4\%3C497\%3ATEO\%22MA\%3E2.0.CO\%3B2-T
}

Intertemporal Allocation under Additive Preferences: Implications for Cross-Section Data Roger R. Betancourt

Southern Economic Journal, Vol. 37, No. 4. (Apr., 1971), pp. 458-468.

Stable URL:

http://links.jstor.org/sici?sici=0038-4038\%28197104\%2937\%3A4\%3C458\%3AIAUAPI\%3E2.0.CO\%3B2-M

Estimation of Demand Systems Generated by the Gorman Polar Form; A Generalization of the S-Branch Utility Tree

Charles Blackorby; Richard Boyce; R. Robert Russell

Econometrica, Vol. 46, No. 2. (Mar., 1978), pp. 345-363.

Stable URL:

http://links.jstor.org/sici?sici=0012-9682\%28197803\%2946\%3A2\%3C345\%3AEODSGB\%3E2.0.CO\%3B2-U

The Time Series Consumption Function Revisited

Alan S. Blinder; Angus Deaton; Robert E. Hall; R. Glenn Hubbard

Brookings Papers on Economic Activity, Vol. 1985, No. 2. (1985), pp. 465-521.

Stable URL:

http://links.jstor.org/sici?sici=0007-2303\%281985\%291985\%3A2\%3C465\%3ATTSCFR\%3E2.0.CO\%3B2-6

\section{Selection Criteria for a Microeconometric Model of Labour Supply}

Richard Blundell; Costas Meghir

Journal of Applied Econometrics, Vol. 1, No. 1. (Jan., 1986), pp. 55-80.

Stable URL:

http://links.jstor.org/sici?sici=0883-7252\%28198601\%291\%3A1\%3C55\%3ASCFAMM\%3E2.0.CO\%3B2-Y 
http://www.jstor.org

\title{
LINKED CITATIONS
}

- Page 4 of 16 -

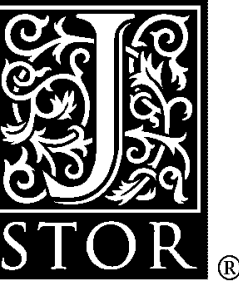

\author{
Unemployment and Female Labour Supply \\ Richard Blundell; John Ham; Costas Meghir \\ The Economic Journal, Vol. 97, Supplement: Conference Papers. (1987), pp. 44-64. \\ Stable URL: \\ http://links.jstor.org/sici?sici=0013-0133\%281987\%2997\%3C44\%3AUAFLS\%3E2.0.CO\%3B2-E
}

Testing for Linear Engel Curves and Additively Separable Preferences Using a New Flexible Demand System

Richard Blundell; Ranjan Ray

The Economic Journal, Vol. 94, No. 376. (Dec., 1984), pp. 800-811.

Stable URL:

http://links.jstor.org/sici?sici=0013-0133\%28198412\%2994\%3A376\%3C800\%3ATFLECA\%3E2.0.CO\%3B2-\%23

Modelling the Joint Determination of Household Labour Supplies and Commodity Demands Richard Blundell; Ian Walker

The Economic Journal, Vol. 92, No. 366. (Jun., 1982), pp. 351-364.

Stable URL:

http://links.jstor.org/sici? sici=0013-0133\%28198206\%2992\%3A366\%3C351\%3AMTJDOH\%3E2.0.CO\%3B2-\%23

\author{
A Household Production Specification of Demographic Variables in Demand Analysis \\ Richard Blundell; Ian Walker \\ The Economic Journal, Vol. 94, Supplement: Conference Papers. (1984), pp. 59-68. \\ Stable URL: \\ http://links.jstor.org/sici?sici=0013-0133\%281984\%2994\%3C59\%3AAHPSOD\%3E2.0.CO\%3B2-K
}

\author{
A Life-Cycle Consistent Empirical Model of Family Labour Supply Using Cross-Section Data \\ Richard Blundell; Ian Walker \\ The Review of Economic Studies, Vol. 53, No. 4, Econometrics Special Issue. (Aug., 1986), pp. \\ 539-558. \\ Stable URL: \\ http://links.jstor.org/sici?sici=0034-6527\%28198608\%2953\%3A4\%3C539\%3AALCEMO\%3E2.0.CO\%3B2-4
}

\section{Surveys in Applied Economics: Models of Consumer Behaviour}

Alan Brown; Angus Deaton

The Economic Journal, Vol. 82, No. 328. (Dec., 1972), pp. 1145-1236.

Stable URL:

http://links.jstor.org/sici?sici=0013-0133\%28197212\%2982\%3A328\%3C1145\%3ASIAEMO\%3E2.0.CO\%3B2-1 
http://www.jstor.org

\title{
LINKED CITATIONS
}

\author{
- Page 5 of 16 -
}

Habit Persistence and Lags in Consumer Behaviour

T. M. Brown

Econometrica, Vol. 20, No. 3. (Jul., 1952), pp. 355-371.

Stable URL:

http://links.jstor.org/sici?sici=0012-9682\%28195207\%2920\%3A3\%3C355\%3AHPALIC\%3E2.0.CO\%3B2-M

A Profitable Approach to Labor Supply and Commodity Demands over the Life-Cycle Martin Browning; Angus Deaton; Margaret Irish

Econometrica, Vol. 53, No. 3. (May, 1985), pp. 503-544.

Stable URL:

http://links.jstor.org/sici?sici=0012-9682\%28198505\%2953\%3A3\%3C503\%3AAPATLS\%3E2.0.CO\%3B2-P

Some Statistical Models for Limited Dependent Variables with Application to the Demand for Durable Goods

John G. Cragg

Econometrica, Vol. 39, No. 5. (Sep., 1971), pp. 829-844.

Stable URL:

http://links.jstor.org/sici?sici=0012-9682\%28197109\%2939\%3A5\%3C829\%3ASSMFLD\%3E2.0.CO\%3B2-K

\section{Transcendental Logarithmic Utility Functions}

Laurits R. Christensen; Dale W. Jorgenson; Lawrence J. Lau

The American Economic Review, Vol. 65, No. 3. (Jun., 1975), pp. 367-383.

Stable URL:

http://links.jstor.org/sici?sici=0002-8282\%28197506\%2965\%3A3\%3C367\%3ATLUF\%3E2.0.CO\%3B2-F

Econometric Modelling of the Aggregate Time-Series Relationship Between Consumers' Expenditure and Income in the United Kingdom

James E. H. Davidson; David F. Hendry; Frank Srba; Stephen Yeo

The Economic Journal, Vol. 88, No. 352. (Dec., 1978), pp. 661-692.

Stable URL:

http://links.jstor.org/sici?sici=0013-0133\%28197812\%2988\%3A352\%3C661\%3AEMOTAT\%3E2.0.CO\%3B2-J 
http://www.jstor.org

\section{LINKED CITATIONS}

- Page 6 of 16 -

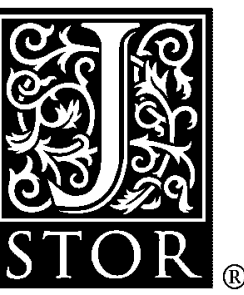

\section{Review: [Untitled]}

Reviewed Work(s):

Permanent Income, Wealth, and Consumption. by Thomas Mayer Angus Deaton

The Economic Journal, Vol. 84, No. 333. (Mar., 1974), pp. 200-202.

Stable URL:

http://links.jstor.org/sici?sici=0013-0133\%28197403\%2984\%3A333\%3C200\%3APIWAC\%3E2.0.CO\%3B2-F

The Analysis of Consumer Demand in the United Kingdom, 1900-1970

Angus S. Deaton

Econometrica, Vol. 42, No. 2. (Mar., 1974), pp. 341-367.

Stable URL:

http://links.jstor.org/sici?sici=0012-9682\%28197403\%2942\%3A2\%3C341\%3ATAOCDI\%3E2.0.CO\%3B2-M

\section{Involuntary Saving Through Unanticipated Inflation}

Angus Deaton

The American Economic Review, Vol. 67, No. 5. (Dec., 1977), pp. 899-910.

Stable URL:

http://links.jstor.org/sici?sici=0002-8282\%28197712\%2967\%3A5\%3C899\%3AISTUI\%3E2.0.CO\%3B2-2

\section{An Almost Ideal Demand System}

Angus Deaton; John Muellbauer

The American Economic Review, Vol. 70, No. 3. (Jun., 1980), pp. 312-326.

Stable URL:

http://links.jstor.org/sici?sici=0002-8282\%28198006\%2970\%3A3\%3C312\%3AAAIDS\%3E2.0.CO\%3B2-Q

Functional Forms for Labor Supply and Commodity Demands with and without Quantity Restrictions

Angus Deaton; John Muellbauer

Econometrica, Vol. 49, No. 6. (Nov., 1981), pp. 1521-1532.

Stable URL:

http://links.jstor.org/sici?sici=0012-9682\%28198111\%2949\%3A6\%3C1521\%3AFFFLSA\%3E2.0.CO\%3B2-D 
http://www.jstor.org

\title{
LINKED CITATIONS
}

- Page 7 of 16 -

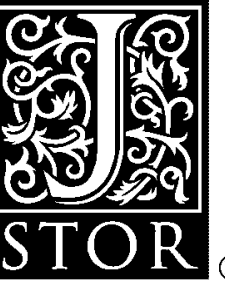

On Measuring Child Costs: With Applications to Poor Countries

Angus S. Deaton; John Muellbauer

The Journal of Political Economy, Vol. 94, No. 4. (Aug., 1986), pp. 720-744.

Stable URL:

http://links.jstor.org/sici?sici=0022-3808\%28198608\%2994\%3A4\%3C720\%3AOMCCWA\%3E2.0.CO\%3B2-3

An Application of the Shephard Duality Theorem: A Generalized Leontief Production Function

W. E. Diewert

The Journal of Political Economy, Vol. 79, No. 3. (May - Jun., 1971), pp. 481-507.

Stable URL:

http://links.jstor.org/sici?sici=0022-3808\%28197105\%2F06\%2979\%3A3\%3C481\%3AAAOTSD\%3E2.0.CO\%3B2-6

\section{Flexible Functional Forms and Global Curvature Conditions}

W. E. Diewert; T. J. Wales

Econometrica, Vol. 55, No. 1. (Jan., 1987), pp. 43-68.

Stable URL:

http://links.jstor.org/sici?sici=0012-9682\%28198701\%2955\%3A1\%3C43\%3AFFFAGC\%3E2.0.CO\%3B2-1

\section{A Disaggregate Analysis of Consumer Choice under Uncertainty}

L. Epstein

Econometrica, Vol. 43, No. 5/6. (Sep. - Nov., 1975), pp. 877-892.

Stable URL:

http://links.jstor.org/sici?sici=0012-9682\%28197509\%2F11\%2943\%3A5\%2F6\%3C877\%3AADAOCC\%3E2.0.CO\%3B2-U

\section{Irreversible Demand Functions}

M. J. Farrell

Econometrica, Vol. 20, No. 2. (Apr., 1952), pp. 171-186.

Stable URL:

http://links.jstor.org/sici?sici=0012-9682\%28195204\%2920\%3A2\%3C171\%3AIDF\%3E2.0.CO\%3B2-Z

\author{
A Method of Generating Best Asymptotically Normal Estimates with Application to the \\ Estimation of Bacterial Densities \\ Thomas S. Ferguson \\ The Annals of Mathematical Statistics, Vol. 29, No. 4. (Dec., 1958), pp. 1046-1062. \\ Stable URL: \\ http://links.jstor.org/sici?sici=0003-4851\%28195812\%2929\%3A4\%3C1046\%3AAMOGBA\%3E2.0.CO\%3B2-U
}


http://www.jstor.org

\title{
LINKED CITATIONS
}

\author{
- Page 8 of 16 -
}

The Adjustment of Consumption to Changing Expectations About Future Income Marjorie A. Flavin

The Journal of Political Economy, Vol. 89, No. 5. (Oct., 1981), pp. 974-1009.

Stable URL:

http://links.jstor.org/sici?sici=0022-3808\%28198110\%2989\%3A5\%3C974\%3ATAOCTC\%3E2.0.CO\%3B2-X

Excess Sensitivity of Consumption to Current Income: Liquidity Constraints or Myopia?

Marjorie Flavin

The Canadian Journal of Economics / Revue canadienne d'Economique, Vol. 18, No. 1, Econometrics Special. (Feb., 1985), pp. 117-136.

Stable URL:

http://links.jstor.org/sici?sici=0008-4085\%28198502\%2918\%3A1\%3C117\%3AESOCTC\%3E2.0.CO\%3B2-V

\section{Community Preference Fields}

W. M. Gorman

Econometrica, Vol. 21, No. 1. (Jan., 1953), pp. 63-80.

Stable URL:

http://links.jstor.org/sici?sici=0012-9682\%28195301\%2921\%3A1\%3C63\%3ACPF\%3E2.0.CO\%3B2-9

\section{Separable Utility and Aggregation}

W. M. Gorman

Econometrica, Vol. 27, No. 3. (Jul., 1959), pp. 469-481.

Stable URL:

http://links.jstor.org/sici?sici=0012-9682\%28195907\%2927\%3A3\%3C469\%3ASUAA\%3E2.0.CO\%3B2-A

\section{Tastes, Habits and Choices}

W. M. Gorman

International Economic Review, Vol. 8, No. 2. (Jun., 1967), pp. 218-222.

Stable URL:

http://links.jstor.org/sici?sici=0020-6598\%28196706\%298\%3A2\%3C218\%3ATHAC\%3E2.0.CO\%3B2-1

\section{Conditions for Additive Separability}

W. M. Gorman

Econometrica, Vol. 36, No. 3/4. (Jul. - Oct., 1968), pp. 605-609.

Stable URL:

http://links.jstor.org/sici?sici=0012-9682\%28196807\%2F10\%2936\%3A3\%2F4\%3C605\%3ACFAS\%3E2.0.CO\%3B2-I 
http://www.jstor.org

\section{LINKED CITATIONS}

- Page 9 of 16 -

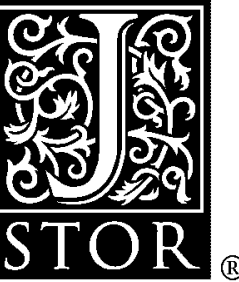

Disequilibrium Econometrics in Simultaneous Equations Systems

C. Gourieroux; J. J. Laffont; A. Monfort

Econometrica, Vol. 48, No. 1. (Jan., 1980), pp. 75-96.

Stable URL:

http://links.jstor.org/sici?sici=0012-9682\%28198001\%2948\%3A1\%3C75\%3ADEISES\%3E2.0.CO\%3B2-2

Stochastic Implications of the Life Cycle-Permanent Income Hypothesis: Theory and Evidence Robert E. Hall

The Journal of Political Economy, Vol. 86, No. 6. (Dec., 1978), pp. 971-987.

Stable URL:

http://links.jstor.org/sici?sici=0022-3808\%28197812\%2986\%3A6\%3C971\%3ASIOTLC\%3E2.0.CO\%3B2-K

The Sensitivity of Consumption to Transitory Income: Estimates from Panel Data on Households

Robert E. Hall; Frederic S. Mishkin

Econometrica, Vol. 50, No. 2. (Mar., 1982), pp. 461-481.

Stable URL:

http://links.jstor.org/sici?sici=0012-9682\%28198203\%2950\%3A2\%3C461\%3ATSOCTT\%3E2.0.CO\%3B2-R

\section{Estimation of a Labour Supply Model with Censoring Due to Unemployment and} Underemployment

John C. Ham

The Review of Economic Studies, Vol. 49, No. 3. (Jul., 1982), pp. 335-354.

Stable URL:

http://links.jstor.org/sici?sici=0034-6527\%28198207\%2949\%3A3\%3C335\%3AEOALSM\%3E2.0.CO\%3B2-S

Generalized Instrumental Variables Estimation of Nonlinear Rational Expectations Models

Lars Peter Hansen; Kenneth J. Singleton

Econometrica, Vol. 50, No. 5. (Sep., 1982), pp. 1269-1286.

Stable URL:

http://links.jstor.org/sici?sici=0012-9682\%28198209\%2950\%3A5\%3C1269\%3AGIVEON\%3E2.0.CO\%3B2-G

Stochastic Consumption, Risk Aversion, and the Temporal Behavior of Asset Returns Lars Peter Hansen; Kenneth J. Singleton

The Journal of Political Economy, Vol. 91, No. 2. (Apr., 1983), pp. 249-265.

Stable URL:

http://links.jstor.org/sici?sici=0022-3808\%28198304\%2991\%3A2\%3C249\%3ASCRAAT\%3E2.0.CO\%3B2-1 
http://www.jstor.org

\section{LINKED CITATIONS}

- Page 10 of 16 -

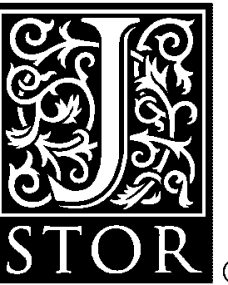

The Permanent Income Hypothesis: Estimation and Testing by Instrumental Variables

Fumio Hayashi

The Journal of Political Economy, Vol. 90, No. 5. (Oct., 1982), pp. 895-916.

Stable URL:

http://links.jstor.org/sici?sici=0022-3808\%28198210\%2990\%3A5\%3C895\%3ATPIHEA\%3E2.0.CO\%3B2-Y

Life Cycle Consumption and Labor Supply: An Explanation of the Relationship between Income and Consumption Over the Life Cycle

James Heckman

The American Economic Review, Vol. 64, No. 1. (Mar., 1974), pp. 188-194.

Stable URL:

http://links.jstor.org/sici?sici=0002-8282\%28197403\%2964\%3A1\%3C188\%3ALCCALS\%3E2.0.CO\%3B2-P

\section{Effects of Child-Care Programs on Women's Work Effort}

James J. Heckman

The Journal of Political Economy, Vol. 82, No. 2, Part 2: Marriage, Family Human Capital, and Fertility. (Mar. - Apr., 1974), pp. S136-S163.

Stable URL:

http://links.jstor.org/sici?sici=0022-3808\%28197403\%2F04\%2982\%3A2\%3CS136\%3AEOCPOW\%3E2.0.CO\%3B2-3

\section{A Life Cycle Model of Female Labour Supply}

James J. Heckman; Thomas E. Macurdy

The Review of Economic Studies, Vol. 47, No. 1, Econometrics Issue. (Jan., 1980), pp. 47-74.

Stable URL:

http://links.jstor.org/sici?sici=0034-6527\%28198001\%2947\%3A1\%3C47\%3AALCMOF\%3E2.0.CO\%3B2-\%23

\section{Additive Preferences}

H. S. Houthakker

Econometrica, Vol. 28, No. 2. (Apr., 1960), pp. 244-257.

Stable URL:

http://links.jstor.org/sici?sici=0012-9682\%28196004\%2928\%3A2\%3C244\%3AAP\%3E2.0.CO\%3B2-K

\section{Welfare Comparison under Exact Aggregation}

Dale W. Jorgenson; Lawrence J. Lau; Thomas M. Stoker

The American Economic Review, Vol. 70, No. 2, Papers and Proceedings of the Ninety-Second Annual Meeting of the American Economic Association. (May, 1980), pp. 268-272.

Stable URL:

http://links.jstor.org/sici?sici=0002-8282\%28198005\%2970\%3A2\%3C268\%3AWCUEA\%3E2.0.CO\%3B2-X 
http://www.jstor.org

\section{LINKED CITATIONS}

- Page 11 of 16 -

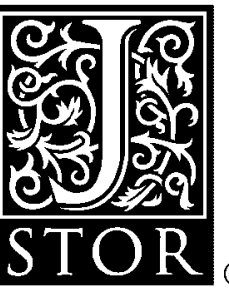

\section{Zero Expenditures and the Estimation of Engel Curves}

Michael Keen

Journal of Applied Econometrics, Vol. 1, No. 3. (Jul., 1986), pp. 277-286.

Stable URL:

http://links.jstor.org/sici?sici=0883-7252\%28198607\%291\%3A3\%3C277\%3AZEATEO\%3E2.0.CO\%3B2-\%23

The Estimation of Partial Adjustment Models with Rational Expectations

John Kennan

Econometrica, Vol. 47, No. 6. (Nov., 1979), pp. 1441-1455.

Stable URL:

http://links.jstor.org/sici?sici=0012-9682\%28197911\%2947\%3A6\%3C1441\%3ATEOPAM\%3E2.0.CO\%3B2-X

A Unified Approach to Incorporating Demographic or Other Effects into Demand Systems Arthur Lewbel

The Review of Economic Studies, Vol. 52, No. 1. (Jan., 1985), pp. 1-18.

Stable URL:

http://links.jstor.org/sici?sici=0034-6527\%28198501\%2952\%3A1\%3C1\%3AAUATID\%3E2.0.CO\%3B2-L

Microeconometric Demand System with Binding Nonnegativity Constraints: The Dual Approach

Lung-Fei Lee; Mark M. Pitt

Econometrica, Vol. 54, No. 5. (Sep., 1986), pp. 1237-1242.

Stable URL:

http://links.jstor.org/sici?sici=0012-9682\%28198609\%2954\%3A5\%3C1237\%3AMDSWBN\%3E2.0.CO\%3B2-J

\section{An Empirical Model of Labor Supply in a Life-Cycle Setting}

Thomas E. MaCurdy

The Journal of Political Economy, Vol. 89, No. 6. (Dec., 1981), pp. 1059-1085.

Stable URL:

http://links.jstor.org/sici?sici=0022-3808\%28198112\%2989\%3A6\%3C1059\%3AAEMOLS\%3E2.0.CO\%3B2-2

A Simple Scheme for Estimating an Intertemporal Model of Labor Supply and Consumption in the Presence of Taxes and Uncertainty

Thomas E. MaCurdy

International Economic Review, Vol. 24, No. 2. (Jun., 1983), pp. 265-289.

Stable URL:

http://links.jstor.org/sici?sici=0020-6598\%28198306\%2924\%3A2\%3C265\%3AASSFEA\%3E2.0.CO\%3B2-S 
http://www.jstor.org

\section{LINKED CITATIONS}

- Page 12 of 16 -

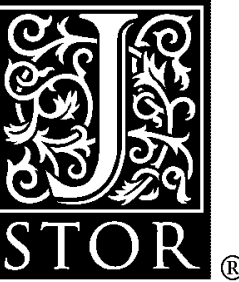

\section{Intertemporal Substitution in Macroeconomics}

N. Gregory Mankiw; Julio J. Rotemberg; Lawrence H. Summers

The Quarterly Journal of Economics, Vol. 100, No. 1. (Feb., 1985), pp. 225-251.

Stable URL:

http://links.jstor.org/sici?sici=0033-5533\%28198502\%29100\%3A1\%3C225\%3AISIM\%3E2.0.CO\%3B2-2

A Life-Cycle Consumption Model with Liquidity Constraints: Theory and Empirical Results Randall P. Mariger

Econometrica, Vol. 55, No. 3. (May, 1987), pp. 533-557.

Stable URL:

http://links.jstor.org/sici?sici=0012-9682\%28198705\%2955\%3A3\%3C533\%3AALCMWL\%3E2.0.CO\%3B2-C

Generalized Costs of Adjustment and Dynamic Factor Demand Theory

Dale T. Mortensen

Econometrica, Vol. 41, No. 4. (Jul., 1973), pp. 657-665.

Stable URL:

http://links.jstor.org//sici?sici=0012-9682\%28197307\%2941\%3A4\%3C657\%3AGCOAAD\%3E2.0.CO\%3B2-V

\section{Aggregation, Income Distribution and Consumer Demand}

John Muellbauer

The Review of Economic Studies, Vol. 42, No. 4. (Oct., 1975), pp. 525-543.

Stable URL:

http://links.jstor.org/sici?sici=0034-6527\%28197510\%2942\%3A4\%3C525\%3AAIDACD\%3E2.0.CO\%3B2-V

Community Preferences and the Representative Consumer

John Muellbauer

Econometrica, Vol. 44, No. 5. (Sep., 1976), pp. 979-999.

Stable URL:

http://links.jstor.org/sici?sici=0012-9682\%28197609\%2944\%3A5\%3C979\%3ACPATRC\%3E2.0.CO\%3B2-K

Testing the Barten Model of Household Composition Effects and the Cost of Children John Muellbauer

The Economic Journal, Vol. 87, No. 347. (Sep., 1977), pp. 460-487.

Stable URL:

http://links.jstor.org/sici?sici=0013-0133\%28197709\%2987\%3A347\%3C460\%3ATTBMOH\%3E2.0.CO\%3B2-O 
http://www.jstor.org

\section{LINKED CITATIONS}

- Page 13 of 16 -

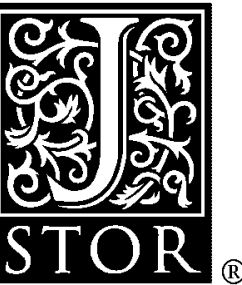

\section{Surprises in the Consumption Function}

John Muellbauer

The Economic Journal, Vol. 93, Supplement: Conference Papers. (1983), pp. 34-50.

Stable URL:

http://links.jstor.org/sici?sici=0013-0133\%281983\%2993\%3C34\%3ASITCF\%3E2.0.CO\%3B2-Z

\section{Myopic and Forward Looking Behavior in a Dynamic Demand System}

Panos Pashardes

International Economic Review, Vol. 27, No. 2. (Jun., 1986), pp. 387-397.

Stable URL:

http://links.jstor.org/sici?sici=0020-6598\%28198606\%2927\%3A2\%3C387\%3AMAFLBI\%3E2.0.CO\%3B2-N

\section{Habit Formation and Dynamic Demand Functions}

Robert A. Pollak

The Journal of Political Economy, Vol. 78, No. 4, Part 1. (Jul. - Aug., 1970), pp. 745-763.

Stable URL:

http://links.jstor.org/sici?sici=0022-3808\%28197007\%2F08\%2978\%3A4\%3C745\%3AHFADDF\%3E2.0.CO\%3B2-G

\section{Conditional Demand Functions and the Implications of Separable Utility}

Robert A. Pollak

Southern Economic Journal, Vol. 37, No. 4. (Apr., 1971), pp. 423-433.

Stable URL:

http://links.jstor.org/sici?sici=0038-4038\%28197104\%2937\%3A4\%3C423\%3ACDFATI\%3E2.0.CO\%3B2-7

\section{Generalized Separability}

Robert A. Pollak

Econometrica, Vol. 40, No. 3. (May, 1972), pp. 431-453.

Stable URL:

http://links.jstor.org/sici?sici=0012-9682\%28197205\%2940\%3A3\%3C431\%3AGS\%3E2.0.CO\%3B2-0

\section{Estimation of the Linear Expenditure System}

Robert A. Pollak; Terence J. Wales

Econometrica, Vol. 37, No. 4. (Oct., 1969), pp. 611-628.

Stable URL:

http://links.jstor.org/sici?sici=0012-9682\%28196910\%2937\%3A4\%3C611\%3AEOTLES\%3E2.0.CO\%3B2-2 
http://www.jstor.org

\section{LINKED CITATIONS}

- Page 14 of 16 -

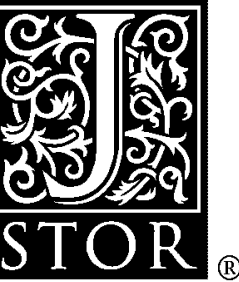

\section{Welfare Comparisons and Equivalence Scales}

Robert A. Pollak; Terence J. Wales

The American Economic Review, Vol. 69, No. 2, Papers and Proceedings of the Ninety-First Annual Meeting of the American Economic Association. (May, 1979), pp. 216-221.

Stable URL:

http://links.jstor.org/sici?sici=0002-8282\%28197905\%2969\%3A2\%3C216\%3AWCAES\%3E2.0.CO\%3B2-I

Demographic Variables in Demand Analysis

Robert A. Pollak; Terence J. Wales

Econometrica, Vol. 49, No. 6. (Nov., 1981), pp. 1533-1551.

Stable URL:

http://links.jstor.org/sici?sici=0012-9682\%28198111\%2949\%3A6\%3C1533\%3ADVIDA\%3E2.0.CO\%3B2-T

An Empirical Method of Approximating the Separable Structure of Consumer Preferences

S. E. Pudney

The Review of Economic Studies, Vol. 48, No. 4. (Oct., 1981), pp. 561-577.

Stable URL:

http://links.jstor.org/sici?sici=0034-6527\%28198110\%2948\%3A4\%3C561\%3AAEMOAT\%3E2.0.CO\%3B2-H

The Estimation of Economic Relationships using Instrumental Variables

J. D. Sargan

Econometrica, Vol. 26, No. 3. (Jul., 1958), pp. 393-415.

Stable URL:

http://links.jstor.org/sici?sici=0012-9682\%28195807\%2926\%3A3\%3C393\%3ATEOERU\%3E2.0.CO\%3B2-R

Estimation of Dynamic Labor Demand Schedules under Rational Expectations

Thomas J. Sargent

The Journal of Political Economy, Vol. 86, No. 6. (Dec., 1978), pp. 1009-1044.

Stable URL:

http://links.jstor.org/sici?sici=0022-3808\%28197812\%2986\%3A6\%3C1009\%3AEODLDS\%3E2.0.CO\%3B2-E

An Exogeneity Test for a Simultaneous Equation Tobit Model with an Application to Labor Supply

Richard J. Smith; Richard W. Blundell

Econometrica, Vol. 54, No. 3. (May, 1986), pp. 679-685.

Stable URL:

http://links.jstor.org/sici?sici=0012-9682\%28198605\%2954\%3A3\%3C679\%3AAETFAS\%3E2.0.CO\%3B2-N 
http://www.jstor.org

\section{LINKED CITATIONS}

- Page 15 of 16 -

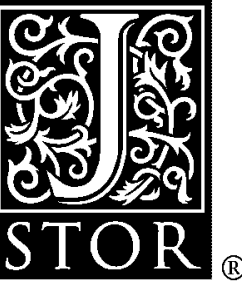

Completeness, Distribution Restrictions, and the Form of Aggregate Functions Thomas M. Stoker

Econometrica, Vol. 52, No. 4. (Jul., 1984), pp. 887-907.

Stable URL:

http://links.jstor.org/sici?sici=0012-9682\%28198407\%2952\%3A4\%3C887\%3ACDRATF\%3E2.0.CO\%3B2-M

\section{Simple Tests of Distributional Effects on Macroeconomic Equations}

Thomas M. Stoker

The Journal of Political Economy, Vol. 94, No. 4. (Aug., 1986), pp. 763-795.

Stable URL:

http://links.jstor.org/sici?sici=0022-3808\%28198608\%2994\%3A4\%3C763\%3ASTODEO\%3E2.0.CO\%3B2-Z

Linear Expenditure Systems and Demand Analysis: An Application to the Pattern of British Demand

Richard Stone

The Economic Journal, Vol. 64, No. 255. (Sep., 1954), pp. 511-527.

Stable URL:

http://links.jstor.org/sici?sici=0013-0133\%28195409\%2964\%3A255\%3C511\%3ALESADA\%3E2.0.CO\%3B2-D

\section{Dynamic Demand Functions: Some Econometric Results}

Richard Stone; D. A. Rowe

The Economic Journal, Vol. 68, No. 270. (Jun., 1958), pp. 256-270.

Stable URL:

http://links.jstor.org/sici?sici=0013-0133\%28195806\%2968\%3A270\%3C256\%3ADDFSER\%3E2.0.CO\%3B2-K

\section{Estimation of Relationships for Limited Dependent Variables}

James Tobin

Econometrica, Vol. 26, No. 1. (Jan., 1958), pp. 24-36.

Stable URL:

http://links.jstor.org/sici?sici=0012-9682\%28195801\%2926\%3A1\%3C24\%3AEORFLD\%3E2.0.CO\%3B2-R

The Nonparametric Approach to Demand Analysis

Hal R. Varian

Econometrica, Vol. 50, No. 4. (Jul., 1982), pp. 945-973.

Stable URL:

http://links.jstor.org/sici?sici=0012-9682\%28198207\%2950\%3A4\%3C945\%3ATNATDA\%3E2.0.CO\%3B2-O 
http://www.jstor.org

\section{LINKED CITATIONS}

- Page 16 of 16 -

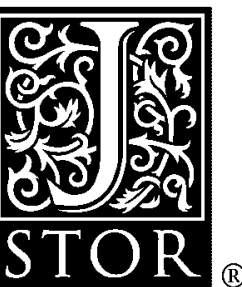

\section{Non-Parametric Tests of Consumer Behaviour}

Hal R. Varian

The Review of Economic Studies, Vol. 50, No. 1. (Jan., 1983), pp. 99-110.

Stable URL:

http://links.jstor.org/sici?sici=0034-6527\%28198301\%2950\%3A1\%3C99\%3ANTOCB\%3E2.0.CO\%3B2-V

\section{Stochastic Life Cycle Theory With Varying Interest Rates and Prices}

M. R. Wickens; H. Molana

The Economic Journal, Vol. 94, Supplement: Conference Papers. (1984), pp. 133-147.

Stable URL:

http://links.jstor.org/sici?sici=0013-0133\%281984\%2994\%3C133\%3ASLCTWV\%3E2.0.CO\%3B2-3

\section{Statistical Laws of Family Expenditure}

Holbrook Working

Journal of the American Statistical Association, Vol. 38, No. 221. (Mar., 1943), pp. 43-56.

Stable URL:

http://links.jstor.org/sici?sici=0162-1459\%28194303\%2938\%3A221\%3C43\%3ASLOFE\%3E2.0.CO\%3B2-S 